Bamboo Fale

\title{
Climate of Change
}

The Development of Hybrid Architecture within Samoa 



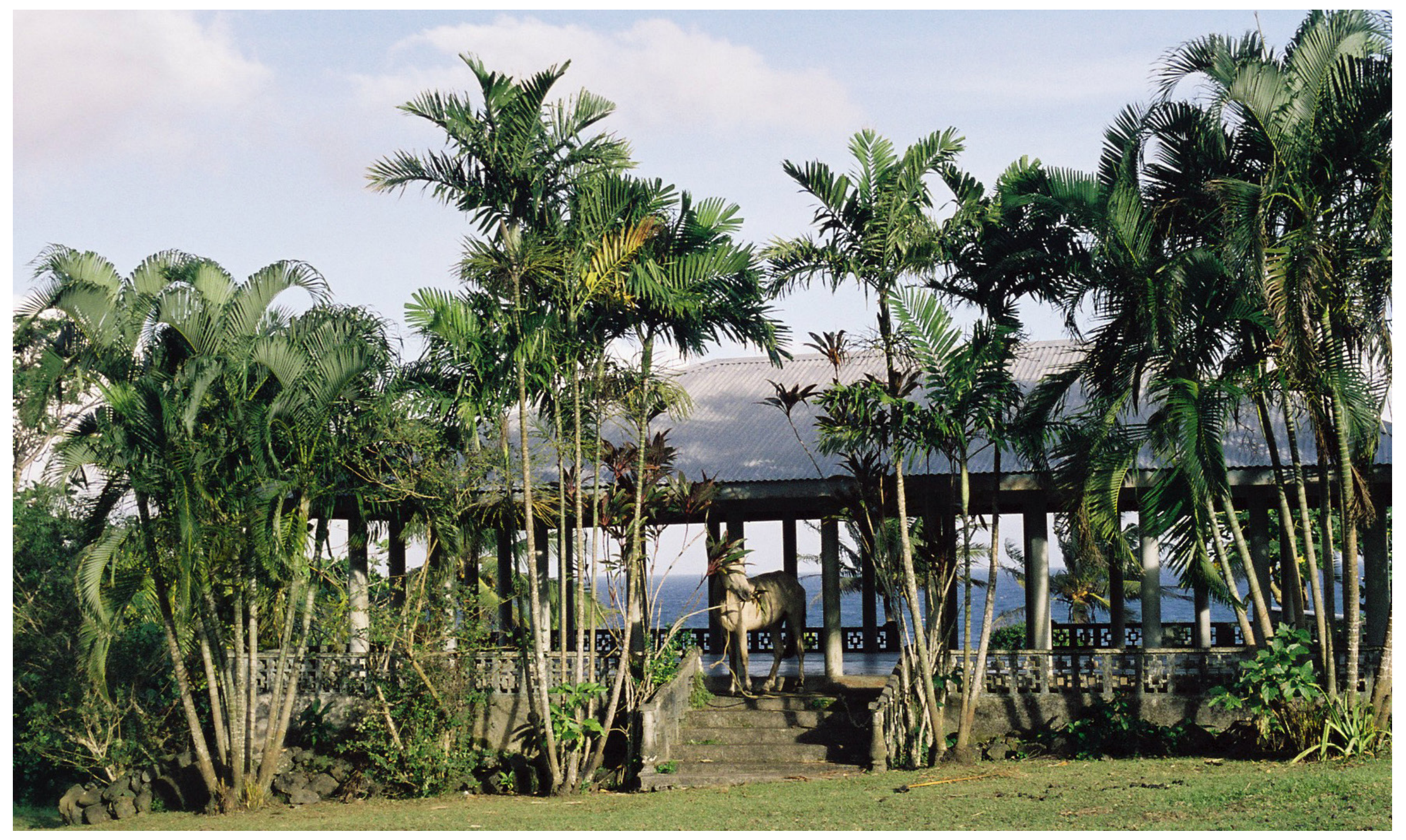

Figure 1. Abandoned fale. 

When one tugs at a single thing in nature, he finds it attached to the rest of the world.

$$
\text { - John Muir }
$$

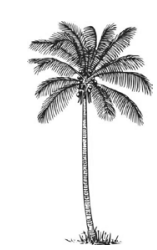




\section{Bamboo Fale \\ Climate of Change}

The Development of Hybrid Architecture within Samoa

Emily Rachel Holmes Cayford

A 120 point thesis submitted to the Victoria University of Wellington in partial fulfilment of the requirements for the degree of Master of Architecture (Professional)

Victoria University of Wellington

School of Architecture

$$
2017 .
$$

Victoria University of Wellington

22 February 2017 


\section{AKNOWLEDGMENTS:}

Thank you first to my family, for constantly asking if I had "finished yet?" and for still supporting me despite snappy replies.

Thank you to my supervisor Regan, for confirming that a trip to Samoa and Fiji was definitely necessary. Thank you for your humour and your constant help at anytime.

Thank you to everyone in the 'Design Like You Give A Damn" thesis group; Jared, Jess, Suchita, Nadrah + Anthony, it was always good to see someone in the same impossible situation as myself.

Thank you to everybody I met in Samoa. To the people who we interviewed, the people who transported us around the island and to those we didn't even meet. You were all astonishingly welcoming, this thesis would not be possible without you all.

And thank you to friends, inside and outside of the studio. You were all huge distractions, but I would have lost my mind without you. 
3 ABSTRACT:

5 CHAPTER ONE WELCOME TO SAMOA

9 SAMOA POPULATION DENSITY:

10 ARCHITECTURE IN SAMOA:

12 TRADITIONAL FALE:

14 FALE PALANGI:

16 WARMING PACIFIC CLIMATE:

19 CHAPTER TWO LITERATURE REVIEW + HYBRIDISATION FRAMEWORK DEVELOPMENT

20 LITERATURE REVIEW:

25 DEVELOPING A HYBRIDISATION FRAMEWORK:

27 DIAMOND ISLAND COMMUNITY CENTRE:

29 TE WHARE WĀNANGA O AWANUIĀRANGI:

31 INDIAN INDUSTRY SOHRABJI GODREJ GREEN BUSINESS CENTRE:

33 JEAN-MARIE TJIBAOU CULTURAL CENTRE:

42 HYBRIDISATION FRAMEWORK SUMMARY:

43 APPLICATION OF FRAMEWORK:

45 CHAPTER THREE METHODOLOGY

50 RESEARCH THROUGH FIELD OBSERVATION + INTERVIEWS:

54 DISCUSSION:

55 METHODOLOGY: MATERIALITY

56 BAMBOO DESIGN PRECEDENTS: 
59 POSITIVE+NEGATIVES OF BAMBOO:

60 METHODOLOGY: SITE + PROGRAM SELECTION

61 DESIGN PROPOSITION:

62 METHODOLOGY: SITE REVIEW

63 SPREP DESIGN:

65 DESIGN INTENTION:

66 METHODOLOGY: RESEARCH THROUGH DESIGN

73 CHAPTER FOUR FINAL DESIGN

75 DESIGN DESCRIPTION:

77 LONGITUDINAL SECTION:

78 FLOOR PLANS:

82 DESIGN ELEVATIONS

86 KEY ELEMENTS OF THE FINAL DESIGN:

90 BAMBOO CONSTRUCTION DETAILS:

93 SPREP DESIGN COMPARISON:

95 CHAPTER FIVE CONCLUSIONS

97 ARCHITECTURAL CONCLUSIONS:

101 CHAPTER SIX BIBLIOGRAPHY + LIST OF FIGURES

102 BIBLIOGRAPHY:

105 LIST OF FIGURES:

111 CHAPTER SEVEN APPENDIX 


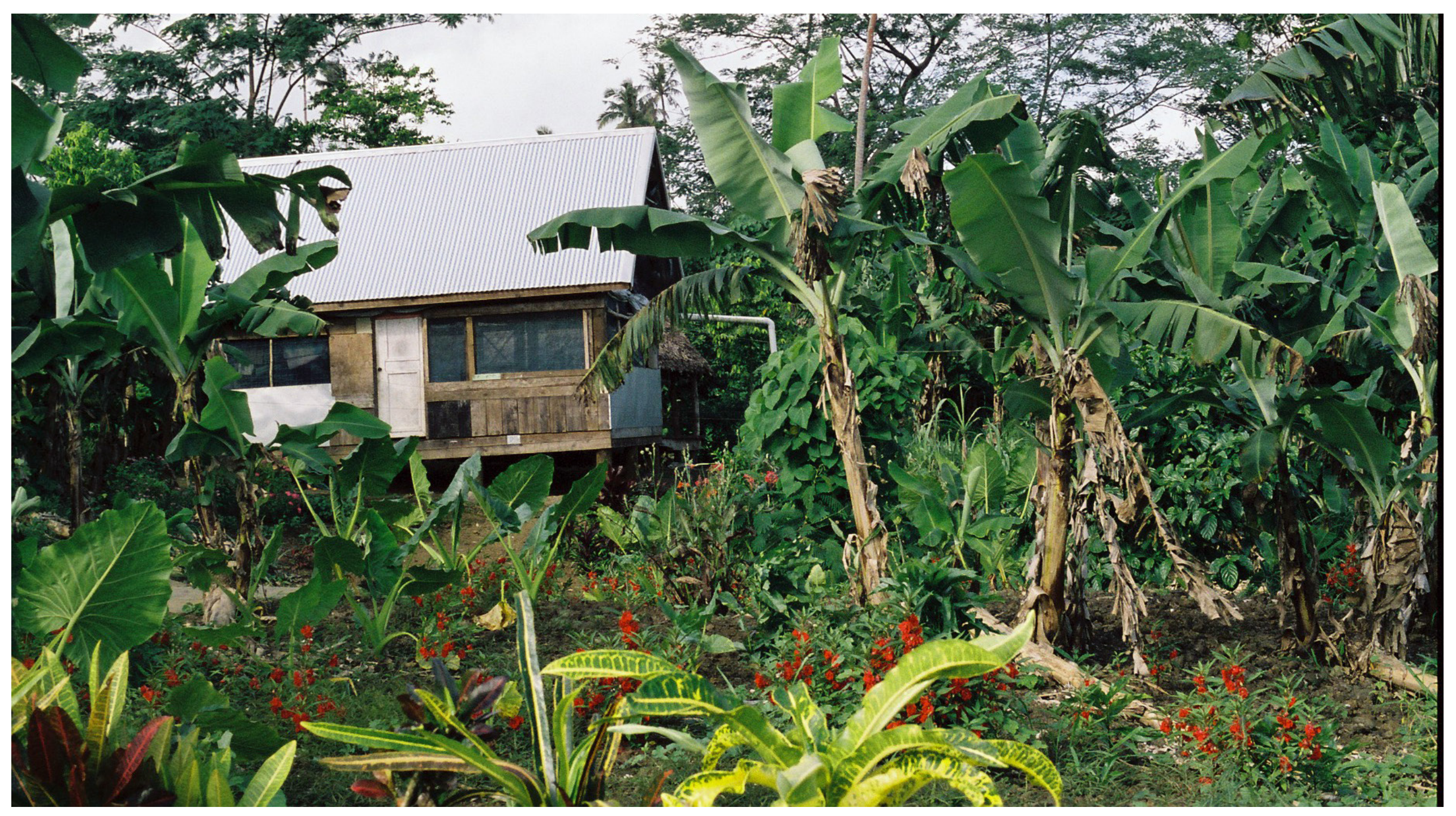


"It is truly frightening to think that our ocean will turn against us. We have been sustained by the ocean for two millennia. It has been bountiful and continues to yield to us its bounty. We have learned that this harmony may be interrupted by the action of nations very distant from out shores. I hope that the appeal of the peoples of the Pacific can help convince industrialised nations to discontinue their profligate contamination of the atmosphere."

- President Amata Kabua of the Marshall Islands, 1988 


\section{ABSTRACT:}

The world is currently sitting on the brink of a massive upheaval as Climate Change continues to intensify. At this stage, there is no apparent turning back: the only remaining option is to adapt. While many countries are already feeling the

effects, some of the most vulnerable lie within the Pacific Islands.

With $70 \%$ of the Samoan population living along their coastline (The World Bank, 2016), the country is identified as one of the most vulnerable Pacific Islands. It is prone to high waves and storm surges, along with tropical cyclones, which destroy livelihoods and housing, as well as claiming lives.

The traditional architecture of Samoa was originally built to withstand such weather events, but has not been adapting to resist the increased cyclone intensity and rising sea levels. The materials and building practices currently used within Samoa do not have the properties to resist these extreme weather events.
Western building practises have been introduced and into the Samoan construction industry, but has not yet successfully been integrated. Combinations of traditional and Western building practises are, instead, resulting in buildings more vulnerable than ever. This issue remains unresolved, with unsuitable housing remaining one of the largest dilemmas currently faced by Samoa's inhabitants.

Samoa recently graduated from the classification: Least Developed Country, to be classified as a Developing Country (Pilot Programme for Climate Resilience). This places Samoa as one of the more developed nations of the Pacific, therefore encouraging Samoa to take the lead in resilience to the ever imposing effects of Climate Change. Samoa has a close relationship with both New Zealand and Australia and therefore has access to building expertise, education and materials. Why, then, is Samoa so lacking in architectural resilience to the effects of Climate Change?
This paper endeavours to investigate this gap and, in turn provide a potential resolution. These solutions could aid other Pacific countries as well as encouraging further architectural resilience that can then be mirrored by the remaining, vulnerable countries of the Pacific.

\section{This thesis first investigates the question:}

"Why has Samoan culture not developed stronger architectural resilience against Climate Change?"

This thesis then evolves to question:

"How can Samoan architecture be hybridised to influence increased architectural resilience against Climate Change?" 


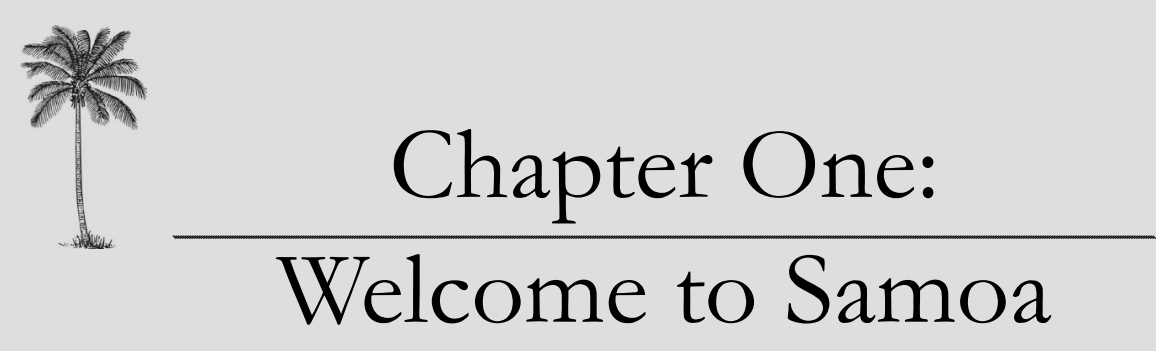


Samoa is made up of two main islands, Savai'i and Upolu, which contains the capital, Apia. The following page displays a map showing the population density of Samoa, with the majority of people living in the capital, Apia. Samoa has a total population of 194,320 people (Climate Change in the Pacific), the majority of which are Samoan citizens.

The focus economy for the country is in agriculture, fishing and tourism, all things that rely heavily on the climate. The typical climate of Samoa is tropical, with high temperatures uniform throughout the year. The country has high humidity levels and experiences its main cyclone and rain season from December to February (Hennessy et al, 2011).

Samoa is a country with strong traditional ties that are clearly seen in their architecture. With strong Western influences and a rapidly changing climate, Samoa finds itself in a complex situation where it seeks to retain cultural values as well as developing with the changing times.

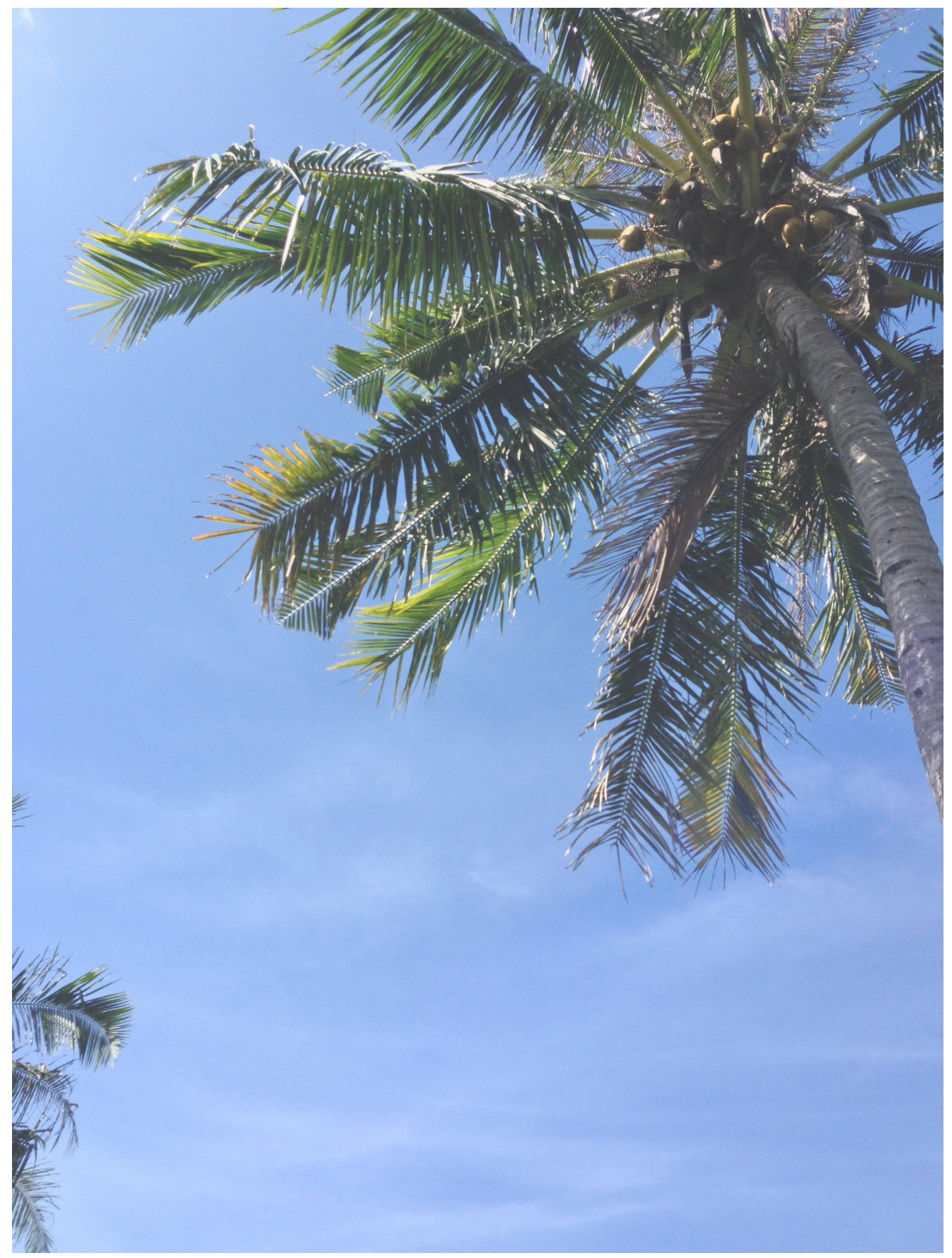


Persons per $\mathrm{km}^{2}$

$1000+$

250-999

25-249

5-24 

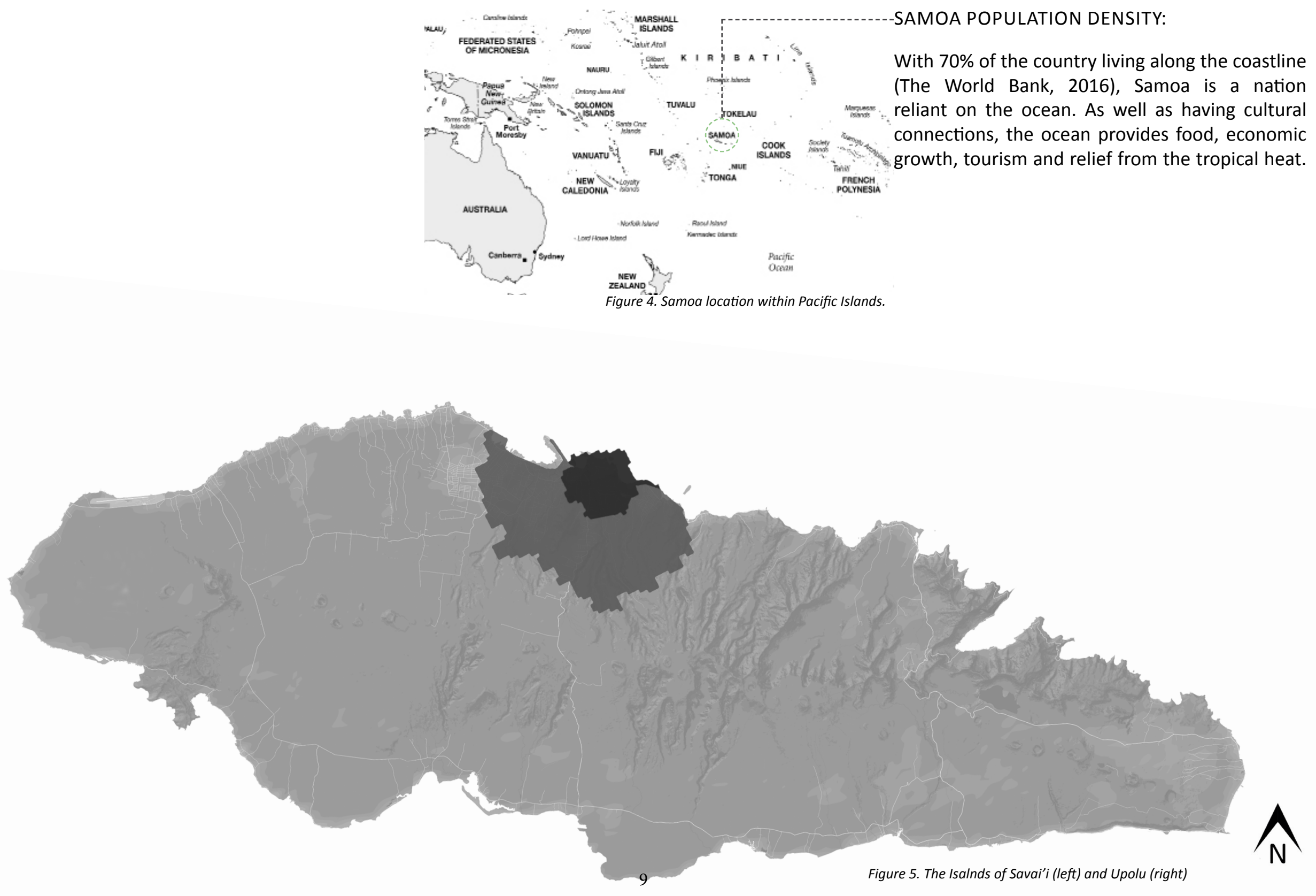


\section{ARCHITECTURE IN SAMOA:}

In the past 150 years Samoa's architecture has developed into a complex hybridisation of their traditional designs mixed with European influences. While there is potential to maximise the benefits of each of these architectural styles, the result has instead been mismatched and unsuitable to the climate and daily ways of life.

This is largely due to limited resources as well as the expense of importing the required building materials. The European architecture found in Samoa has not been suitably developed to suit the harsh climate and so is falling behind as the people of Samoa begin to live more modern lives "you can't live a modern life in a fale" (Architect, Interview). Samoa currently runs the risk of abandoning its traditional architecture altogether, unless significant adaptation can be made.
The Samoa Planning and Urban Management Agency (PUMA) has recently developed several urban guidelines put in place to preserve the traditional architecture of Samoa.

The following extracts are taken from Section 3: Civic Design and Urban Development (The Samoa National Urban Policy).

"Heritage buildings are a unique part of our city scape that adds character, value and life to the city as a whole. The legal mandate must be strengthened to provide protection and equally encourage incentives to promote alternative business revenue generating activities".
These urban guidelines also comment on the need for further sustainable practises when building. This shows the people of Samoa's understanding that changes need to be made and how they are in need of guidance to do so.

"Existing buildings need to be retrofitted to substantially improve their energy efficiency and new building design need to be based on green building standards".

\section{FLOORING MATERIALS}

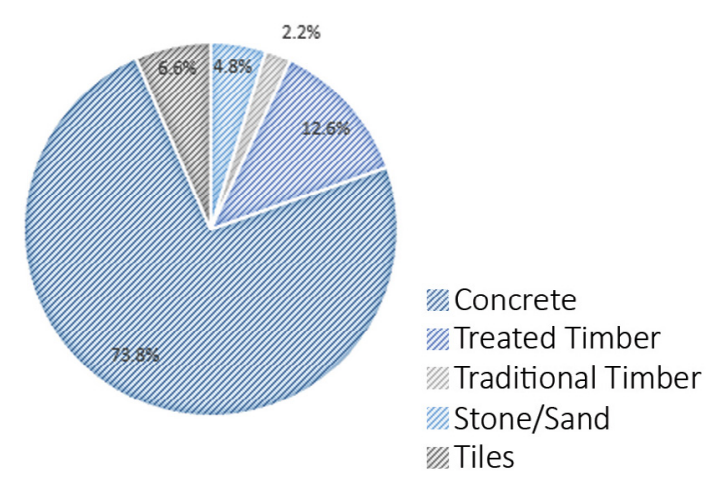

Figure 6: Flooring Materials.

\section{HOUSE TENURE}

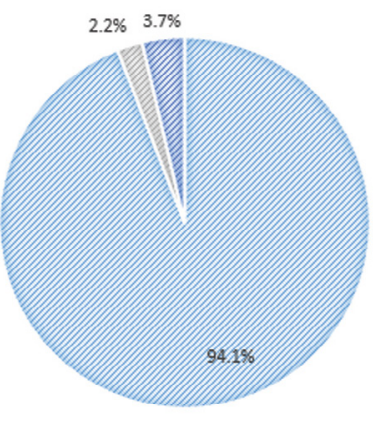

Owned

Wh Owned by Other

Rented 
The graphs below display building information collected in the 2011 Census of Samoa (Samoa Bureau of Statistics, 2011). This information shows the mix of traditional and European materials used in houses today.

Flooring materials being used shows a significant majority using concrete, despite its lack of adaptation to the Samoan climate. The House

Tenure notes that almost $95 \%$ of families own their own houses, so families are not restricted by renting laws.

\section{HOUSING TYPE}

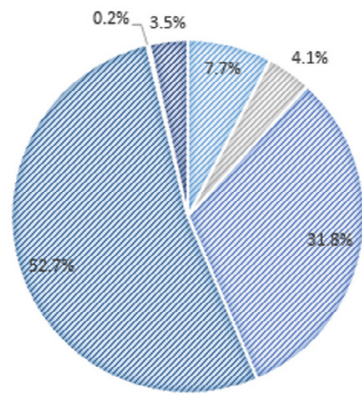

V/. Closed European House Open European House Closed Samoan Fale When Samoan Fale V/. 2+ Storey European House 骖 $2+$ Storey Samoan Fale
Owners of a traditional fale and a westernised house are split 50/50, the positives and negatives of these two housing types are detailed in the next section.

The majority use of corrugated iron as a roofing material illustrates a reliance on imported material, as this is not produced within the country. Wall materials cover a wide range showing that an optimum solution has not yet been found.
WALL MATERIALS

ROOF MATERIALS

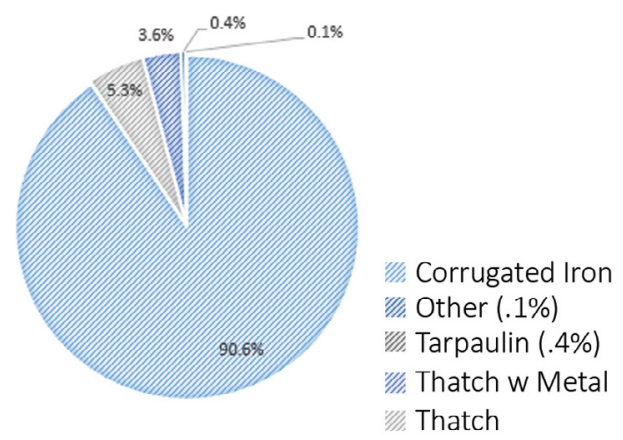

Figure 9: Roof Materials.

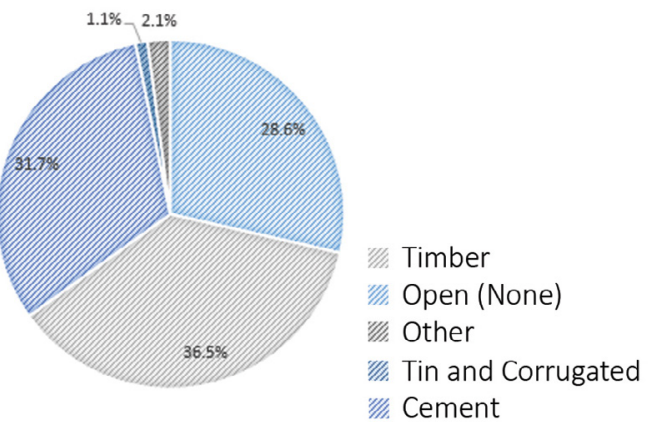

Figure 10: Wall Materials. 


\section{TRADITIONAL FALE:}

The traditional fale, Figure 12, of Samoa is recognisable due to its openness. Traditionally, the people of Samoa do not keep to themselves with immediate family, but prefer to live in villages with extended family. The open fale mirrored this life style where everyone was welcomed anywhere.

"Samoa is the last of the Polynesian countries to make extensive use, even today, of its own traditional architecture in the construction of houses. Nowhere in the Pacific is a more felicitous traditional dwelling to be found... the fale does indeed seem to be without peer in combining so many positive features" (The Samoan Fale, 1992)

"It must also be remembered that Samoa has endured over 2,000 cyclone seasons to perfect their prototype, while Western architecture has been here for only 150 years."

(Takahashi, 2015)

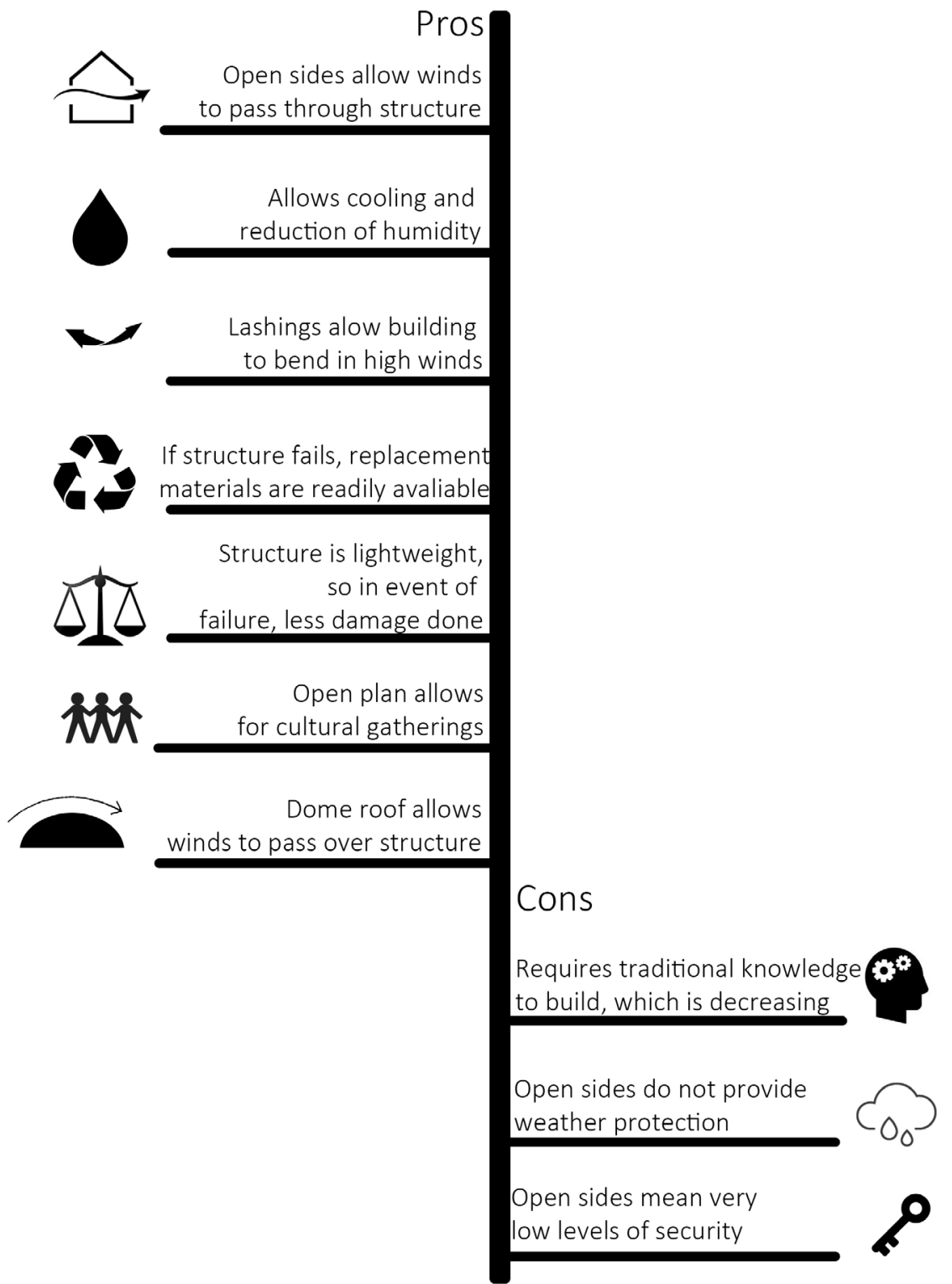




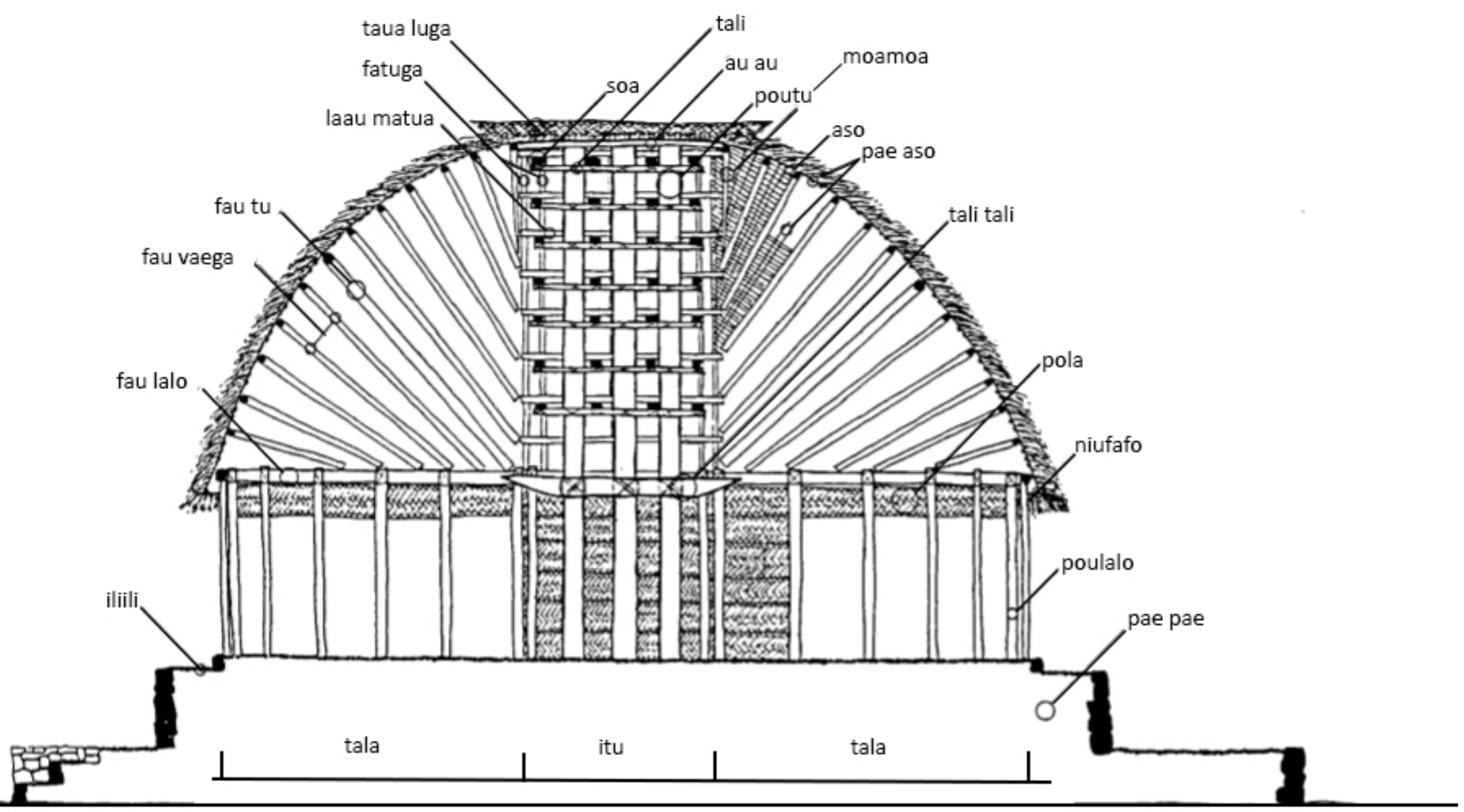




\section{FALE PALANGI:}

Palangi is a Samoan word meaning European. The fale palangi is a house within Samoa that has been designed to replicate the construction techniques of European people. An example of this construction is shown in Figure 14.

"With the coming of independence in 1961 the construction of Western style architecture on the village level was greatly accelerated. Although guest fale are still open structures, the majority are built using Western technology and materials. The stylistic shift coincides with the escalation of Samoan migration to New Zealand as well as the increase in salaried jobs in government and business offices in Apia."

(Allen, 1993)

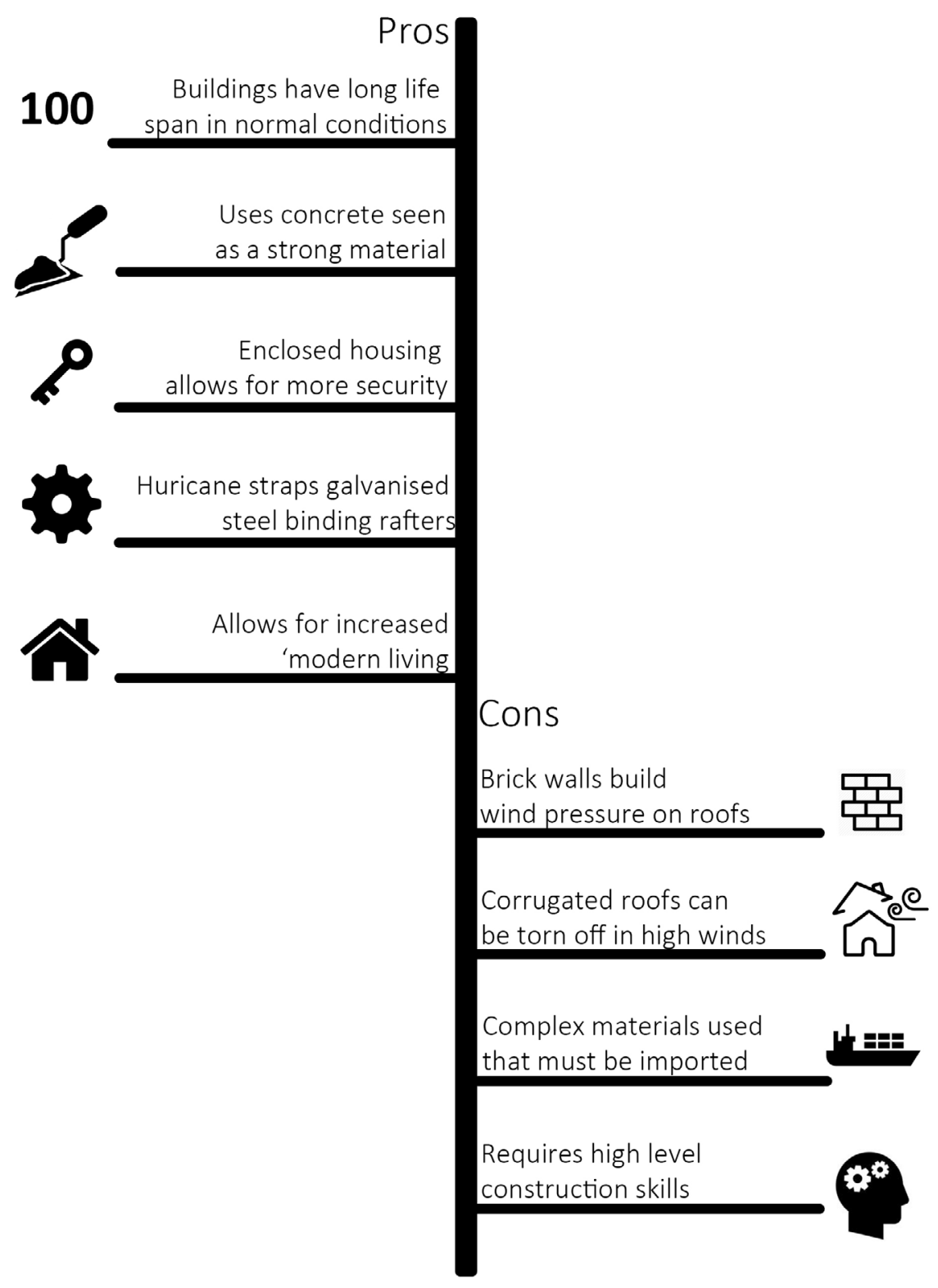




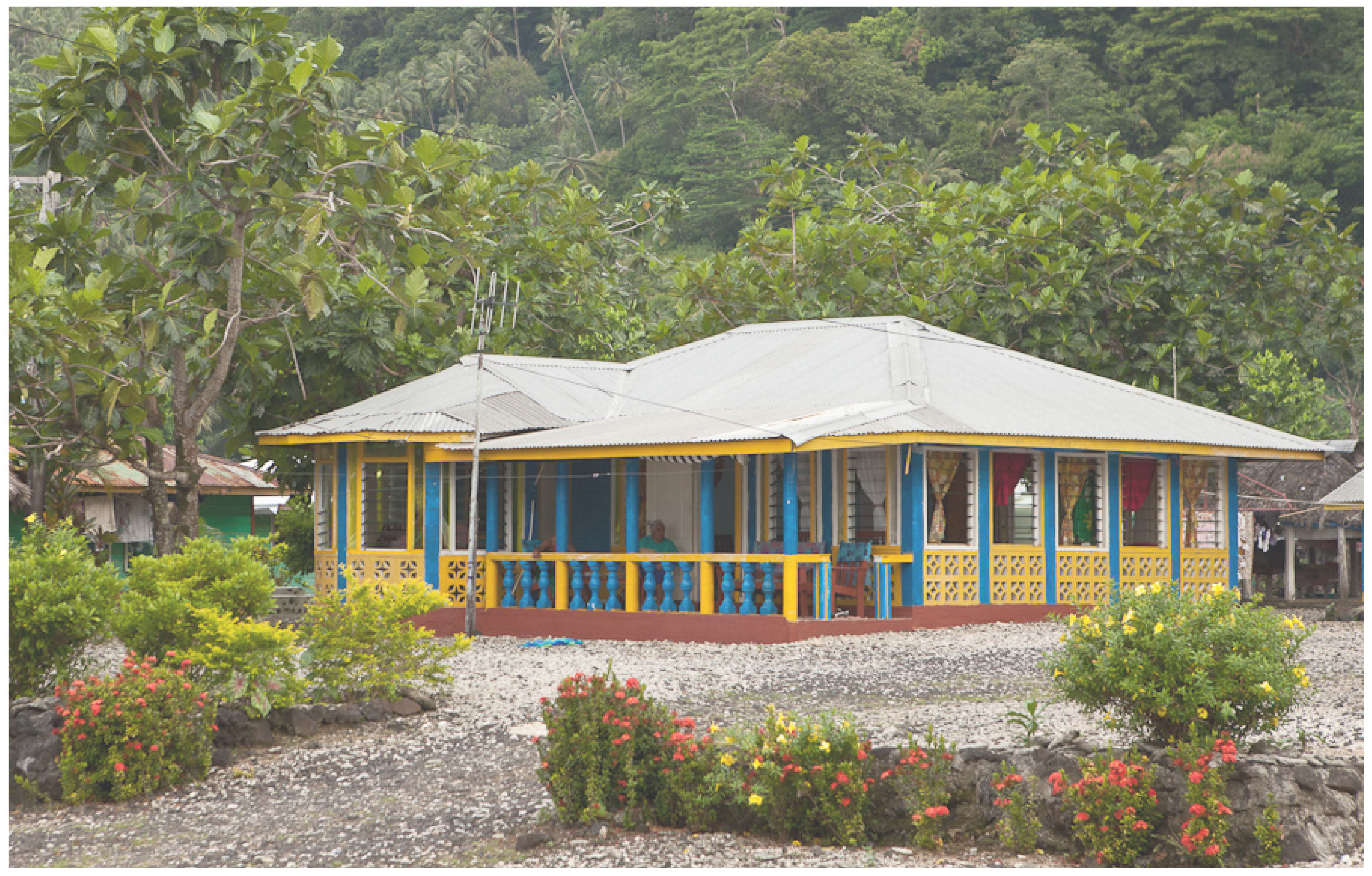




\section{WARMING PACIFIC CLIMATE:}

"2016 is shaping up as the hottest year on record. The first six months of the year were the hottest since records began in 1880, while the Arctic has seen record low sea ice levels. As a result of the growing impacts of climate change, millions of people are experiencing higher temperatures and extreme weather events such as droughts, heat waves, floods and storm surges, putting food and water security at risk, and threatening agricultura supply chains and many coastal cities".

(World Bank, 2016)

Climate Change is no longer an issue for debate, due to the overwhelming mass of data substantiating it. It has been countries similar to Samoa who have been the sacrificial 'canary in the cage', alerting the rest of the world to the very real issues. This is exceptionally unfair as it is the larger countries in the world who have polluted the environment to this point, with the smaller countries being the first to feel the effects.

Samoa has always been a country familiar with extreme weather events and so has been experiencing tropical cyclones and flooding for years. The country has steadily developed its resilience to these weather events as they have been relatively predictable for thousands of years. Due to a sharp increase in the warming of the climate, however, these weather events have taken a sharp turn in intensity and frequency.
Samoa sits within the South Pacific Convergence Zone (SPCZ), a band of low level convergence, which effects the cloud cover and precipitation for areas from The Solomon Islands across to Fiji and Samoa. Due to El Nino, the SPCZ has annually shifted its location, causing the extreme weather found in the Pacific Islands. However, with the climate heating up, El Nino events are growing stronger. This causes the SPCZ to move further north-east than ever before, inducing extreme weather events not previously experienced.

"Due to its strong rainfall gradient, a small displacement in the [South Pacific Convergence Zone] SPCZ's position causes drastic changes to hydro-climatic conditions and the frequency of extreme weather events such as droughts, floods and tropical cyclones experienced by vulnerable island countries in the region." (Hennessey, 2011)

Within the SPCZ sits the western Pacific warm pool. Tropical cyclones only develop where ocean surface temperatures sit above $27 \mathrm{C}$, this is generally a condition found only within the western Pacific warm pool. With the steady increase of ocean temperatures as well as the increase of El Nino events it has been observed that this warm pool is expanding eastwards (Nunn, 2012). This is considered to be a potential reason for the increase in tropical cyclone frequency.
"[An] increased incidence of tropical cyclones reaching countries in the central South Pacific (such as Niue and Samoa) that have

traditionally regarded themselves as beyond the geographical reach of these phenomena" (Nunn, 2012)

In 2013 Samoa's Planning and Urban Management Agency compiled The Samoa National Urban Policy handbook to encourage a "Sustainable, Resilient and Inclusive City". Section 3.3 addresses the issue of the changing climate.

Planning processes have generally not taken Climate Change risks into adequate account and existing infrastructure has generally been designed, constructed and maintained with limited climate data or consideration of the hazards. There are significant areas of existing development at risk from sea level rise, storm surge, flooding, and drainage issues.

This entry indicates the country is aware of these developing risks and encourages the "Development of design standards for flood-proofing buildings and infrastructure". This suggestion is yet to be acted on, however acknowledging the issue suggests that the country is ready to make significant construction changes. 


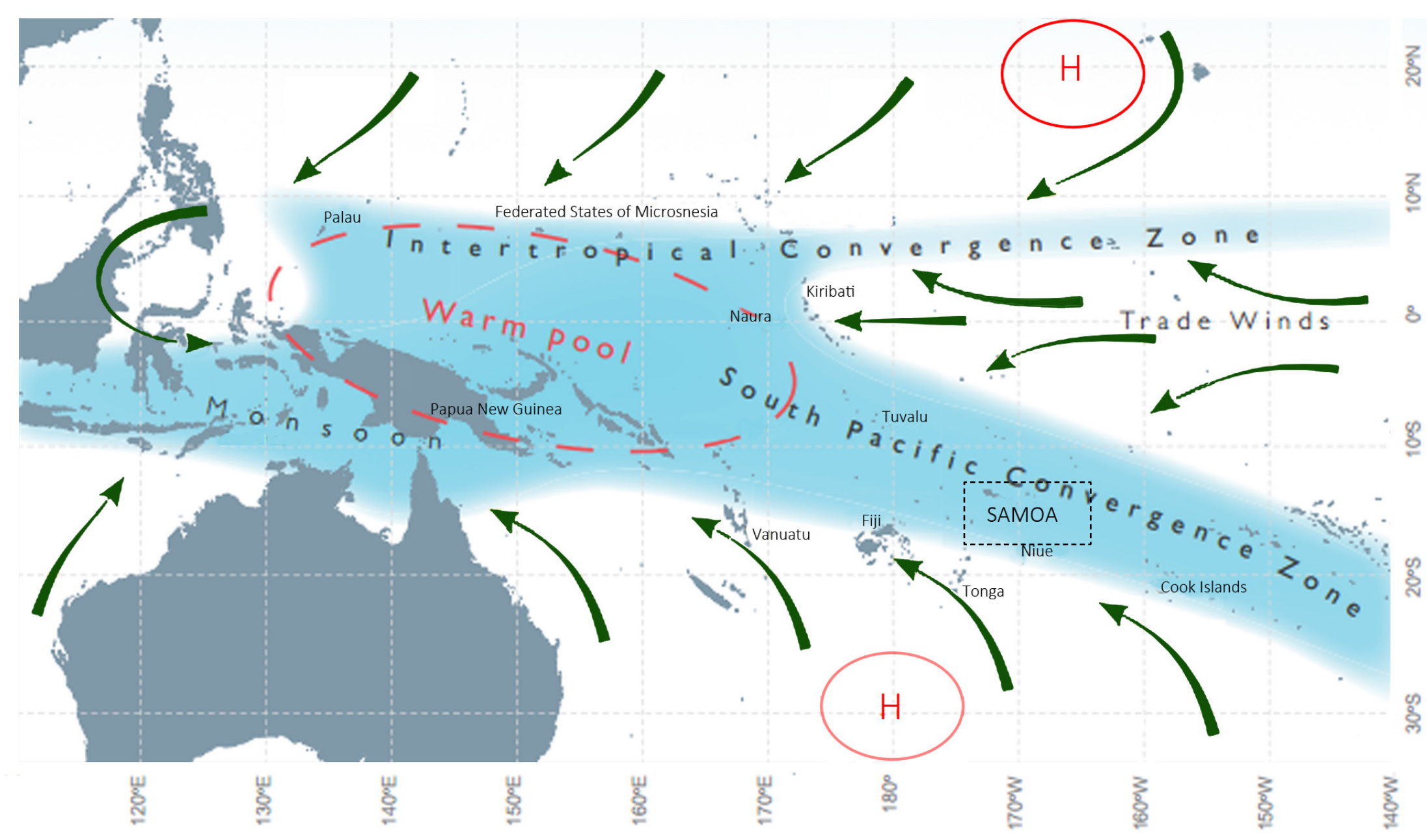




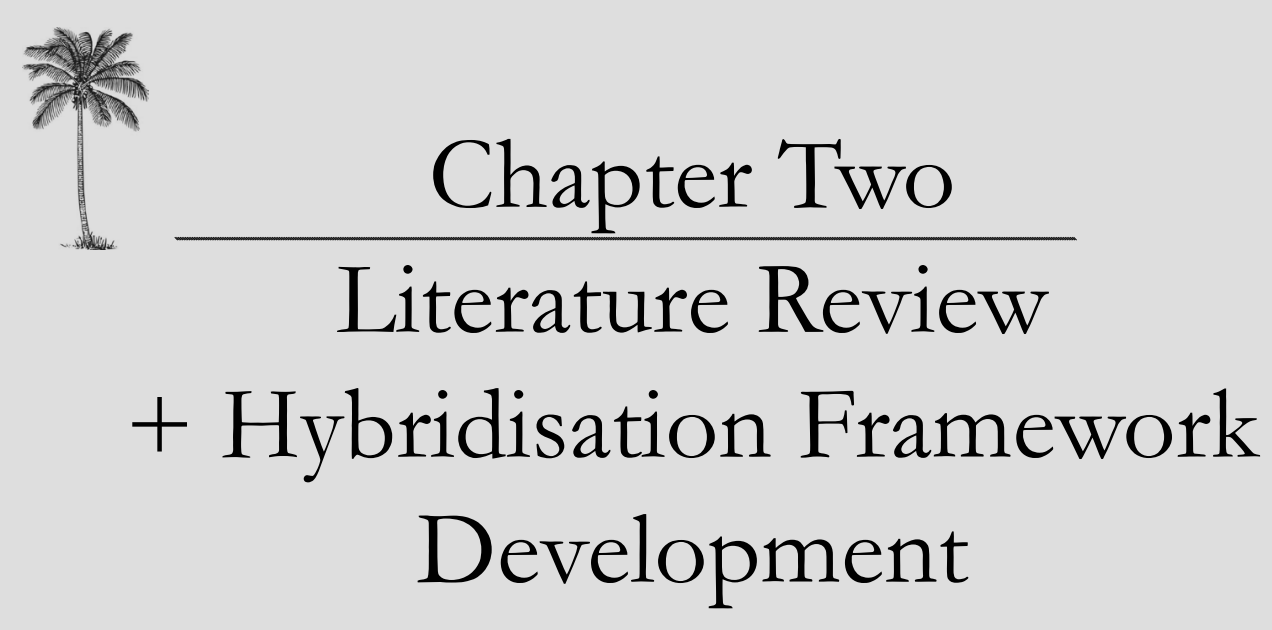




\section{LITERATURE REVIEW:}

The extent of the effect Climate Change is having on the South Pacific, including Samoa, has been detailed in many academic documents. Two papers that focus on problems specifically faced by Pacific Islands are World Bank's, 'Acting on Climate Change \& Disaster Risk for the Pacific' and Patrick Nunn's paper 'Climate Change and Pacific Island Countries'. Samoa is described as one of many countries struggling to mitigate the climate's hazardous effects, emphasising that they must soon develop their architecture and daily living in response to Climate Change (World Bank, 2016).

The future predictions surrounding Climate Change are dire. Within the Pacific region temperatures are predicted to rise 1.4-3.7 degrees celsius, causing a sea level rise of approximately $100 \mathrm{~cm}$

(Nunn, 2012). The International Climate Change Adaptation Initiative projections suggest that while tropical cyclones within the Pacific may decrease in frequency, their intensity could see an $11 \%$ increase in wind speeds and $20 \%$ increase in rainfall (Hennessy, 2011).

With a large majority of Samoa's population living along the coast line, any climate changes will have a significant impact on the daily lives of Samoa's people. An increase in Climate Change intensity will not only cause strong cyclones, but will cause storm surges along with sea levels rising. It is therefore vital that the architecture of Samoa has resilience to these weather events, in order to protect inhabitants.
Samoa's housing was developed to suit the country's extreme climate, buthas be compromised by the introduction of westernised technology as well as the effects of Climate Change.

"Within the past 150 years or so, globalization (through periods of both colonization and independence) has reconfigured human interactions with natural environments on many [Pacific] islands, rendering many of these less sustainable than in the past" (Nunn, 2012).

The introduction of foreign building practises and materials has led to the development of housing that is unsuitable to the climate of Samoa.

These designs are not only uncomfortable in the Samoan climate, but can also be insensitive to Samoan cultural traditions.

An example of this is seen in a design done by IPA Engineering \& Management Consultants. A Samoa Tsunami Relief Shelter was constructed, Figure 16. The design was simple, but a lack of communication resulted in a latrine being built right beside the main living area. This is unheard of in Samoa tradition, where bathroom facilities are stationed far from living quarters. The result of this was a structure that could not be inhabited and was used only for storage (Panko et al, 2010).

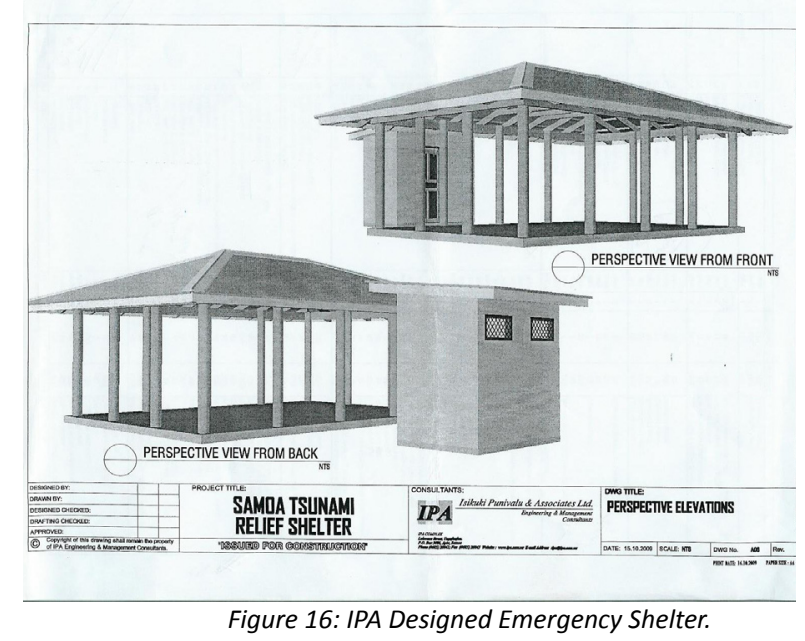


It is shown, in Figure 17, that tropical cyclones are the most damaging in terms of economic loss. As Climate Change is set to increase the intensity of tropical cyclones, this loss will only worsen. This perpetuates the cycle of Samoan inhabitants losing their housing and then rebuilding in the same style as before, only to lose their home once again.

"Vulnerability is exacerbated by poor socioeconomic development planning, which has increased exposure and disaster losses, and by climate change, which is predicted to amplify the magnitude of cyclones, droughts and flooding". (World Bank, 2016)

Here, World Bank warns against a continuation of the current way the world is treating the changing climate. The current approach is one that focuses on disaster relief, rather than mitigating the damages these disasters cause in the first place by focusing on adaptation methods.

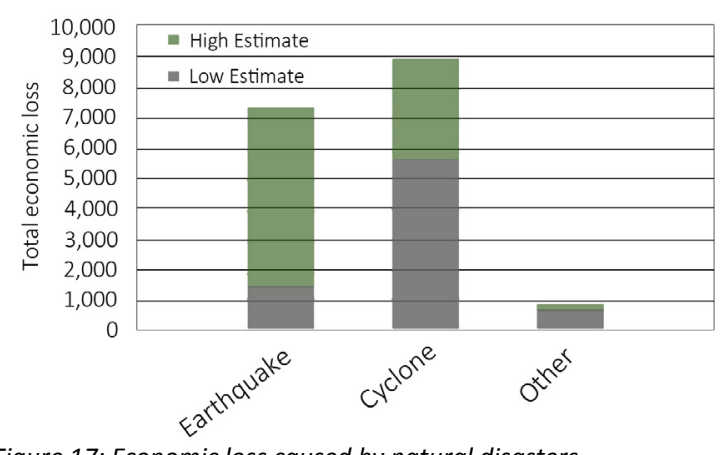

Figure 17: Economic loss caused by natural disasters.
While World Bank, like many other reports, reinforces the idea that Samoa needs to develop its current way of living, it does not suggest why the country is struggling to make these much needed changes. Reasons for Samoa's lack of architectural resilience remain largely undocumented, a gap in knowledge that needs to be addressed.

Nunn's paper reiterates how outside response has been inadequate pointing out that assistance has been "largely reactive not proactive". This adds to the problem that the people of Samoa are not being assisted in their need to adapt.

Figure 18 depicts the most destructive tropical cyclones to hit Samoa in the past 16 years. Due to low population density, fatalities are usually low, with the bulk of the damage being seen in infrastructure loss. This data suggests how inadequate the construction in Samoa is. To be hit so hard so often by a repeating weather event displays a huge lack of adaptation, an issue that must be rectified.
With the growing threat of Climate Change will come issues the world has not yet faced. One of these will be in the form of Climate Change refugees. As New Zealand has open immigration laws to Samoa, the bulk of Samoan refugees would be relocated to New Zealand. With such a strong relationship already existing between the two countries, responsibility lies with New Zealand to assist Samoa in developing their construction industry and adopting suitable architectural techniques.

\begin{tabular}{|c|c|c|c|}
\hline \multicolumn{2}{|c|}{ Cyclone $\nabla$ Year } & - & Infrastructure \\
\hline Ofa & 1991 & 4 & 12 \$200million \\
\hline Tui & 1998 & 1 & 1 Crop losses \\
\hline Heta & 2004 & 5 & $0 \$ 100$ million \\
\hline Evan & 2012 & 4 & 14 \$200million \\
\hline Amos & 2016 & 3 & 0 minim \\
\hline
\end{tabular}


While a simple solution may be to allow a mass immigration of Samoan residents, this will have several negative outcomes. An obvious problem will be the pressure this puts on the New Zealand economy - but a stronger social effect will be forced upon the people of Samoa. Samoa is a country gradually incorporating many modernised elements into their community, but remains one of the most traditional countries of the Pacific. The sense of community and the calmer way of life is unique to Samoa and would not translate to the average modern life of a New Zealander.

Preserving the architecture of Samoa not only allows them to remain in their homes, but allows them to hold onto their culture.
For Samoan families, their family fale was far more than a machine for living, it was also a place of celebration with weddings and funerals commonly being held within the fale.

(Housing New Zealand, 2009).

While Samoa is one of the further developed Pacific Islands, its built resilience is severely lacking, which is preventing the country from reaching self-sufficiency. This lack of action is leading to the nation's loss of livelihood, culture and, most importantly, population. Due to a close relationship with New Zealand, the country has access to high levels of construction education and materials. However, the amount of architectural damage caused by recent weather events implies that construction education is not being provided along with materials

Samoa's relationship with NZ and Australia is reflected to the point where Samoa's own building code is roughly based on the two countries' building codes. Although the provision of a code to follow is encouraging, it is of little use if no education is provided concerning how to enforce and implement this code. While these countries provide Samoa with a lot of support, especially post-disaster, it is clear that more focus could be directed to disaster mitigation through education. It is also important that this building code be revised to suit the extreme climate of Samoa and to implement a specialised construction education. 


\section{DEVELOPING A HYBRIDISATION FRAMEWORK:}

The people of Samoa personify a complex mix of long lasting traditions with a taste for modern living. A rapidly changing climate then strikes the combination, resulting in a complicated building brief. Research from the literature review made it clear that research and collaboration was vital to the success of a new design introduced to Samoa. To reach this goal it was essential that the design process be carefully controlled through a developed framework.

No such framework currently exists and so the next step of this thesis is the development of the Hybridisation Framework.

The use of a framework ensures that this design does not encounter any of the problems past collaboration projects have had. The framework is designed so that the resultant design can balance all the complications faced in Samoa, while making an impact and benefiting the people of Samoa.

This framework should also recognise any cultural sensitivities within a country. As has been discussed in the literature review, outsider help can have disastrous outcomes and must be approached with the utmost care.
To develop the Hybridisation Framework, buildings from across the globe were studied, including landmark buildings,

hybrid designs and combinations of the two.

Each of these buildings were then dissected into their most notable areas within 'Design' 'Construction' and 'Use'. It is important to note that these elements are chosen from popular architectural, as well as, public reviews, these are not purely the author's views.

After separating each of these designs into their most important elements, the next step is to determine themes across the the key elements of each building.

Narrowing each element into a basic category resulted in four main categories.

\section{-CLIMATE \\ -CULTURE -COMMUNITY -CONTEMPORARY}

In the next steps of this design, each decision was reflected back onto this framework to ensure it's compliance with each category. This gave the project a narrower design brief, which gave the project focus.
The design projects analysed to develop the Hybridisation Framework are as follows.

- The Diamond Island Community Centre. (Vo Trong Nghis Architects).

- Te Whare Wānanga O Awanuiārangi.(designTRIBE Architects)

- Indian Industry Sohrabji Godrej Green Business Centre.

(Karan Gover and Associates)

- Jean-Marie Tjibaou Cultural Centre.

(Renzo Piano) 


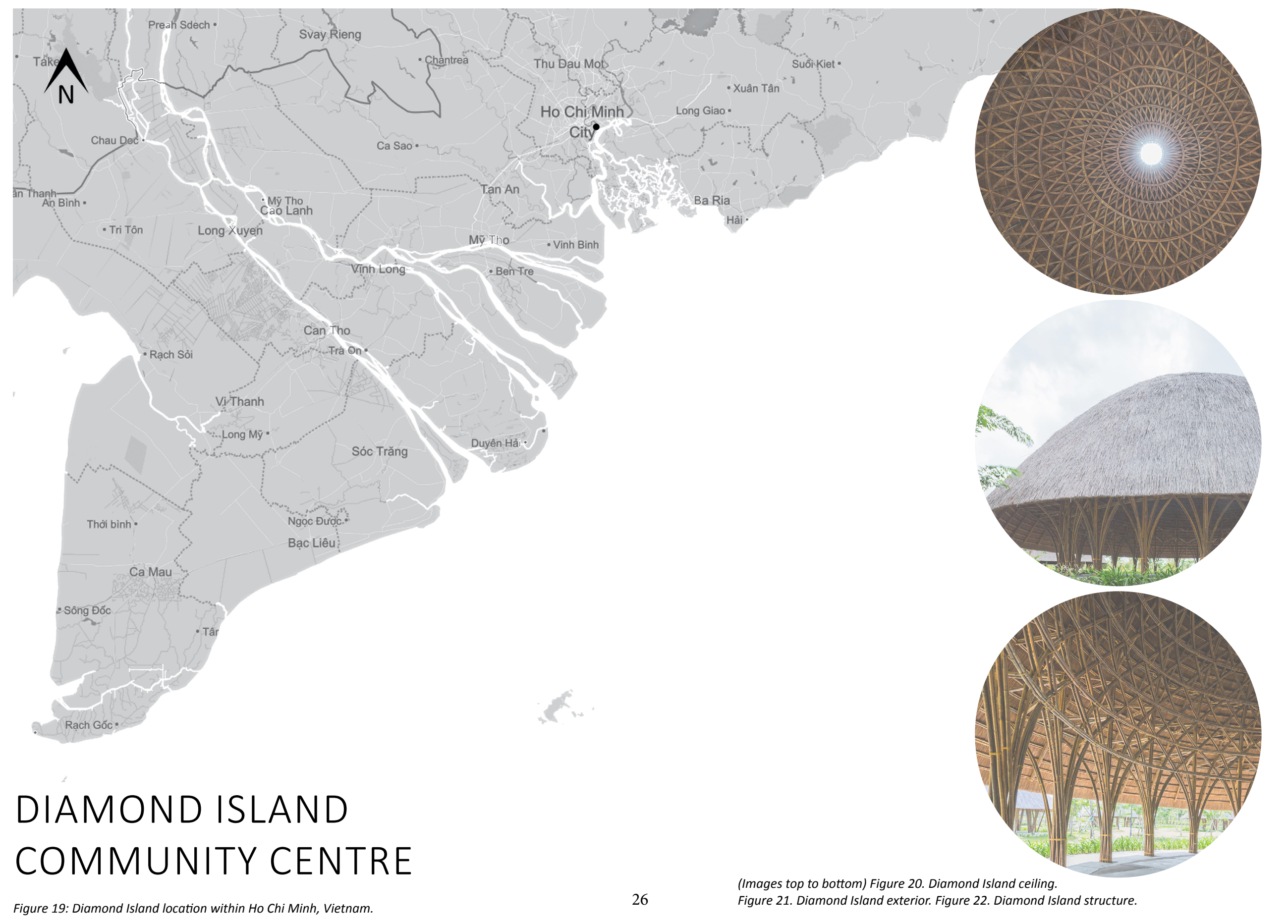




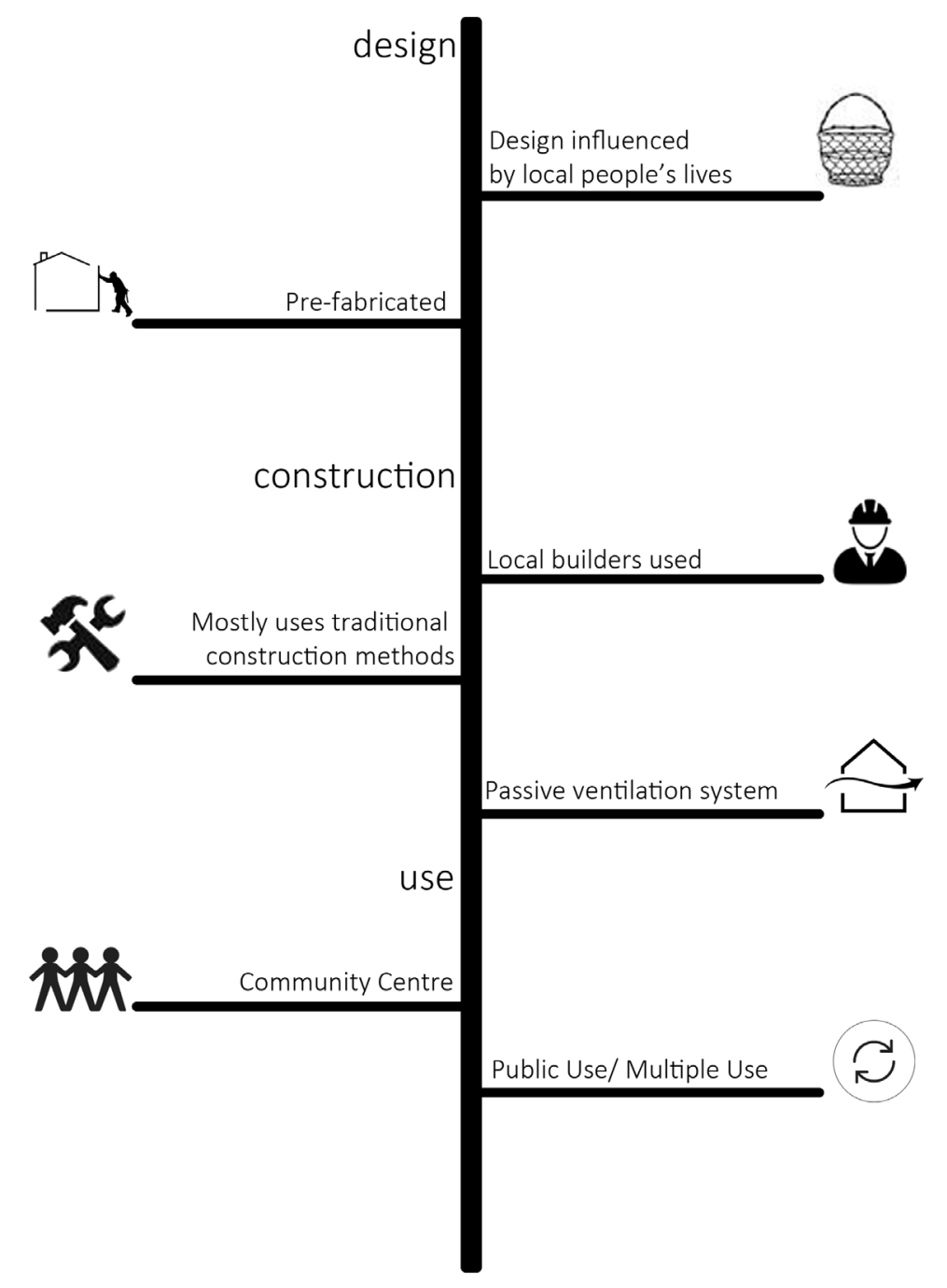

Vo Trong Nghia Architects.

2015

This design consists of eight small and large pavilions constructed across Diamond Island, beside the Saigon River. The pavilions act as community centres as well as being used for events

The designs are made entirely of bamboo and were constructed by local workers who built on-site. This design was not constructed to be vernacular, but rather to demonstrate how traditional construction methods can produce a sustainable design.

"As a result, the project is a fusion of traditional folk art and contemporary architecture".

(Diamond Island Community Centre, 2015).

Figure 23: Key Elements of Diamond Island Community Centre. 


\section{TE WHARE WĀNANGA O AWANUIĀRANGI}
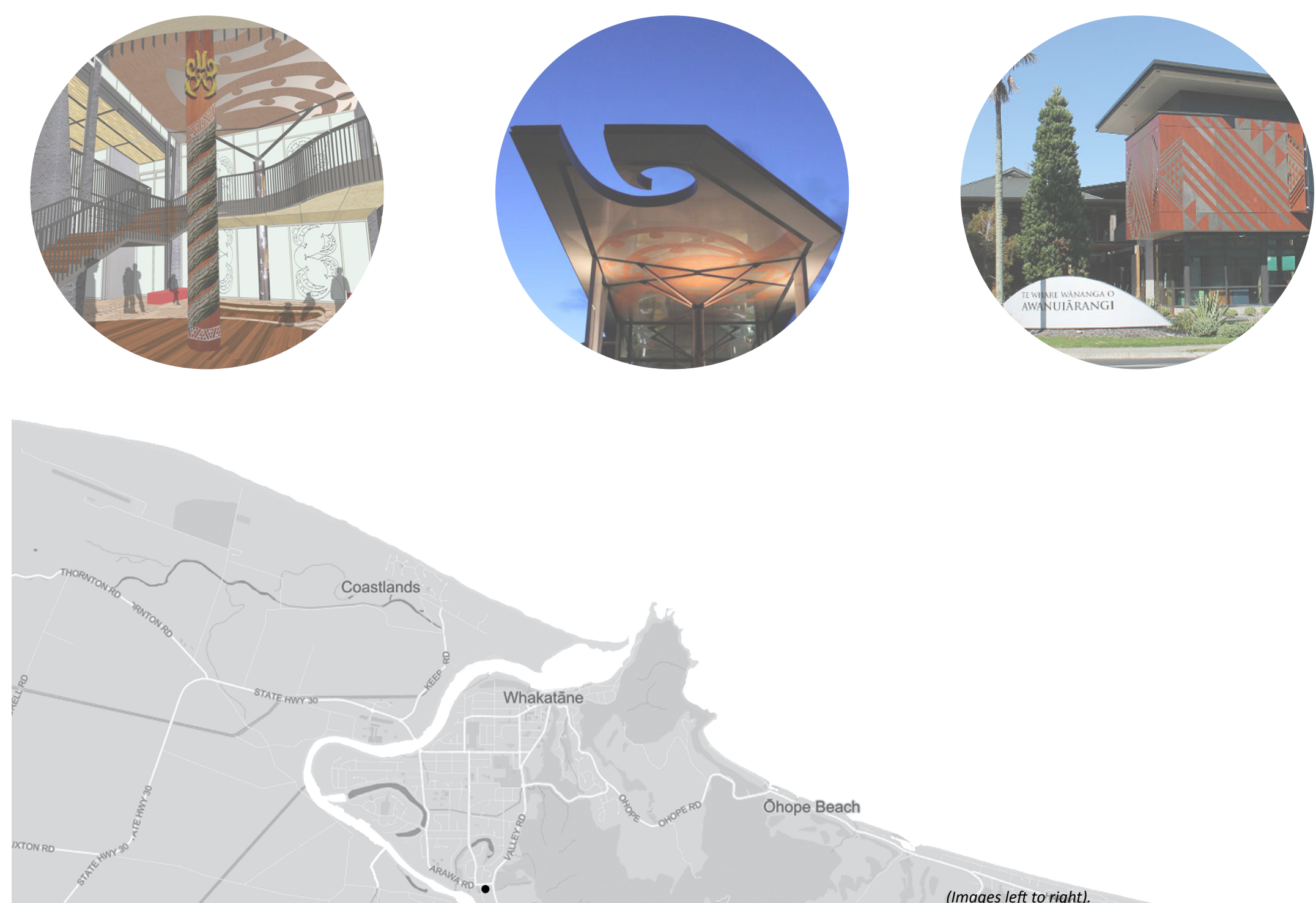

Figure 24. Te Whare Wānanga o Awanuiārangi location within Whakatane, NZ. 


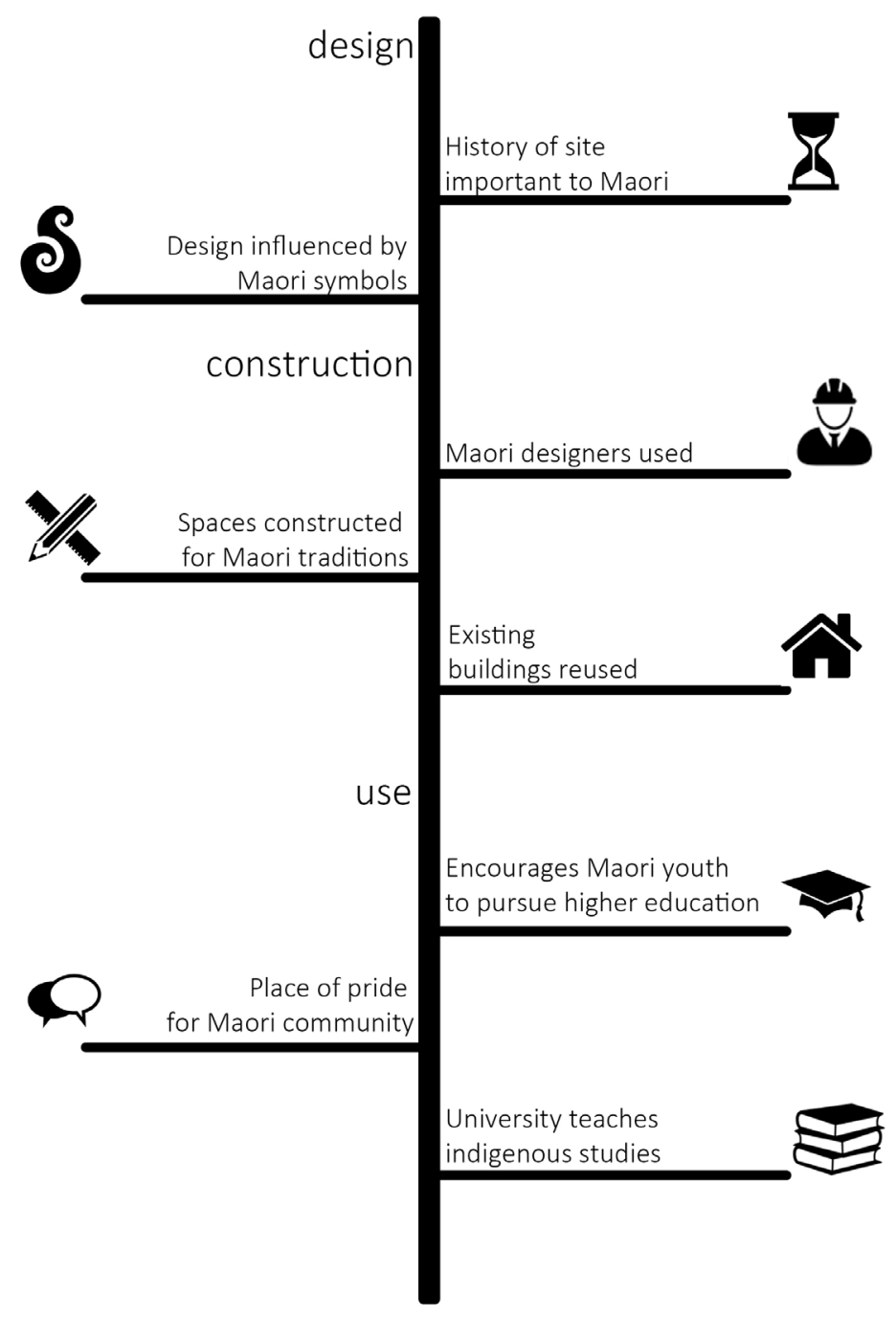

TE WHARE WĀNANGA O AWANUIĀRANGI:

designTRIBE Architects

2013

The redevelopment of this university campus was designed to reflect the Maori heritage of the area. Architect, Miles Heine described the project as an attempt to "capture the imagination of the Maori tertiary population" (2016).

"Wherever possible, in keeping with traditional Maori design and construction approaches, structural elements of the buildings are articulated to reflect their symbolic as well as true structural role" (Heine,2016). 


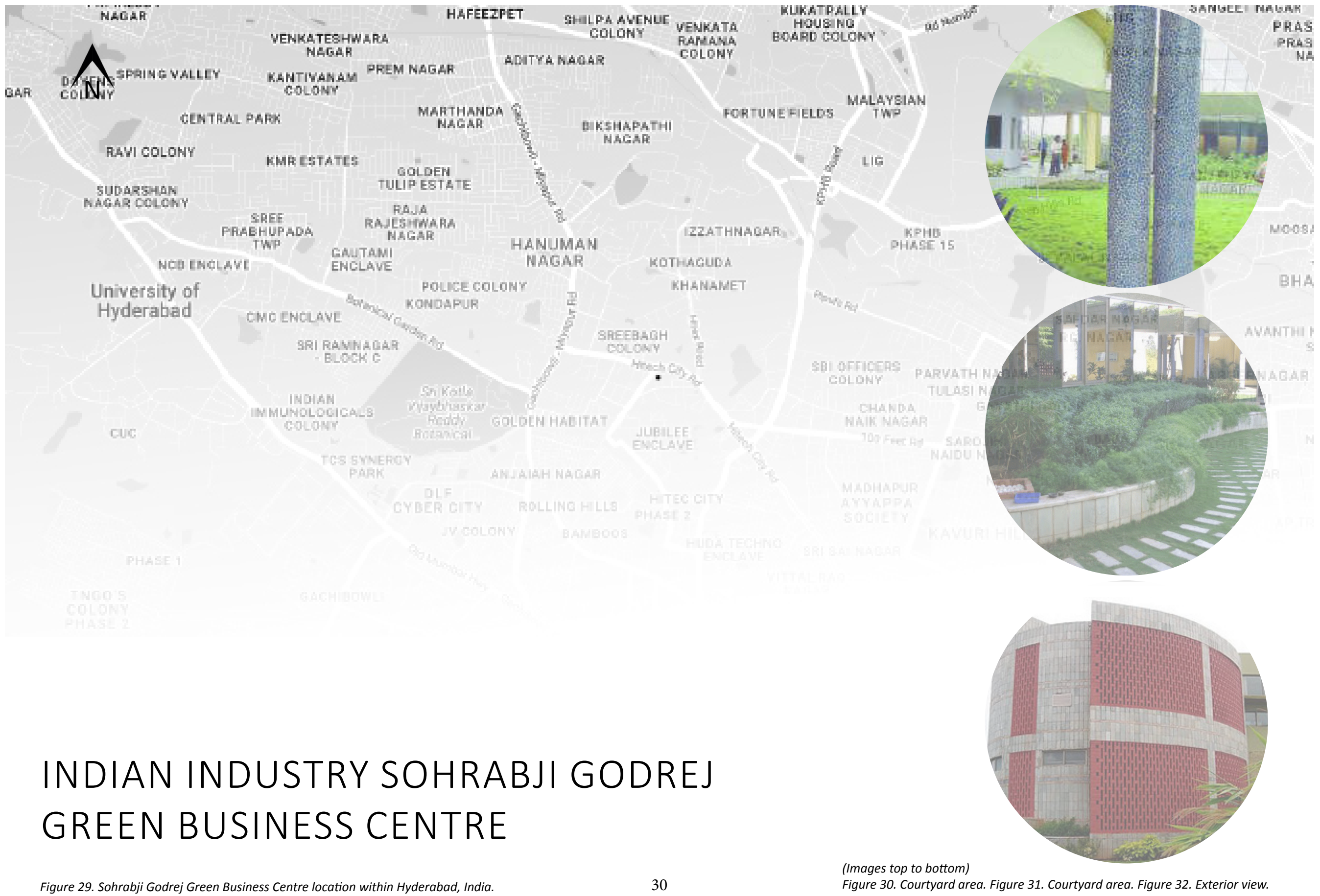




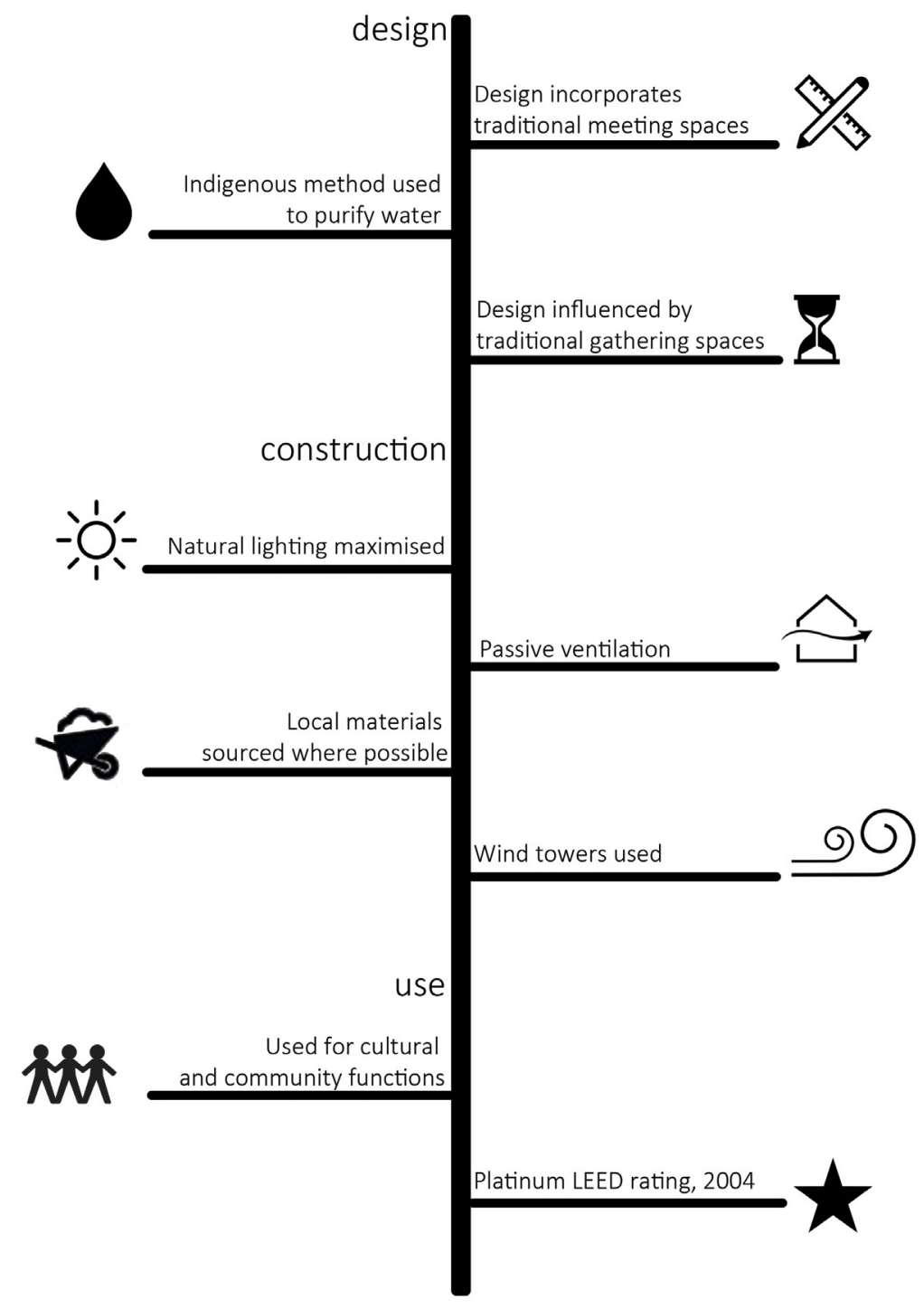

INDIAN INDUSTRY SOHRABJI GODREJ GREEN

BUSINESS CENTRE:

Karan Grover and Associates

2004

Regarded as one of the best examples of passive architecture in the world, this design was the first outside of the US to win the platinum award under the LEEDS rating system.

Ancient Indian civilisations have always respected the environment. The sustainable designs are heavily influenced by ancient Indian spiritual thoughts linking the cosmos directly to human existence.

"[This building] demonstrates that aesthetics need not be sacrificed in order to combine traditional and cultural methods with elements of modern technology".

(Jadhay, 2007). 


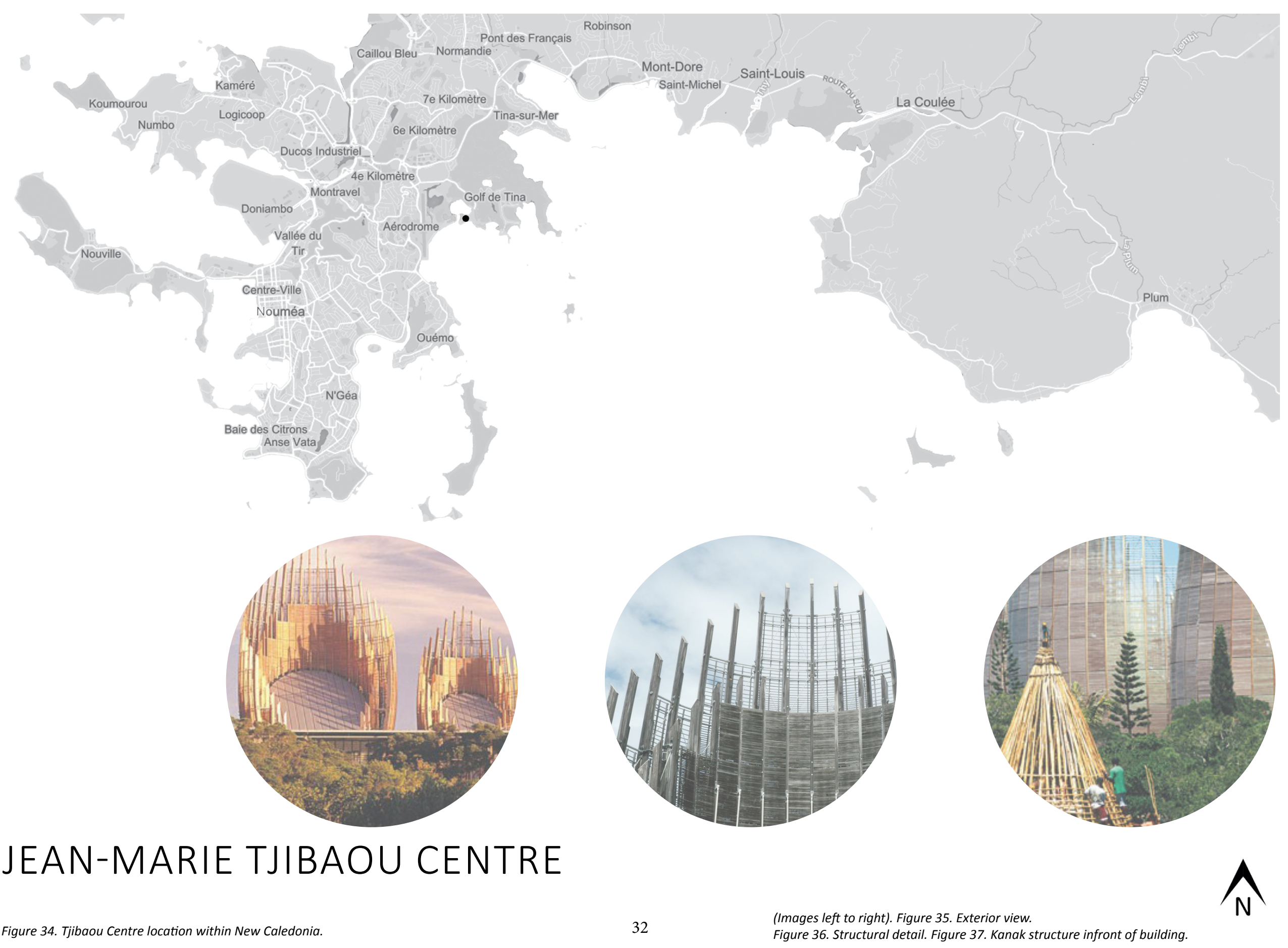




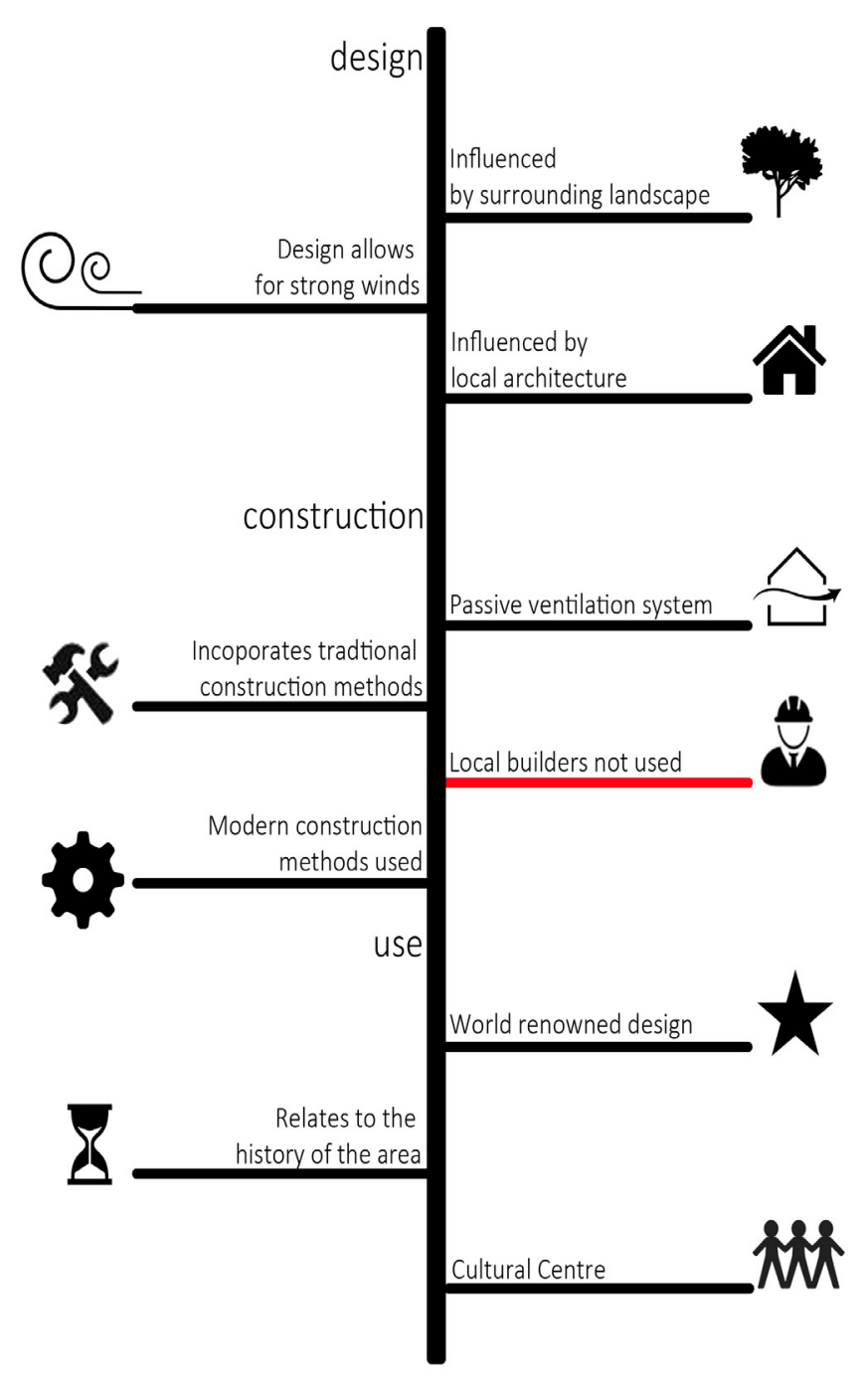

\section{Renzo Piano}

1998

The Tjibaou Centre is an exemplar of how architectural intervention can revitalise a city, an influence that this thesis intends to make.

This centre has a strong political history, named after Jean Marie, who helped lead the independence movement, until his assassination. The centre combines the traditional building techniques of the Kanak people with modern ideas to create this piece of art.

"The form of the shells negotiates a blend of traditional construction methods and a tapered, dematerialising profile that beautifully plays off the texture of the surrounding trees".

(Centre Culturel Jean-Marie Tjibaou, 2015).

In the next section the key elements of each of these buildings have been caterogised into the following:

- Climate

- Community

- Culture

- Contemporary 

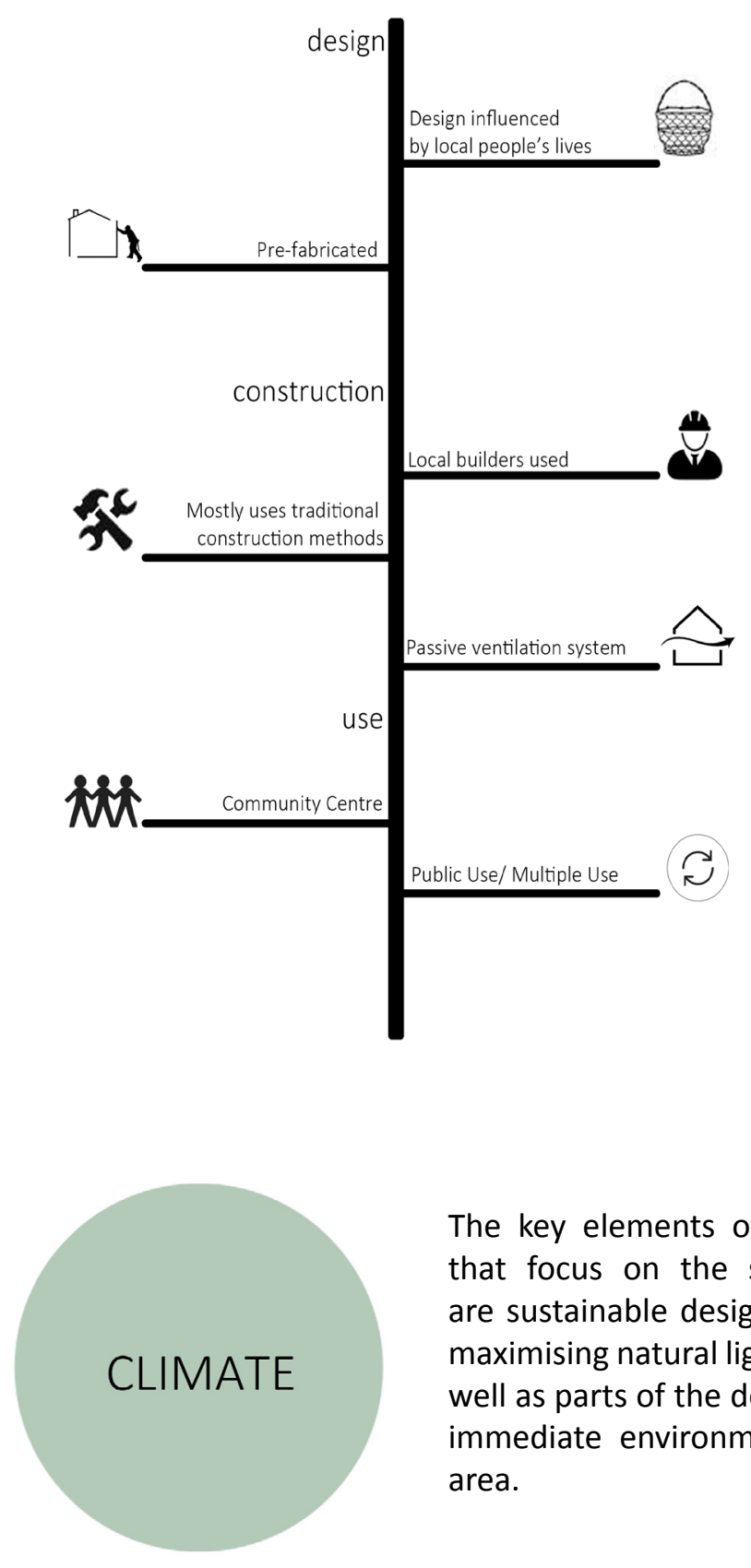

The key elements of the four buildings that focus on the surrounding climate are sustainable design elements, such as maximising natural light, of the building as well as parts of the design that reflect the immediate environment of the building area.

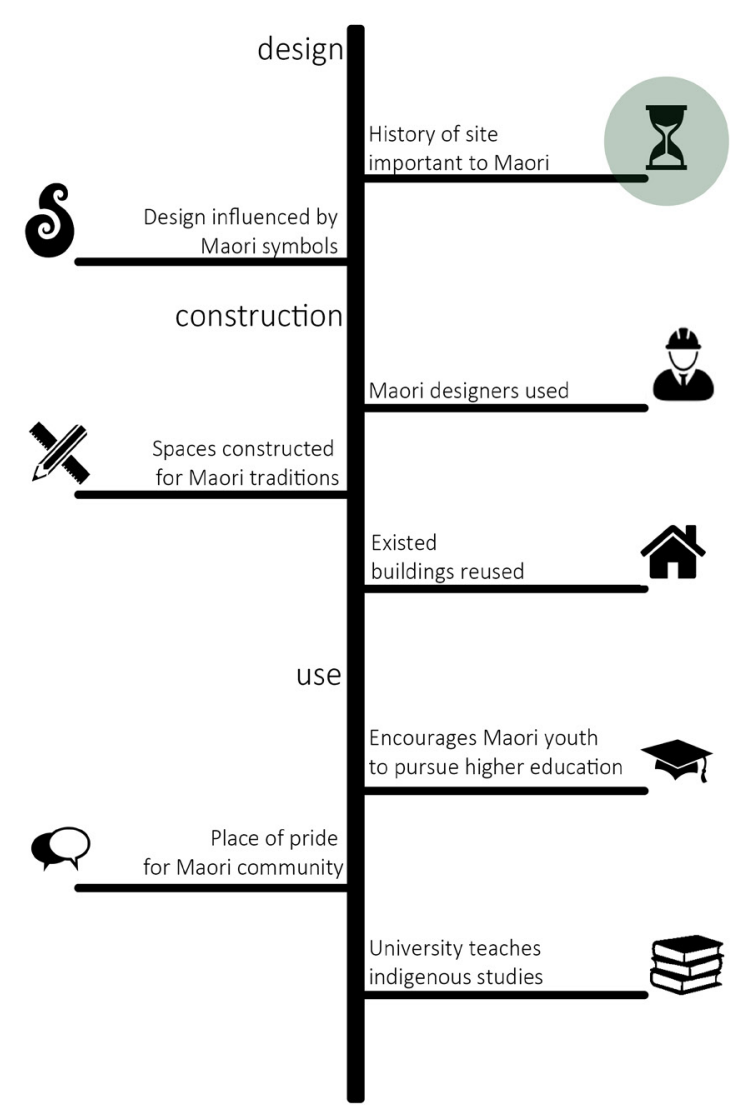


INDIAN INDUSTRY SOHRABJI GODREJ GREEN BUSINESS CENTRE

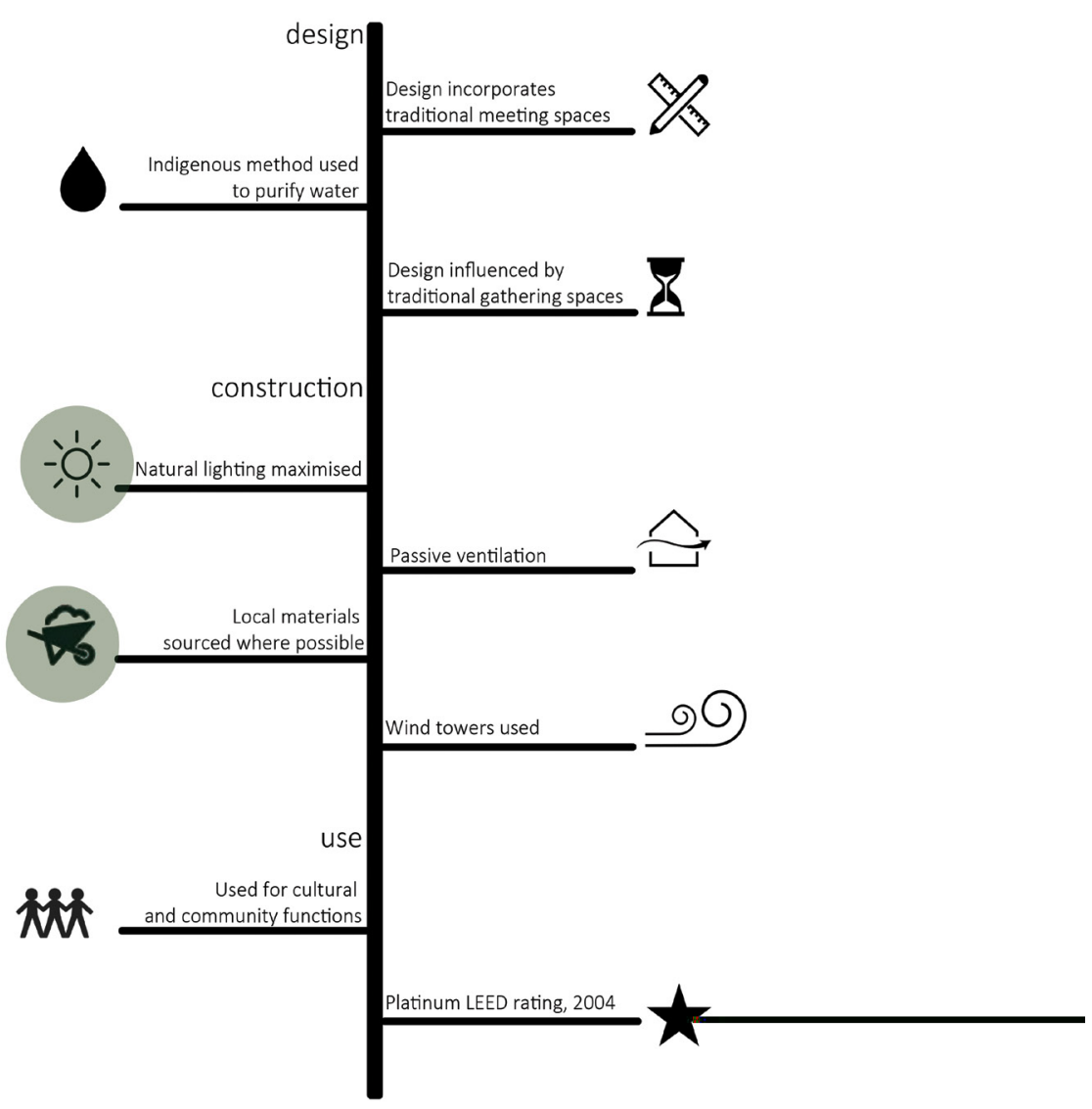

JEAN-MARIE TJIBAOU CULTURAL CENTRE

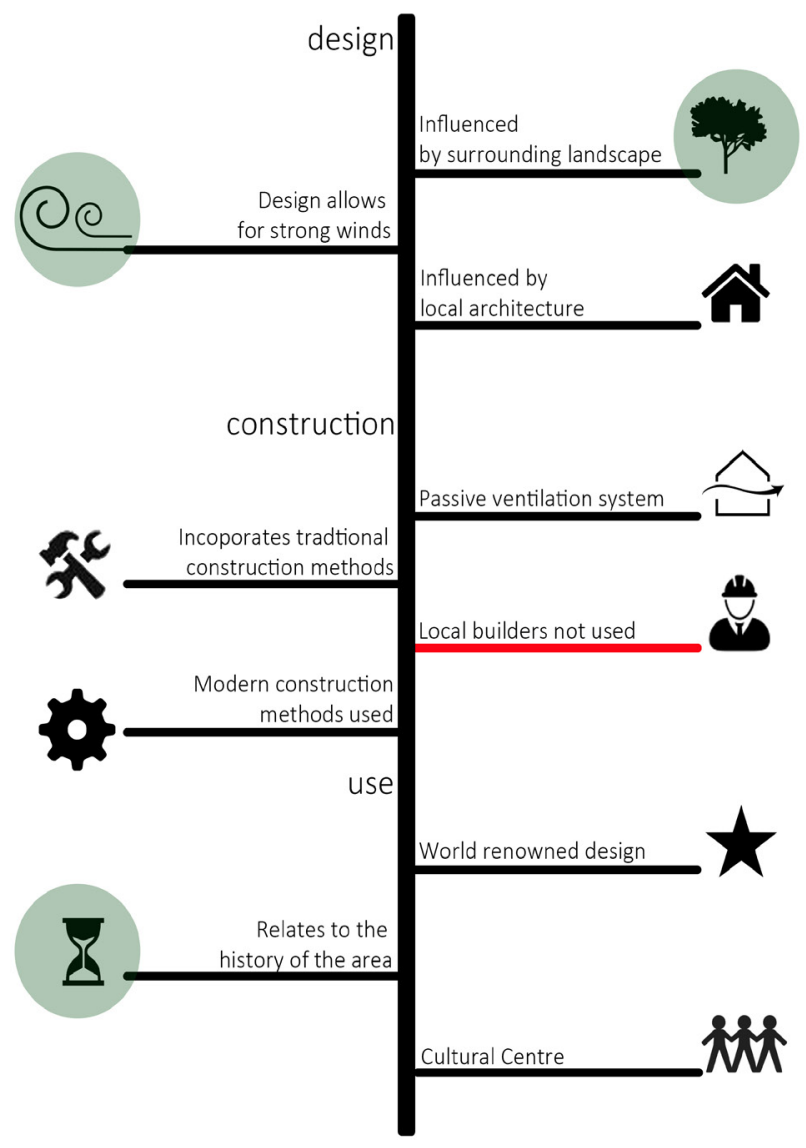



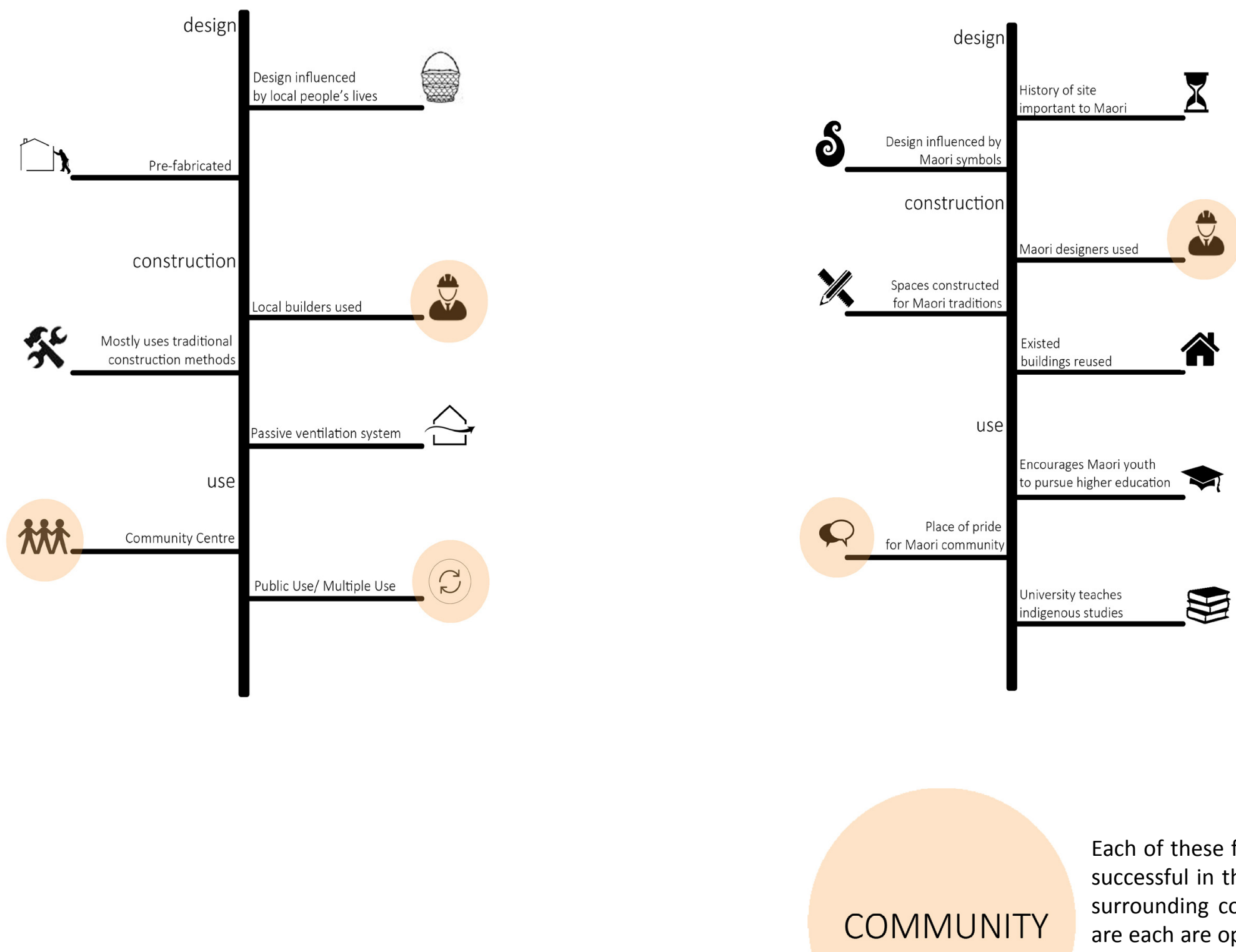

Each of these four buildings have been successful in their incorporation of the surrounding community. The buildings are each are open to the community or provide a service to the community. 
INDIAN INDUSTRY SOHRABJI GODREJ GREEN BUSINESS CENTRE

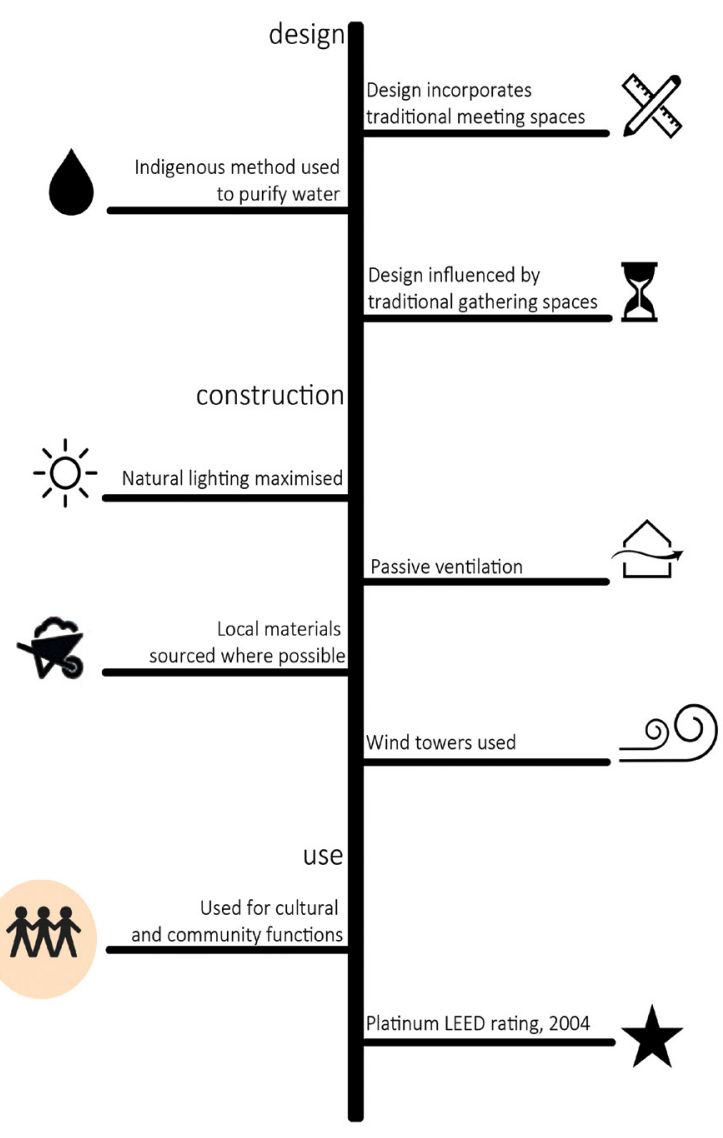

JEAN-MARIE TJIBAOU CULTURAL CENTRE

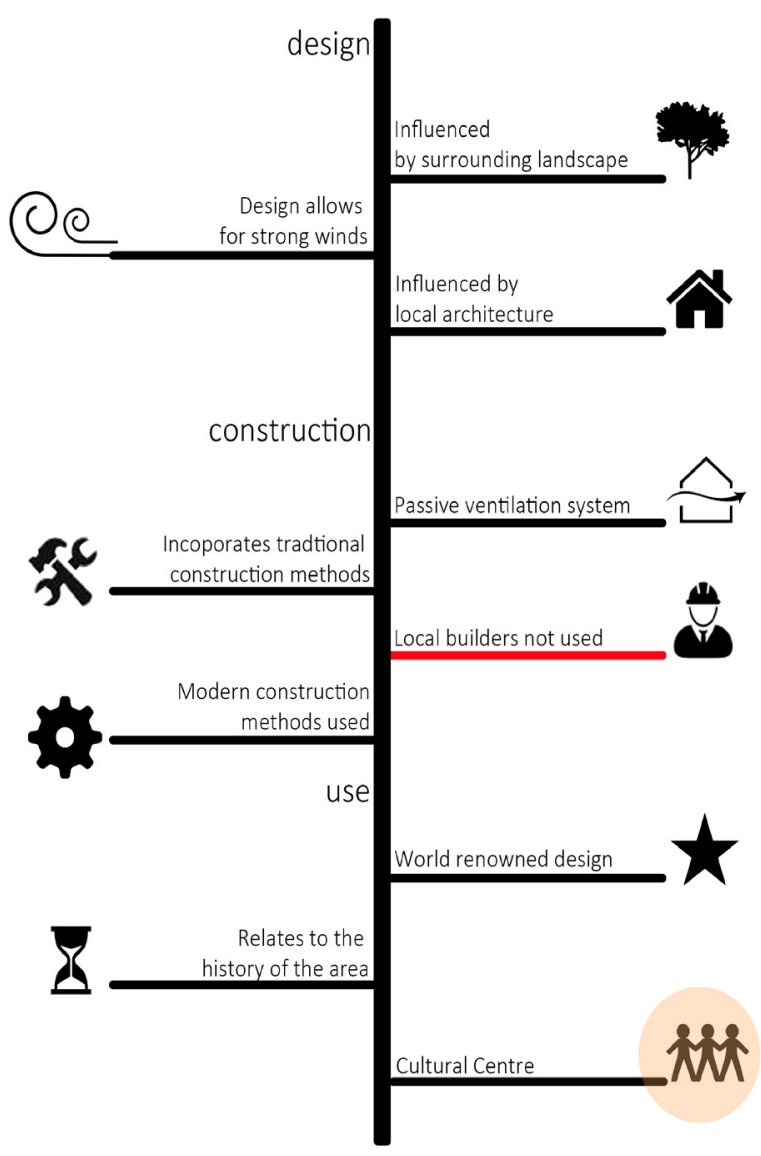



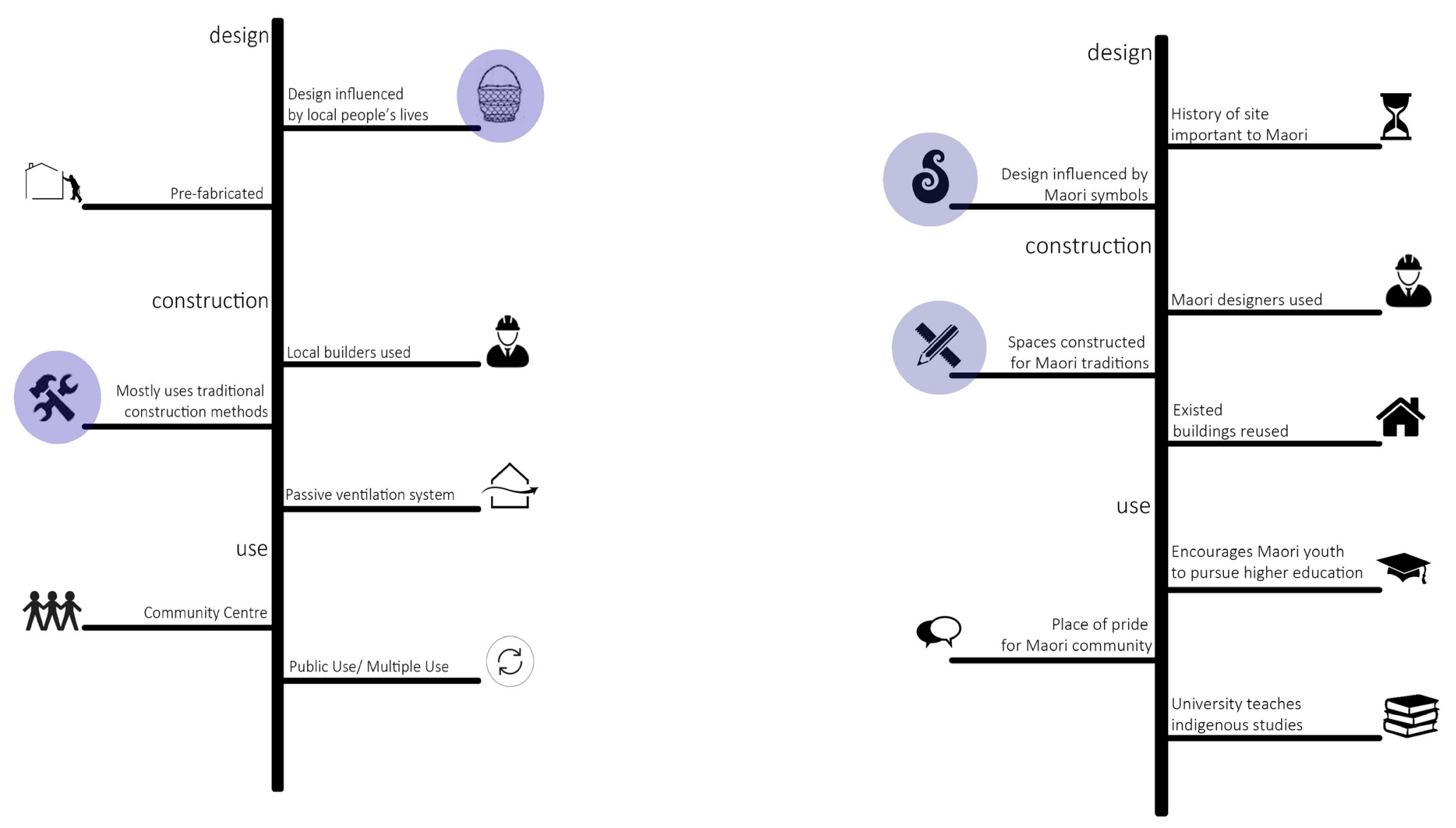

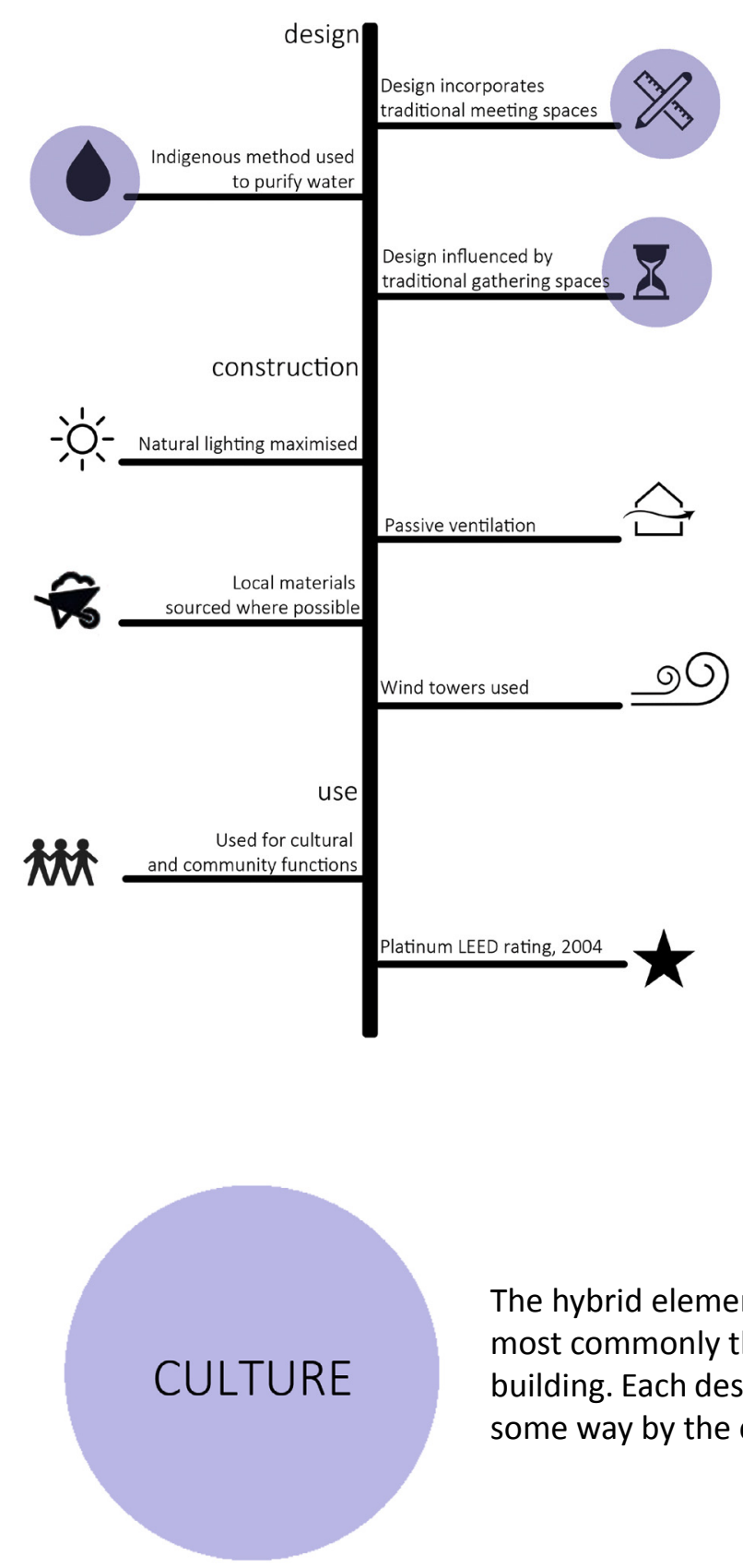

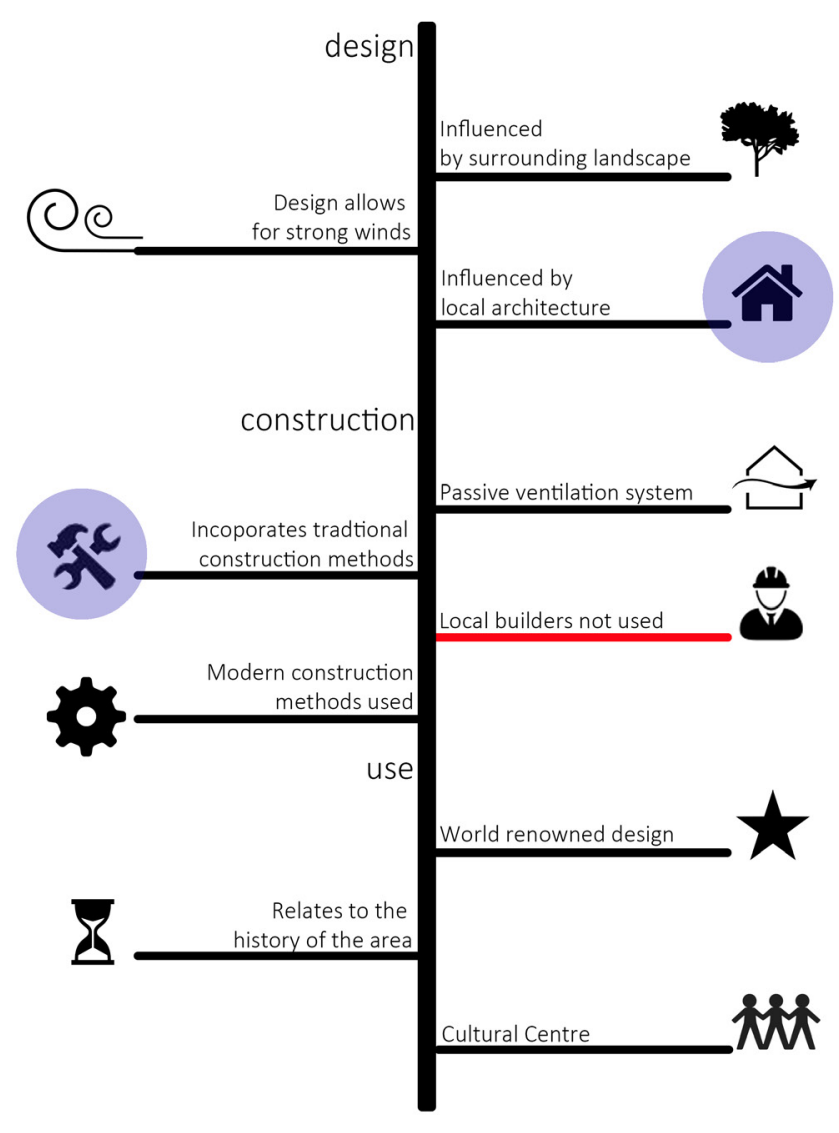

The hybrid element of each building is seen most commonly through the design of each building. Each design has been influenced in some way by the culture of the area. 

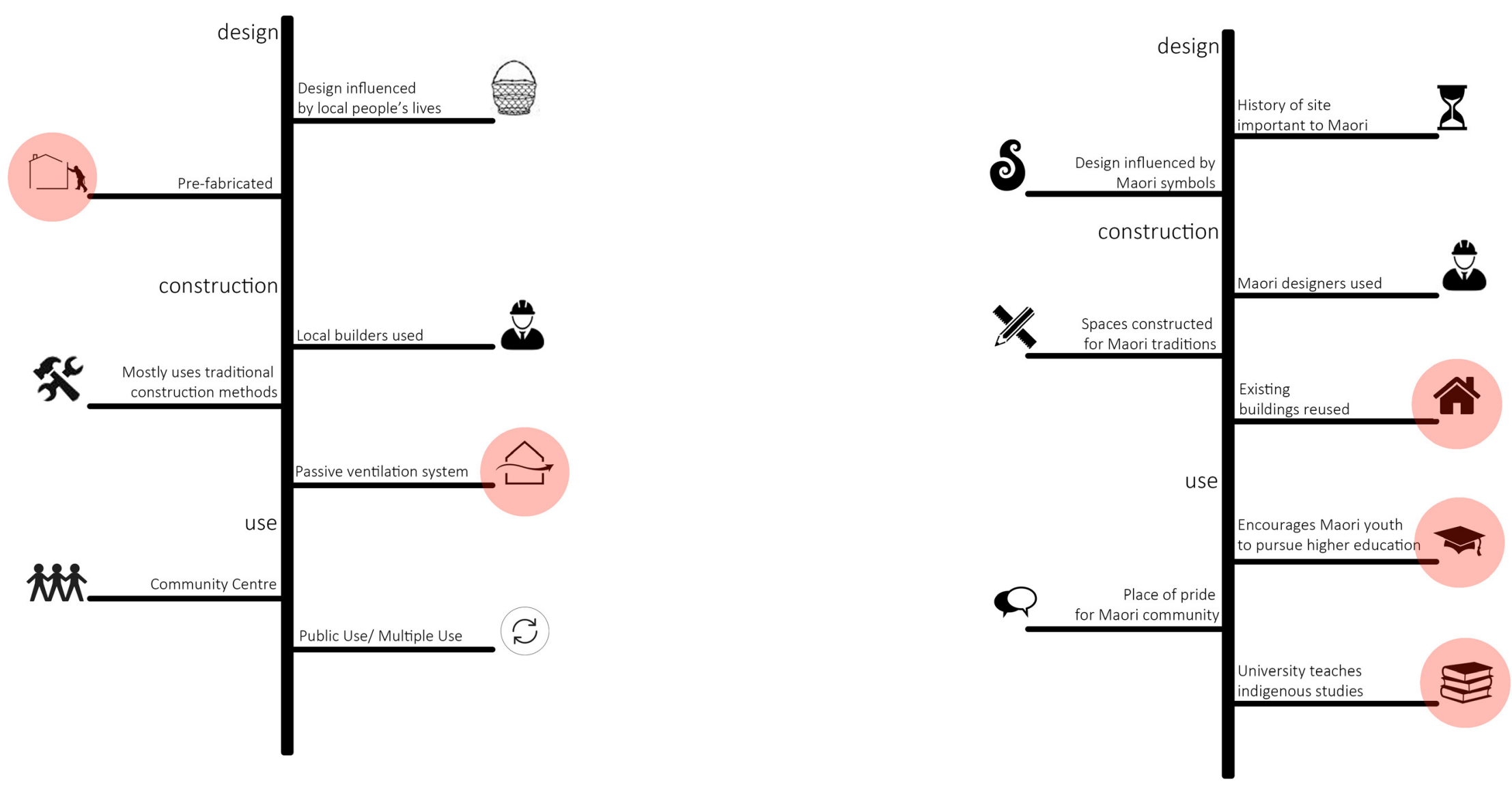

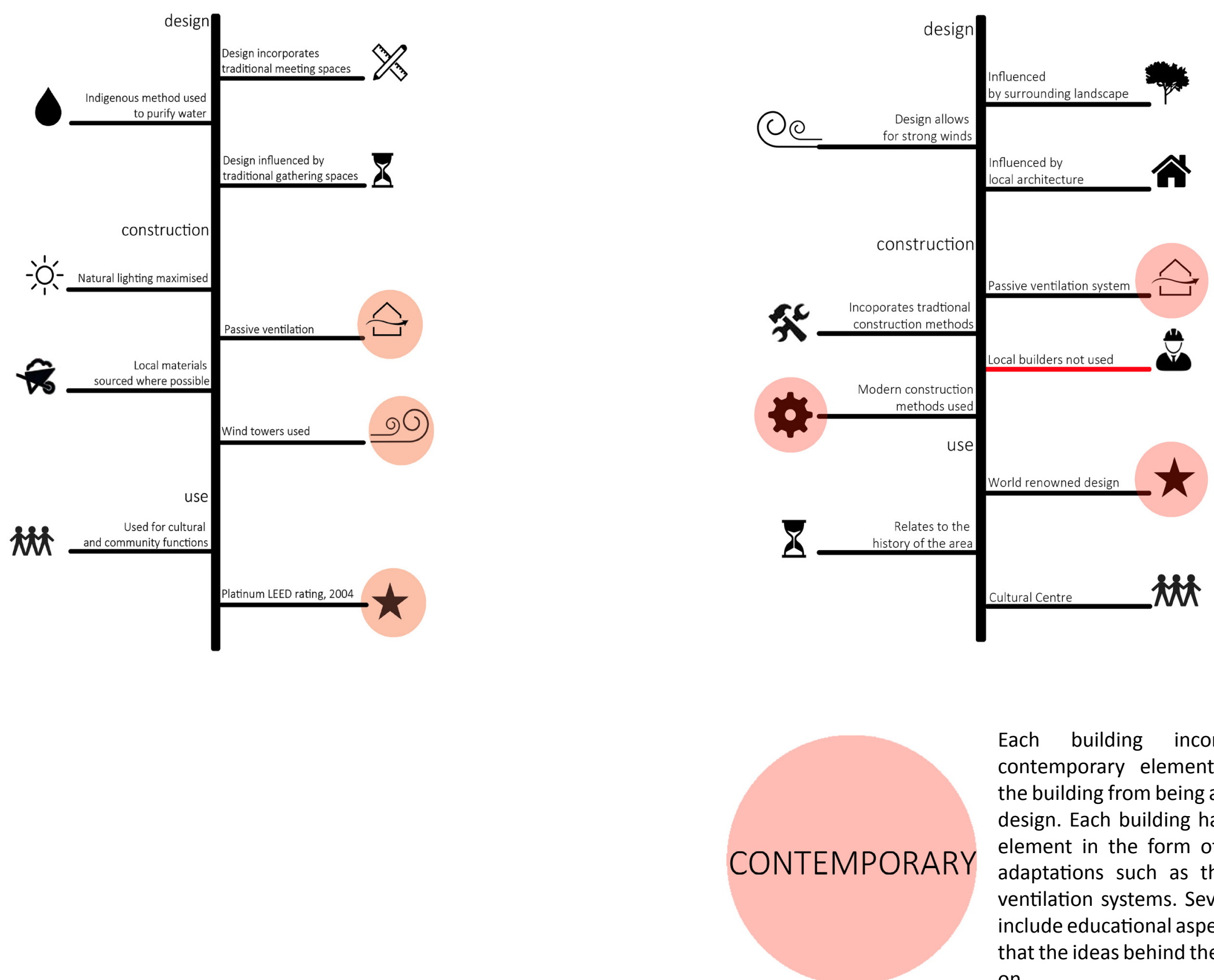

Each building incorporates several contemporary elements, which prevent the building from being a simple vernacular design. Each building has a contemporary element in the form of modern building adaptations such as the use of passive ventilation systems. Several buildings also include educational aspects that encourage that the ideas behind the design are carried on. 


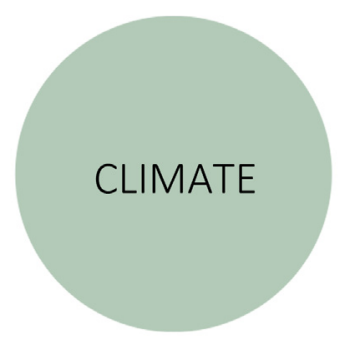

The design should respond to the climate of its surrounding area. This does not only apply to cases of extreme weather, but should be suitable for all weather recorded in the area. To accurately respond to the climate a design can integrate itself, rather than sealing itself off from outside elements.

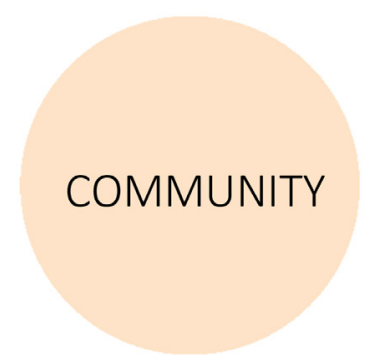

The design should benefit the surrounding community. The design could offer a use to the public, such as educational classes. It design should also be open to the community and seen as an extension of their daily lives, rather than a segregated space.

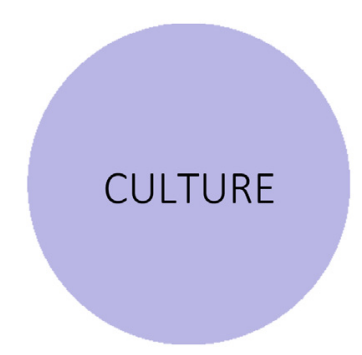

Retaining culture in a hybrid design is vital. This section will require the most care to accurately interpret and apply cultural aspects of an area. It is essential that these elements are then merged with other key elements so to produce a successful hybrid building

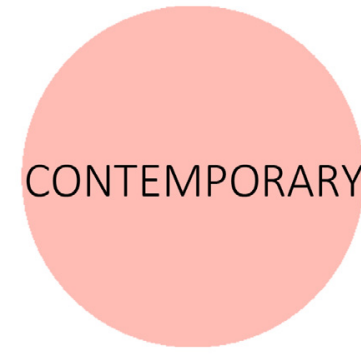

In a hybrid design it is important that modern aspects are utilised, but do not dominate the design. Modern construction techniques, aesthetics and additions should be integrated into the design in a suitable manner. 


\section{APPLICATION OF FRAMEWORK:}

The next step in this thesis is to take this

Hybridisation Framework and use it to develop a proposed design. The purpose of this framework

is that it could be applied throughout the Pacific to large scale buildings.

Before the framework can be applied, a methodology process must be followed. The next section of this thesis details the methodology process followed. 
Chapter Three

Methodology 
This thesis covers the following methodology processes:

\section{- RESEARCH THROUGH INTERVIEWS AND FIELD} OBSERVATION

\section{- RESEARCH THROUGH MATERIALITY \\ - RESEARCH THROUGH SITE AND PROGRAM SELECTION}

\section{- RESEARCH THROUGH DESIGN}

Step One of the methodology will assist with confirming information found within the literature review and to determine a resolution to the first research question: "Why has Samoan culture not developed stronger architectural resilience against Climate Change?"

Combined with the Hybridisation Framework, Steps Two - Four will assist in developing a design and resolution to the research question "How can Samoan architecture be hybridised to influence increased architectural resilience against Climate Change?"

As shown on the next page, in Figure 39 , this specific methodology is a part of the entire methodology of this thesis, leading towards a resolution to the issues outlined within the abstract. 


\section{Research Question One}

Why has Samoan culture not developed

stronger architectural resilience against

Climate Change?

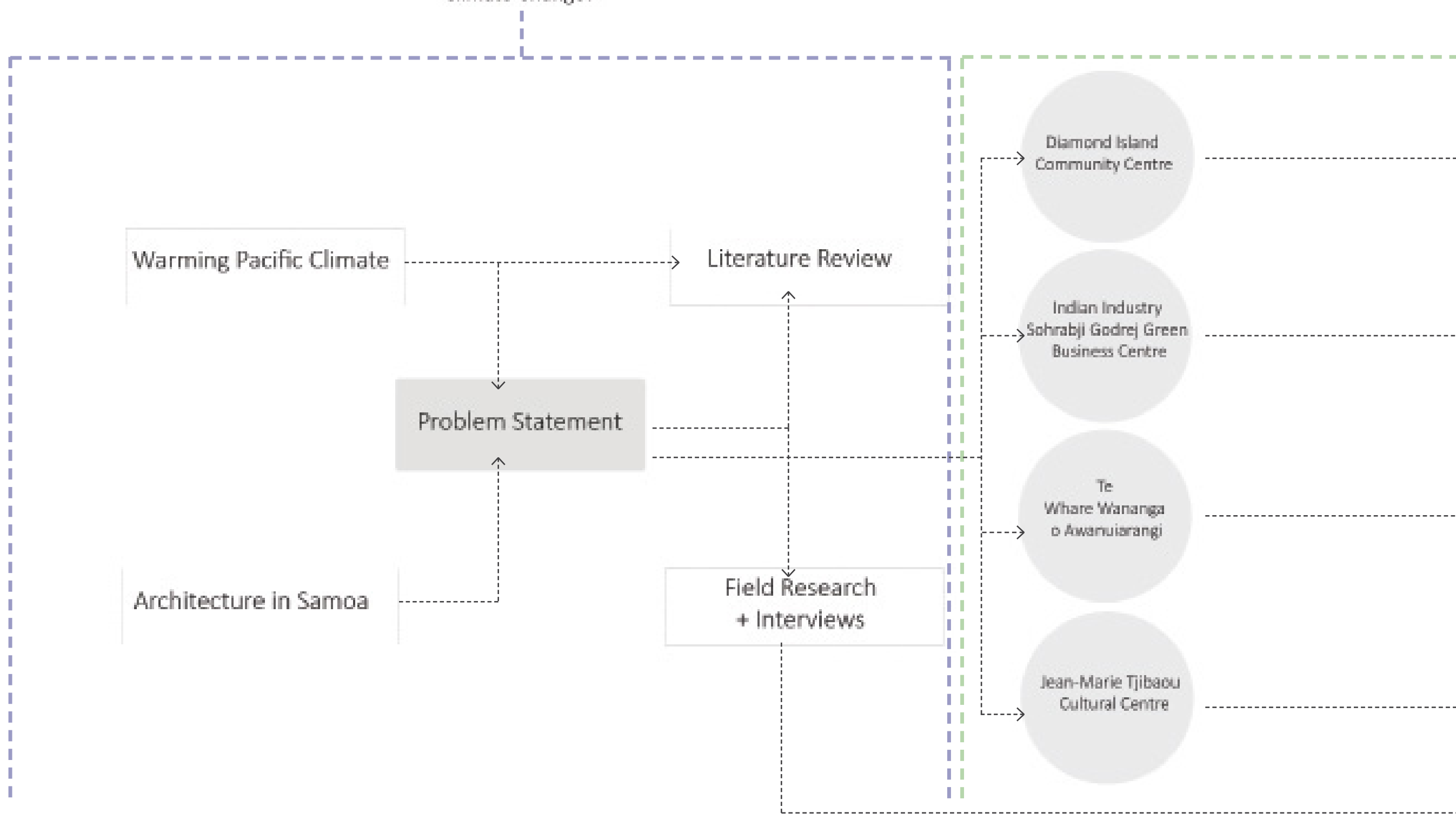




\section{Research Question Two}

How can Samoan architecture be

hybridised to influence increased architectural resilience against

Climate Change?

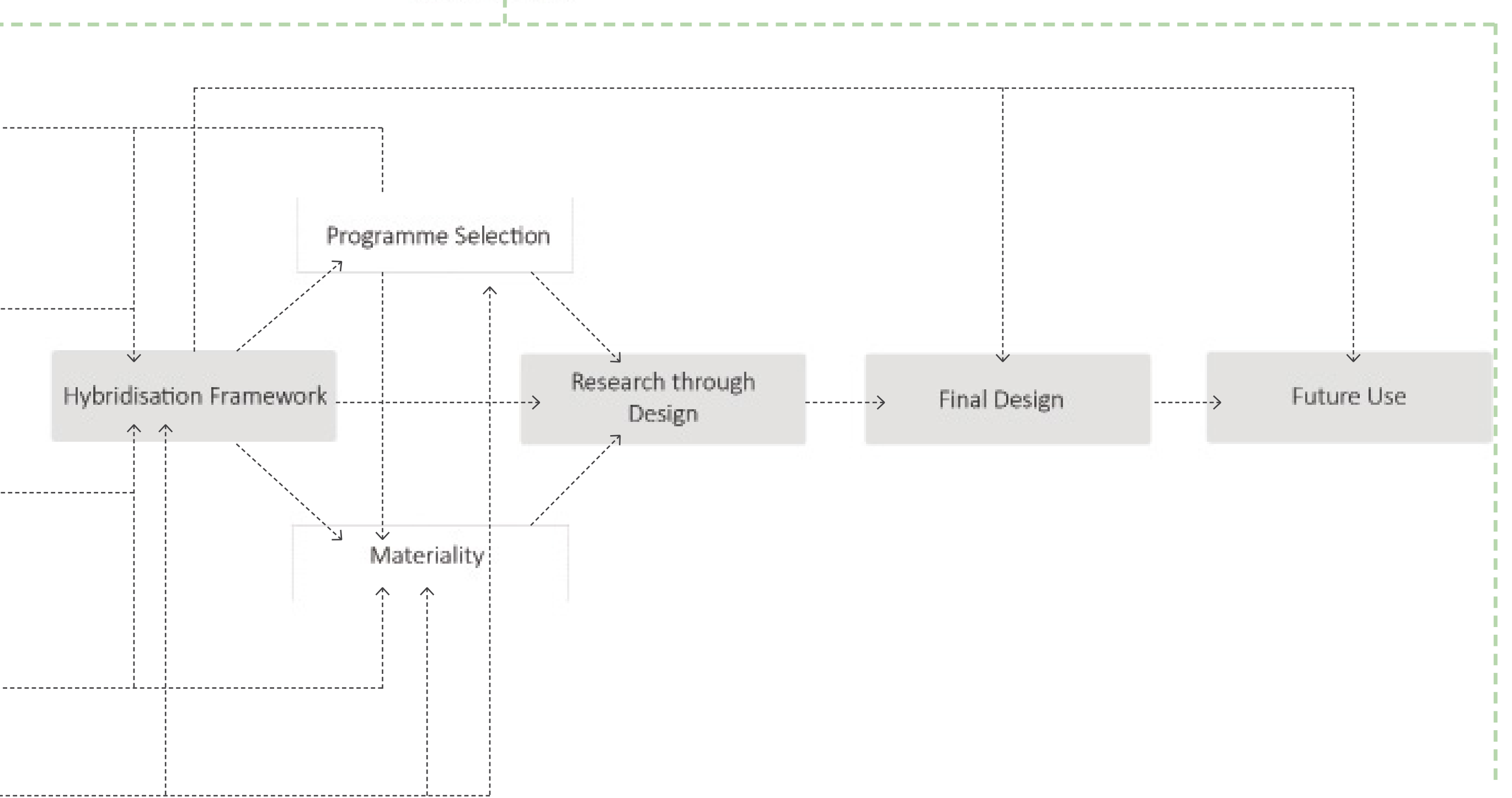


RESEARCH THROUGH FIELD OBSERVATION + INTERVIEWS:

Samoa is currently one of the most developed countries within the Pacific Islands. While Climate Change is intensifying weather events, Samoa has never been ignorant of extreme weather. The original fale was designed to suit the climate of Samoa, but has not been sufficiently adapted to intensifying weather as well as the increasingly modern lifestyle of the average inhabitant. The history of the construction industry within Samoa is largely undocumented and so it was key to implement an on-site study for this area of research.

This research was carried out over ten days during a trip to Samoa's main island, Upolu, in June 2016. The first half of this trip was dedicated to interviews with experts within the varying fields of architecture, urban planning and humanitarian work in Apia, Samoa. The second half of this trip involved collaboration with the Samoan Red Cross Association, including trips to various villages across the island of Upolu. Due to time limitations, expert interview subjects were chosen from those available and working in Apia within the construction/architecture industry, ranging from Urban Designers to Quantity Surveyors. Local interview subjects consisted of those who volunteered, from several villages, all located within Upolu.

This methodology allowed the research to include the personal opinions of people who had experienced disasters, such as Cyclone Evan, first hand. This allows a depth that cannot be achieved through Online fact checking.

Field observations were also made as well as research into the focus topics: Samoa and Climate Change. Field observations were most beneficial when inhabitants from small villages were interviewed. With a background knowledge of architecture and construction, the replies given during an interview could be analysed in relation to the surrounding housing.

Each interview subject for this research signed a consent form (Appendices $2 \& 3$ ), allowing their answers to be shared. A condition of this consent is that the interviewee is not to be named, nor will any information be released that could identify them. Therefore, references used in these interviews identify the subject by their job title only. Residents from smaller villages are identified as 'Resident\#'.

The local people of Samoa have a far more expansive knowledge of Climate Change than the average New Zealander. The likely reason for this is that most Samoan inhabitants have seen the effects themselves in recent years. This puts them in an optimum position, where adaptations to improve their architectural resilience will be welcomed. Interviews conducted with local residents provided insider knowledge as to how inhabitants are already resisting the effects of Climate Change.
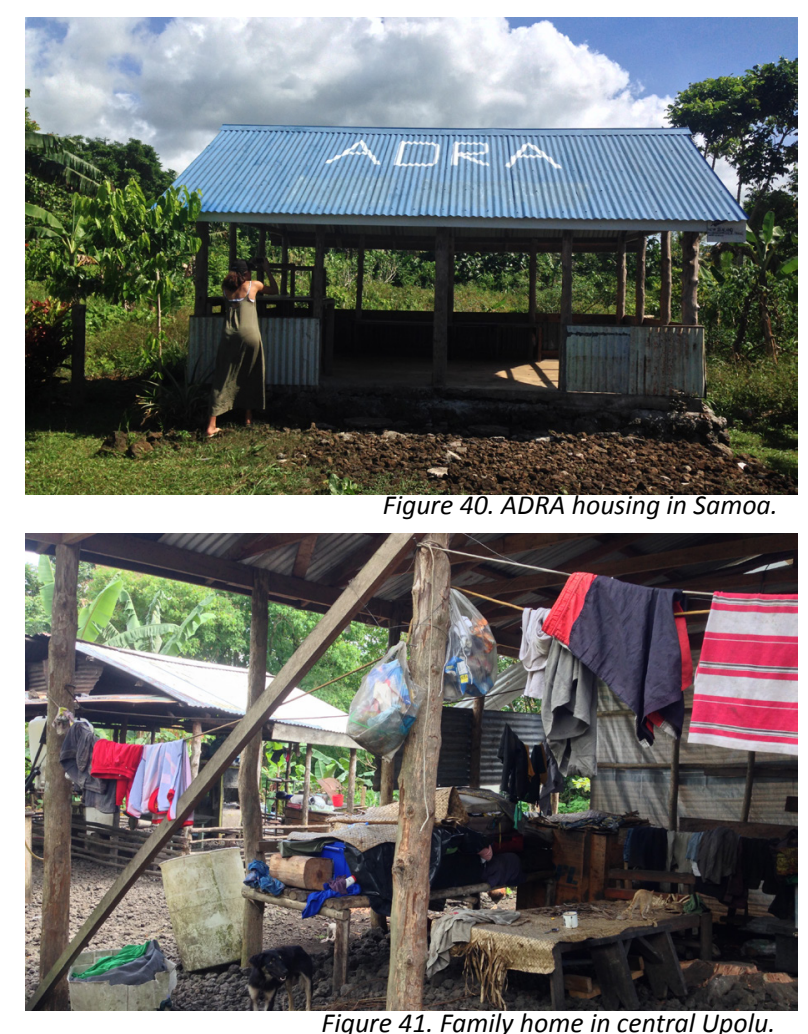

Figure 41. Family home in central Upolu.

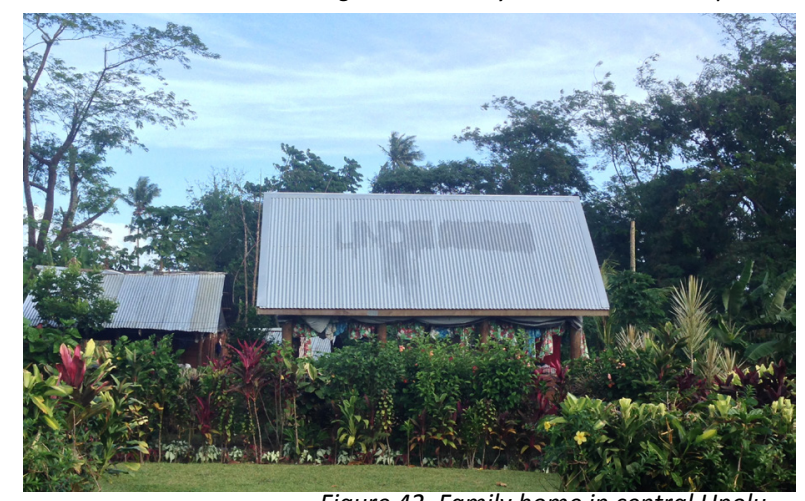


The Influence of Western Housing:

Samoa is one of few countries in the unique position of retaining an extremely strong sense of tradition while also having immense influences from the modern world. The result of this is that Samoa's architecture has progressed in an unsuitable fashion, leaving the people with many homes that do not suit any climate.

The original Samoan fale was developed over thousands of years to suit the extreme climate of Samoa, which includes heavy rains, high humidity, and tropical cyclones. This design was suitable for many years and is still widely in use today, but required adaptation for two reasons. The first was that the traditional fale did not suit the growing modernism of Samoa. This meant that families owned more electrical equipment and other valuables meaning that families had possessions to lose. The open walled fale was deemed unsuitable as the structure offered very little security. "You can't have electricity. There's no security. You can't own anything. You can't leave your children alone" (Architect, 2016). The fale also dealt with the overall perception that living in a fale meant you could not provide your family with a modern life.

The fale palangi, a westernised house, grew in demand within Samoa after Europeans arrived Owning a fale palangi provided security as well as the perception of wealth (Quantity Surveyor, 2016).
However, the designs for these houses were European and were not adapted to suit Samoa's extreme climate

This housing was not designed for the high humidity and did not provide adequate ventilation. Without open walls, the high winds of cyclones would lift off roofs, sending corrugated iron flying through the towns. Finally, the bulk of materials used could not be produced within Samoa, this meant that any repairs came at an extortionate cost as they had to be shipped in. The perils of owning a fale palangi were summarised in an interview with a Climate Consultant living in Upolu "We build these palangi houses which we cannot afford, we can build one time, but that's it. We can't maintain it and we build sub-standard structures" (2016).

The use of these two housing types are still prevalent in Samoa, despite their unsuitability. To combat the flaws of each design, many families have both, standing separately, on their land. This is undoubtedly not the best solution, especially as neither provides protection in the event of a tropical cyclone. The research trip into Upolu investigated this predicament and through interviews and field observation, highlighted the key reasons the people of Samoa have struggled to move forward with resilient architecture.
Land Ownership:

Within Samoa there are three forms of land ownership. These are customary, freehold and public land. Public land is owned by the government and makes up 7\% of Samoa's land, while freehold is privately owned land and makes up $12 \%$ of Samoa. The most common land type is customary land, which is owned communally in accordance to the traditional customs of the Samoan people (Ye, 2009).

With $81 \%$ of Samoa's land labeled as customary land, any government-driven projects to move residents inland is confronted with immediate issues. This is that the bulk of the land is not owned by the government, specifically the Land Titles Investigation Commission, and so cannot be handed out, "the Commission has no authority to make any determination or order if it finds that land in issue is customary land" (Ye, 2009).

With the land lying in the ownership of the matai (chief), residents often find themselves with no land to move to. Therefore they are forced to remain by the coast in threatened areas. This is a key issue preventing Samoa from developing resilience as this lack of land choice restricts many changes that could be made. 
The Building Code:

Code compliance is another significant issue that was uncovered during the interviews with experts in the building industry. One reason is affordability, this was described by a Climate Consultant, "people can't afford it, they can't afford those materials" (Climate Change Consultant, 2016). Nor can families afford the labour required to construct buildings up to code compliance. Samoa has minimal resource production facilities and so many materials are shipped in from overseas, hence their high price.

Gaining a building permit involves applying to Planning and Urban Management Agency (PUMA), a division of the Ministry of Natural Resources and Environment begun in 2002. This area of construction generally works well, although at a low speed. The main issues discussed arise after the permit has been approved and the house has been built. Samoa currently has no law enforced that these buildings are then inspected. This means that after gaining a permit, residents can essentially build as they please, to the level of compliance they choose. This issue was outlined by a Quantity Surveyor working within Apia, "lots of residential housing just gets constructed and no one comes and checks what's happening. They don't check the foundations, or the structure" (2016).
Both of these issues could be largely resolved if there was better construction education available readily within Samoa. Again, this problem was identified by a Climate Consultant interviewed, "your average carpenters on the ground know nothing about it [the building code]" (Consultant, Climate Change, 2016). With a lack of skilled builders Samoa is set to consistently continue the pattern of 'building back the same', rather than the encouraged, 'build back better'.
Collaboration Issues:

Currently, the main way Samoa gains assistance from outside countries is from humanitarian organisations providing aid. While these organisations have only good intentions, time can often become the most important factor, with cultural and climate understanding taking a back seat.

While these organisations provide a lot of valuable support, it is plain to see that those who know best are the community themselves. This is why a higher standard of self-sufficiency should be aimed for within the Samoan community. Where help is required from external parties, collaborations must be enforced to ensure that a design will be beneficial, rather than a hindrance. An interview with an Urban Design Advisor, working within Apia, reinforced this idea "You need to collaborate with the locals and the villagers for so long before you can even come up with a good design" (2016).

A key point investigated during interviews within Samoa, revolved around the difficulties of collaboration between outside countries and Samoa. This difficulty is described by World Bank as a recurring problem, laced with good intentions, that needs to be managed.

"Weak coordination between institutions limits the impact of interventions, and the institutional rigidity of donor organizations can make cooperation and partnership still more difficult" (World Bank, 2013). 
The Tsunami House:

This was the design which has now been developed into the Tsunami House (Figures $43+44$ ). This design was adapted by the Samoan government and was offered to families who had lost their homes (Resident, 2016). The design follows the basic principles of a traditional fale with its open spaces, allowing weather to pass through. Seven years on from the tsunami these designs could still be seen across the island of Upolu. Demonstrating the adaptability of Samoan people, many of the tsunami houses now have add-on structures. These are generally in the design of a fale palangi, allowing the household some enclosed spaces for security.

The tsunami house itself has proved its performance in the case of extreme weather, but it is unlikely that the attached enclosed housing would fare as well. Residents also stated that they could not remain in this housing during times of extreme weather as it did not offer protection to inhabitants (Resident, 2016). The development of this design displays how traditional housing is most likely the most appropriate, whereas the need for inhabitant protection calls for a hybrid design. However, the issues regarding the building code are preventing the people of Samoa from moving forwards with these ideas.
Relocation:

Since the 2009 tsunami tragedy, the southern coast villages have been relocated to the top of the cliffs, where the residents now live amongst their plantations. However, while this elevated land is clearly the safer option, many families are still moving back to the coastline and rebuilding. In the case of the subjects interviewed from these areas, the reasons included an innate wish to be near the ocean as well as the hotter climate that comes from living further inland.

Interviewed residents also commented that they had to return daily to the base of the cliff to collect water from reservoirs, because rain was not common enough for their rainwater tanks to suffice (Resident2, 2016). A final reason was that the majority of their deceased had been buried on the foreshore, and tradition dictates that they reside nearby. While adaptations have been made, such as the construction of escape routes snaking up the cliff, the people moving back to the coast are still in an immensely dangerous position.

In these situations, it is not necessarily construction problems standing in the way of the inhabitant's safety, but rather, tradition. The prevalence of traditions in countries similar to Samoa is not something to be ignored as it is certainly an aspect of daily lives that built resilience will have to construct any adaptations around.
"How do you re-build and design for a village after a devastating natural disaster, when the people remain spiritually and spatially connected to the heritage of the ruins and uninhabitable fale? Is the re-building of the village in a traditional sense truly an attempt to return to "paradise" if that is not the safest option for disaster proofing?"

(Feaunati, 2014).
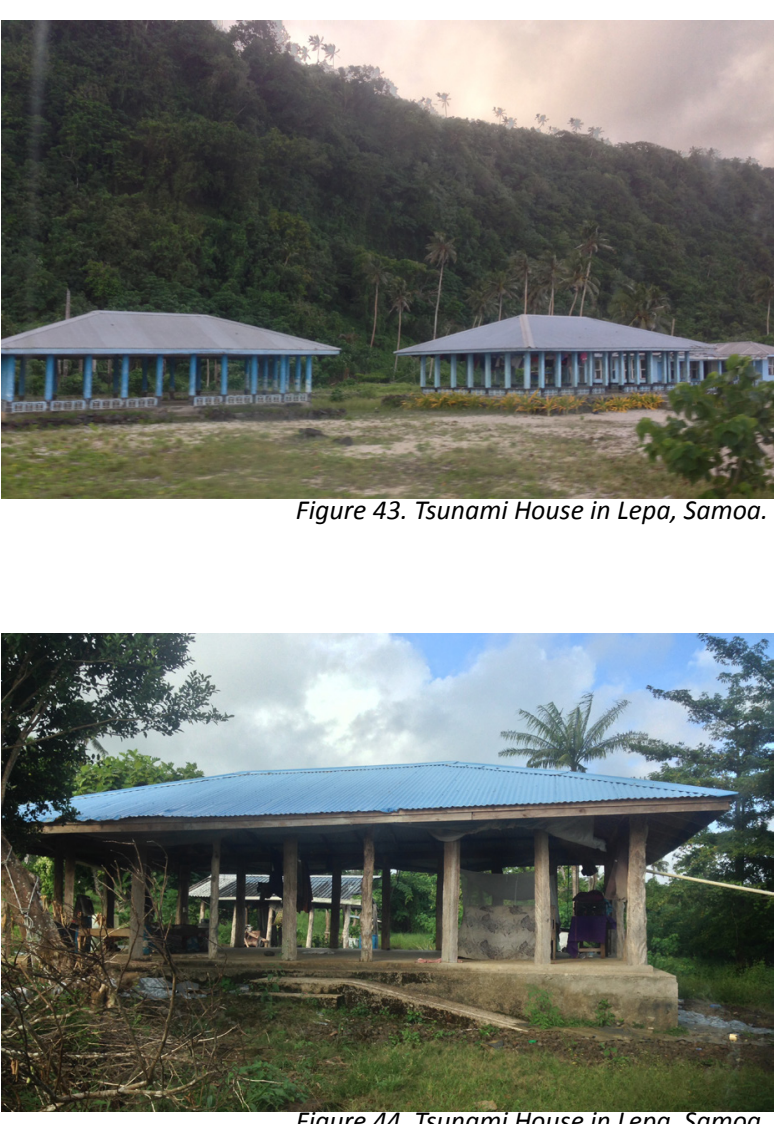


\section{DISCUSSION:}

The interviews conducted within Samoa highlighted several clear issues that are preventing the country from developing its architectural resilience against Climate Change, the key reason being a severe lack of education diminishing the architectural resilience of Samoan architecture. This lack of education combined with the pressure to use more Westernised materials has resulted in the ineffective mix of architectural styles seen in Samoa today.

Another issue surrounding the building code is not just that the materials are often too expensive, but that the builders do not have adequate knowledge of how to use appropriate alternate materials for the climate. This means that low cost architecture is being built well below compliance without the home owner's knowledge. With the implementation of a specialised construction education, climate responsive building techniques could be enforced. These could include basic measures to reduce wind loads and elevate structures in flood prone areas. These simple measures being taught to local builders could significantly decrease damage during extreme weather events.
Many of Samoa's current issues do come down to government regulations, a political minefield that cannot be addressed with ease, especially from outside of Samoa. An area that could be easily addressed is the architecture of Samoa. Education could be provided covering how this can be adapted to improve Samoa's resilience against the effects of Climate Change. 


\section{METHODOLOGY: MATERIALITY}

As has been discussed in the section, 'Research Through Field Observation + Interviews', Samoa has a very limited construction industry. This provides an opportunity for a new building material to be introduced, one that is cost effective for the country as well as appropriate for the climate and conditions. While timber is already a popular choice in Samoa, it is a material that comes with many drawbacks. The main issue is the lack of a large timber industry within Samoa. The lack of a larger forestry industry is due to the limited space available to grow the timber needed to maturity (Quantity Surveyor, 2016). In 2014 sawn timber was Samoa's 5th largest import, costing the nation $\$ 6.7$ million USD (Yasmi, 2010). This leads to the second issue: the timber arriving is westernised. This means that local builders must continue to use western construction techniques, which are both expensive and unsuitable to the climate.

An idea that has been considered in the past, and should be immediately encouraged, is the use of bamboo as a key construction material.

The implementation of a bamboo industry is highly plausible, especially when rated next to timber. Bamboo grows much faster and grows in far more compact environments than timber. It has successfully been grown in Samoa before and so could quickly become an accessible resource.
The group Matuaileeo Environment Trust Inc (METI), are an NGO team put together to develop the first ever permaculture course for Samoa. This course is designed to encourage a renewal of sustainability in the Samoan community.

"the challenge seems to be not exactly teaching about natural systems and farming, but encouraging the renewed appreciation of traditional methods and the informed rejection of unsustainable Western influences." (Magee, 2009).

This course encompasses a series of training courses, including the introduction of bamboo as a building material. This is encouraged through the development of a bamboo nursery, displaying the most beneficial varieties of bamboo. After the tsunami that struck in 2009, METI contributed their expertise to construct cheap bamboo domes, to house those who had lost their homes. The domes proved more popular than government aid provided tents as they were far cooler to inhabit. $\mathrm{METI}$ also made sure to teach local villagers the construction methods involved in making these structures so as to encourage self-sufficiency in the future. (Magee, 2009).

The flexibility of bamboo justifies its use in strong wind conditions as well as its possible adaptation into the dome-like structures favoured in Samoa.
The use of nails when fixing bamboo splits the wood and therefore strips it of its strength. This means that the primary way of fixing bamboo is through lashing. Page 59 shows a comparison between the traditional lashing of bamboo and the traditional lashing that was commonly used in Samoa. The similarities suggest that the construction knowledge needed to work with bamboo, already exists within the traditions of Samoa.

This style of construction was traditionally used as it allowed the joins of buildings to have some flexibility. This meant that in high winds the joints could move slightly, relieving the pressure put on them, making them less likely to break. This pressure on joints has been a recurring problem seen in the fale palangi especially where the roof is fixed to the walls by rigid nails. By using traditional construction techniques the people of Samoa will also be given further independence as they will not require outsider help if their buildings are damaged.

For this thesis, it is proposed that all bamboo fixings could be done in a traditional manner, wherever possible, to promote a similar style to be used in all housing around Samoa. 


\section{BAMBOO DESIGN PRECEDENTS:}

Despite bamboo's many positive properties, it is often ignored as it is seen as 'the poor man's material' due to its low cost, high availability and short life span. Similarly to how Samoa views its architecture, this is a misleading perception. In recent years, several ways of treating bamboo, to give it longer life, have been developed. This means that bamboo is now a low cost, highly available material that will last an average timber building's life span.

The treatment of the bamboo used for construction purposes is instrumental. Without any treatment, the bamboo is a target for termites, which are already an issue within Samoa. Chemical treatments are not preferred due to their toxicity as well as their potential to leach into waterways. However, in keeping with bamboo's sustainable image, a natural treatment has been developed, using salt water. This simply involves first drying the bamboo in the sun and then soaking the bamboo for two months. This leeches out the sugar of the bamboo, the part that the termites are after (Schroder, 2014).

Bamboo is still a material being introduced into the architectural world, but has begun to make its mark. The following Figures 45 to 49 display examples of bamboo being used to create exemplary pieces of architecture.

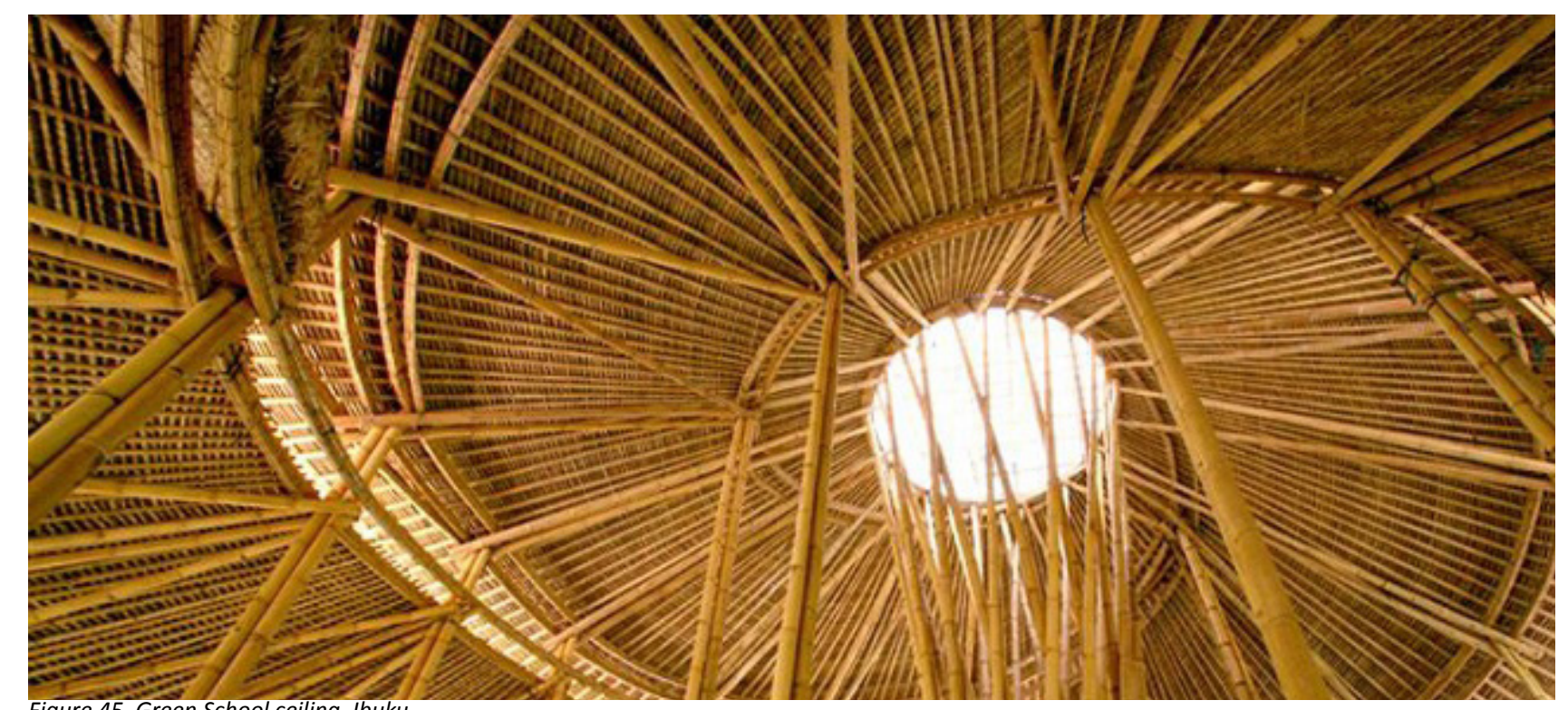

Figure 45. Green School ceiling, lbuku. 


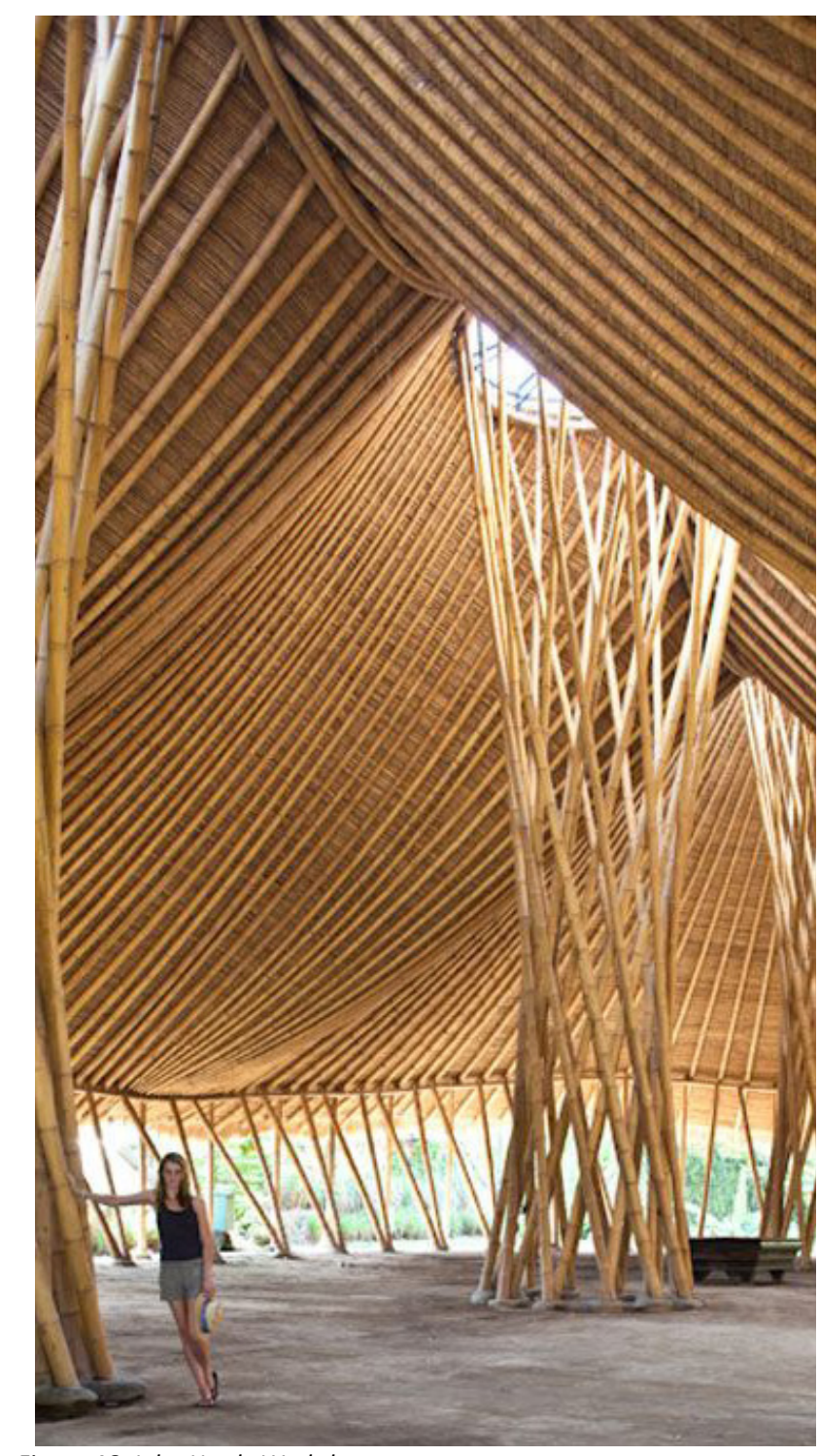

Figure 46. John Hardy Workshop.

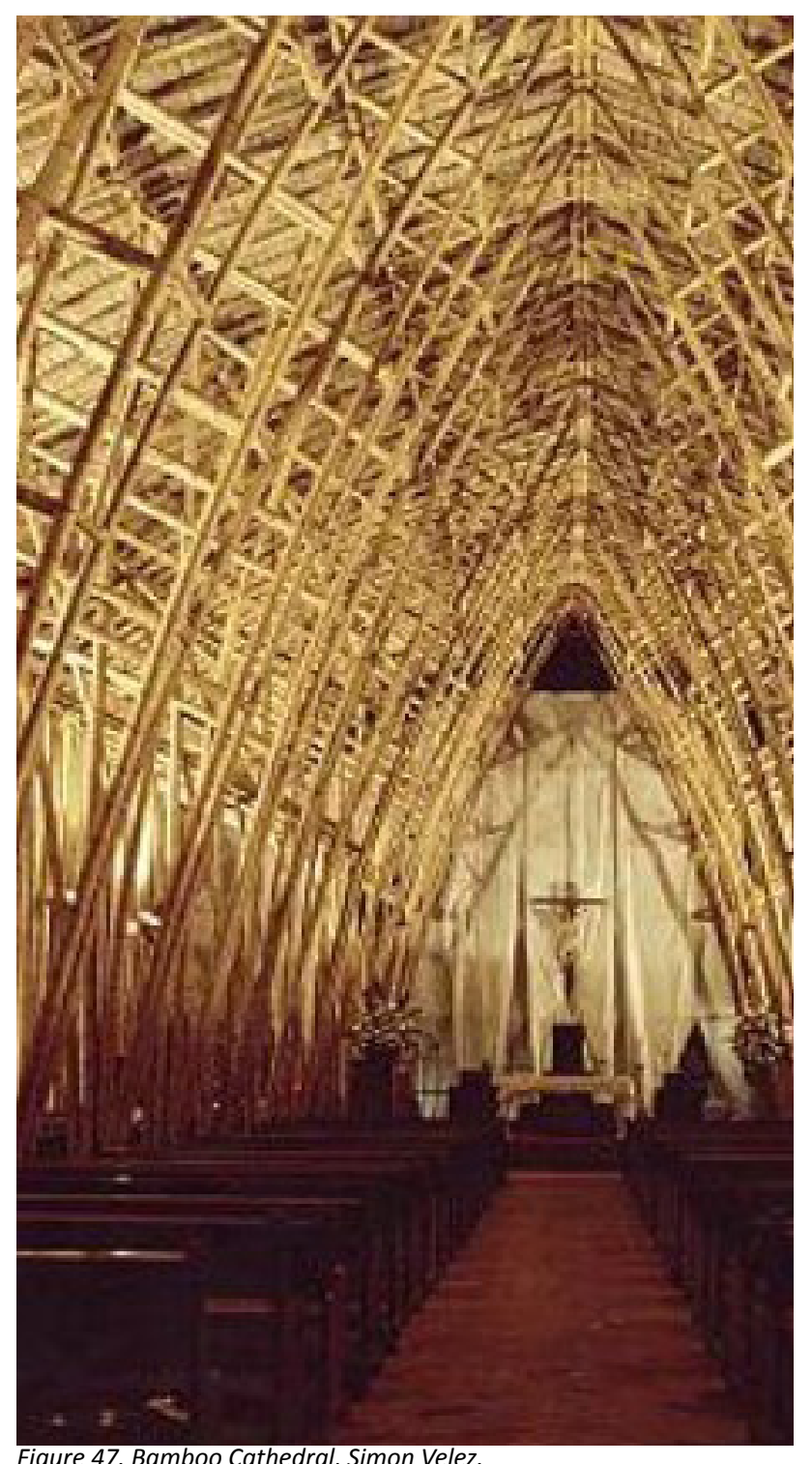

57

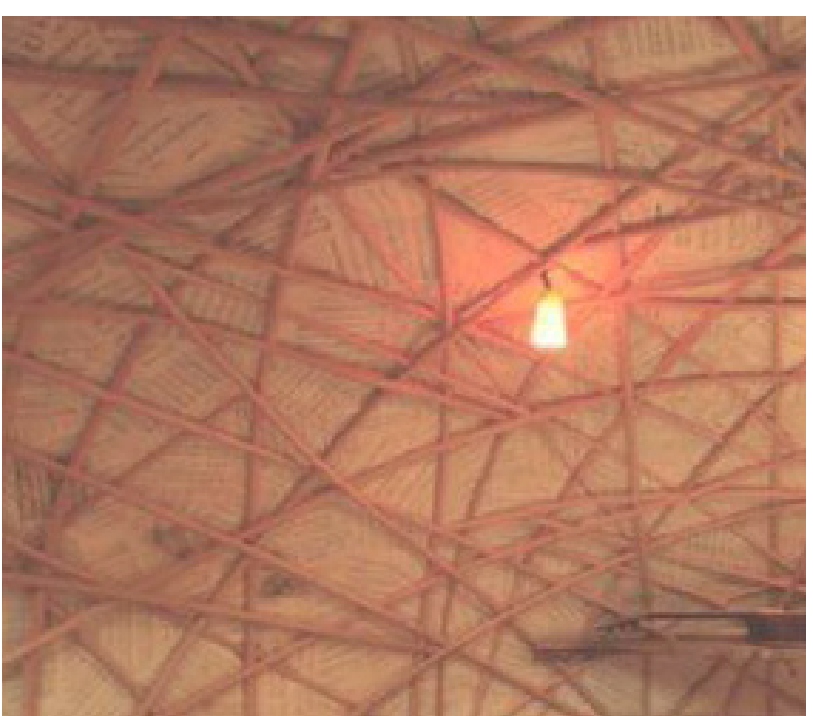

Figure 48. Ecological Children Activity and Education Centre, $24 \mathrm{H}$ Architecture.

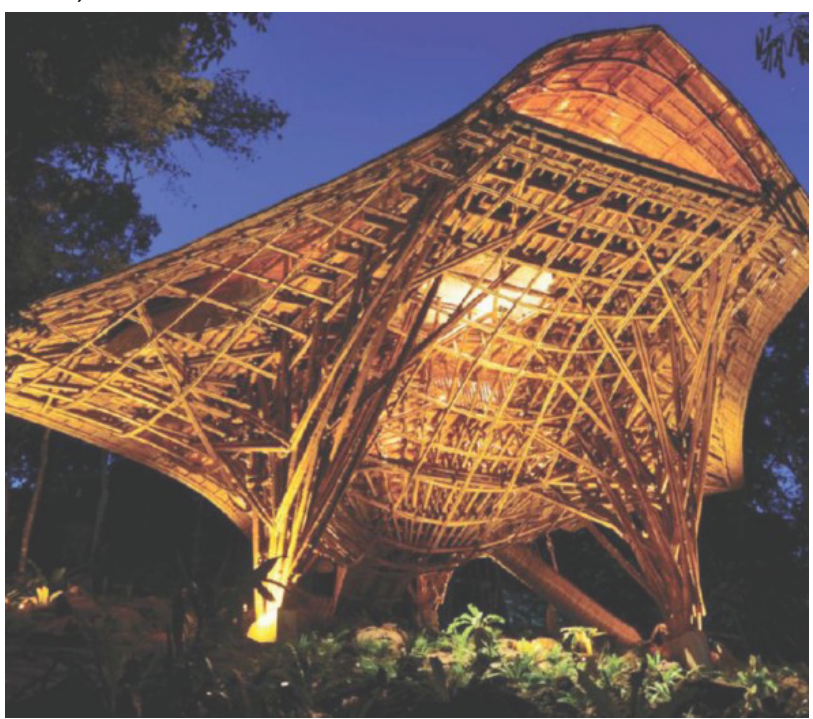

Figure 49. Ecological Children Activity and Education Centre, 24H Architecture. 
The bamboo plant encompasses many different species, only some of which could survive in Samoa's humid environment. Two that have previously been successfully introduced to Samoa and are proposed for this thesis design are,

1. Dendrocalamus asper 'rough bamboo'

-Used for construction

-Grows to $20-30 \mathrm{~m}$ tall

- Average diameter: $8-20 \mathrm{~cm}$

-Internodes $20-45 \mathrm{~cm}$

-Used for heavy construction.

('Dendrocalamus asper', 2014)

\section{Guadua angustifolia 'vegetable steel'}

-Used for construction

-15-30m height

-Average diameter: $9-15 \mathrm{~cm}$

-Harvested every 4-5 years

-Used for house construction

-Preferred for architectural purposes.

('Trees vs. Guadua angustifolia', 2014)

By introducing bamboo as a viable material, resultant designs could influence not only Samoan construction methods, but methods used all throughout the Pacific. By having access to their own materials, the people of Samoa would be free to develop their own architecture as extreme weather worsens, allowing them a self-sufficiency in times of disaster.
Bamboo is also suitable to Samoan construction as the traditional lashing techniques used for bamboo are very similar to those used for lashings in a traditional fale.

An example of lashing techniques is shown in Figure 50-52, with variations of the lashing techniques tested. This testing gave an indication of the ease at which the process can be learnt and the resultant strength of the bound pieces. The use of lashing is not as rigid as other fixings and so is suitable for high wind situations to reduce high tension areas.

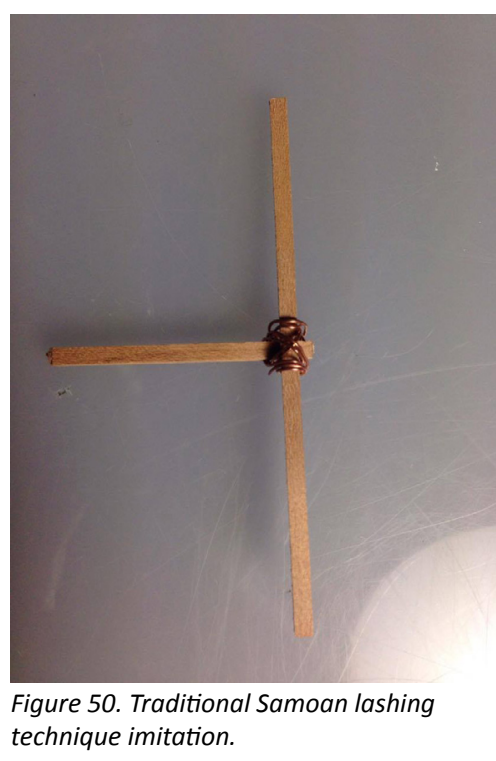

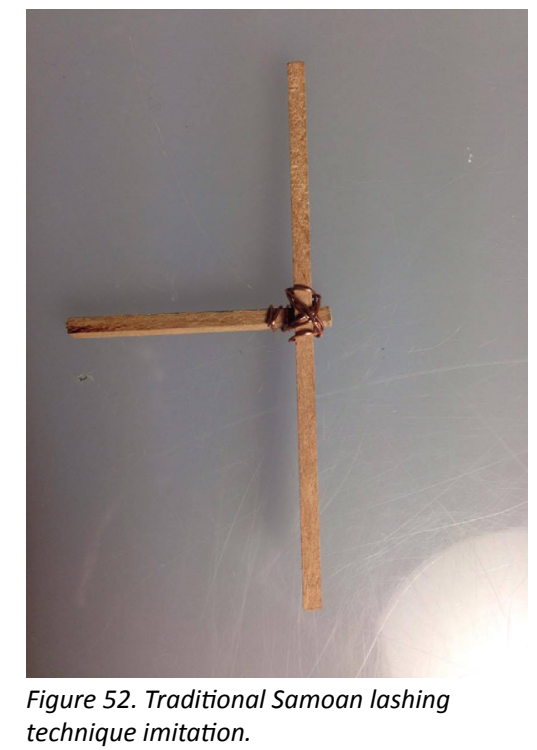



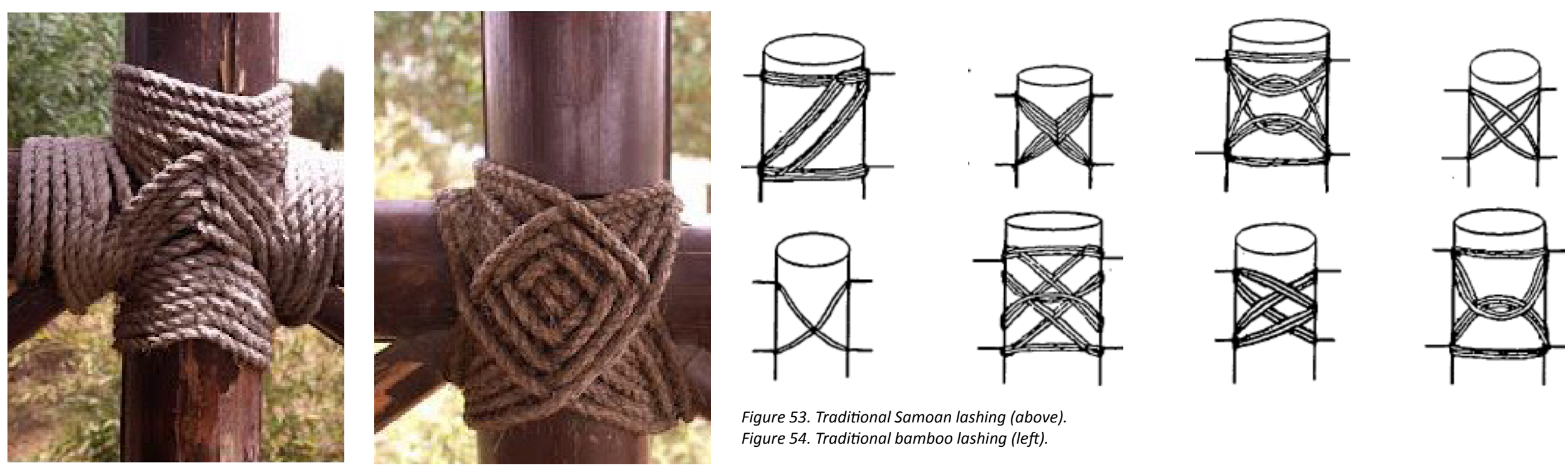

Figure 53. Traditional Samoan lashing (above). Figure 54. Traditional bamboo lashing (left).

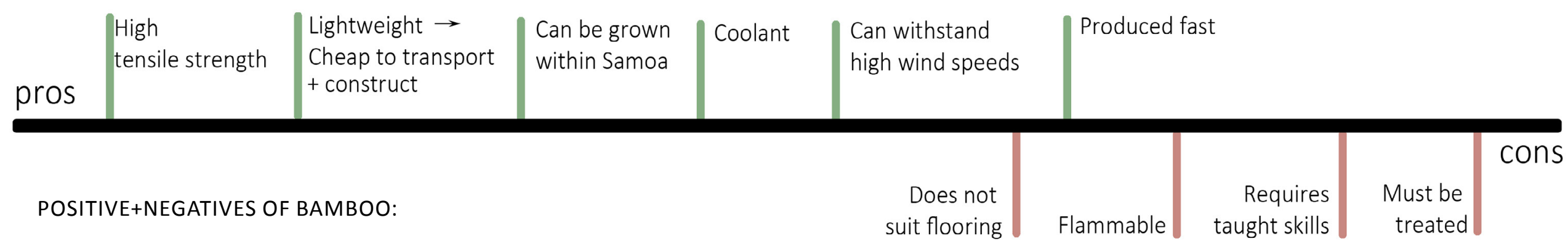




\section{METHODOLOGY: SITE + PROGRAM SELECTION}

Before the research trip it was not yet clear what type of design project would be the most effective. Trips to stricken coastline villages suggested the need for more emergency housing. The problem with emergency housing was that it had not had any effect on the Samoan construction industry, a larger impact needed to be made. Throughout the interviews references to a Climate Change research centre were made, but with no real detail. Further research and communication finally determined that the Secretariat of the Pacific Regional Environment Programme (SPREP) Facility of Samoa has plans to construct a Pacific Climate Change Centre (PCCC), with construction to begin in June 2017. It is to be funded by the Japan International Cooperation Agency and the Government of Samoa. This centre is to be the first of its kind within the South Pacific.

"The PCCC will enhance opportunities for Pacific island members to access climate finance, better coordinate adaptation and mitigation measures and build capacity in climate change science and meteorology, through a dedicated training space and education and outreach programmes." (Pacific Climate Change Centre to begin construction in June next year).

Emails to the SPREP facilities were made to garner more information, to very little avail (Appendices 26-30). This meant that information had to be procured from all other resources available, as well as a consultant's visit to the SPREP grounds.

The presence of an internationally recognised research centre in Samoa will have a huge impact on Samoa's relevance in the fight against Climate Change. This building has the potential to be recognised around the world and certainly has the potential to influence the people of Samoa. It is the ideal program for a landmark building.

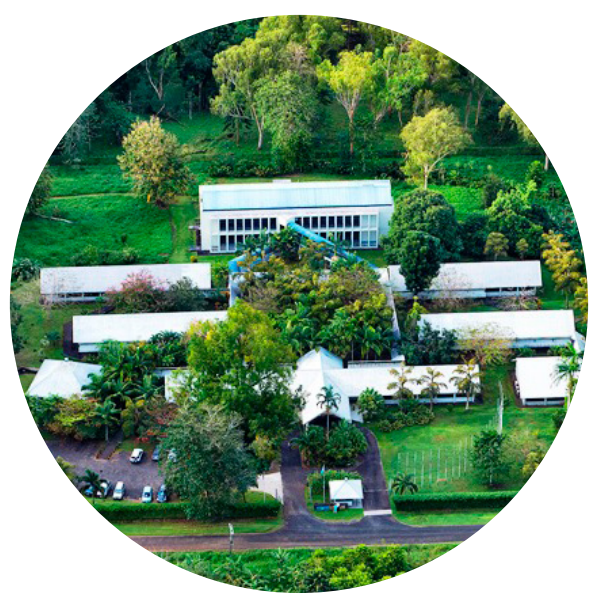

Figure 55. SPREP Facilities layout.

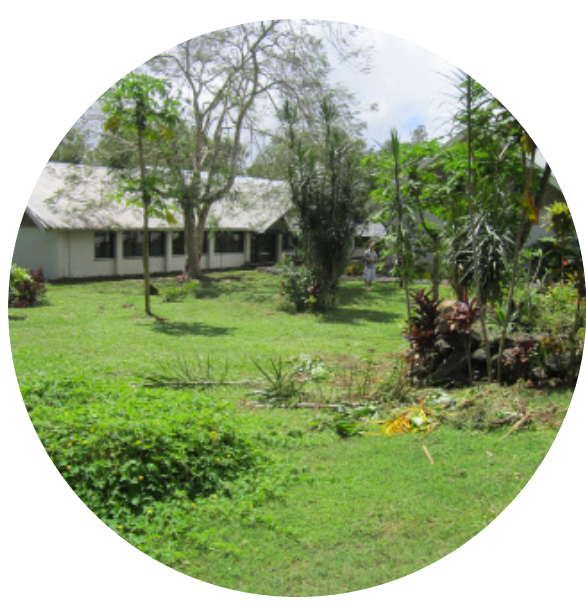

Figure 56. Proposed site for PCCC. 


\section{DESIGN PROPOSITION:}

This thesis proposes to take the program and site of this Pacific Climate Change Centre and create a new design. This design will follow the earlier proposed hybrid framework. The goal of this design is to answer this thesis question "How can Samoan architecture be hybridised to influence increased architectural resilience against Climate Change?".

This design will propose an adapted Samoan architectural design that aims to influence the architecture of Samoa. The design will not only be designed with resilience to the climate in mind, but will be a centre for researching how the effects of changing climate can be mitigated. 
The site location of the PCCC is an uncomplicated area. The site sits on a small gradient near the base of Mt Vaea. The location selected for the PCCC is within the ground of the SPREP campus, this means that the space is already largely excavated. The SPREP campus sits just off the Cross Island Road, approximately $4 \mathrm{~km}$ from Apia Central.

As this site is so far inland it does not hold the risks of coastal living, such as storm surges. Inland areas are generally significantly hotter as there are no ocean air currents to diminish the heat (Nunn, 2012). Figure 58 shows that the prevailing wind is easterly, but it is generally not to a strength that has a high effect on construction. While this site will not be effected by flooding, it will still feel the effects of a tropical cyclone as anywhere on the island would and so much be designed appropriately.
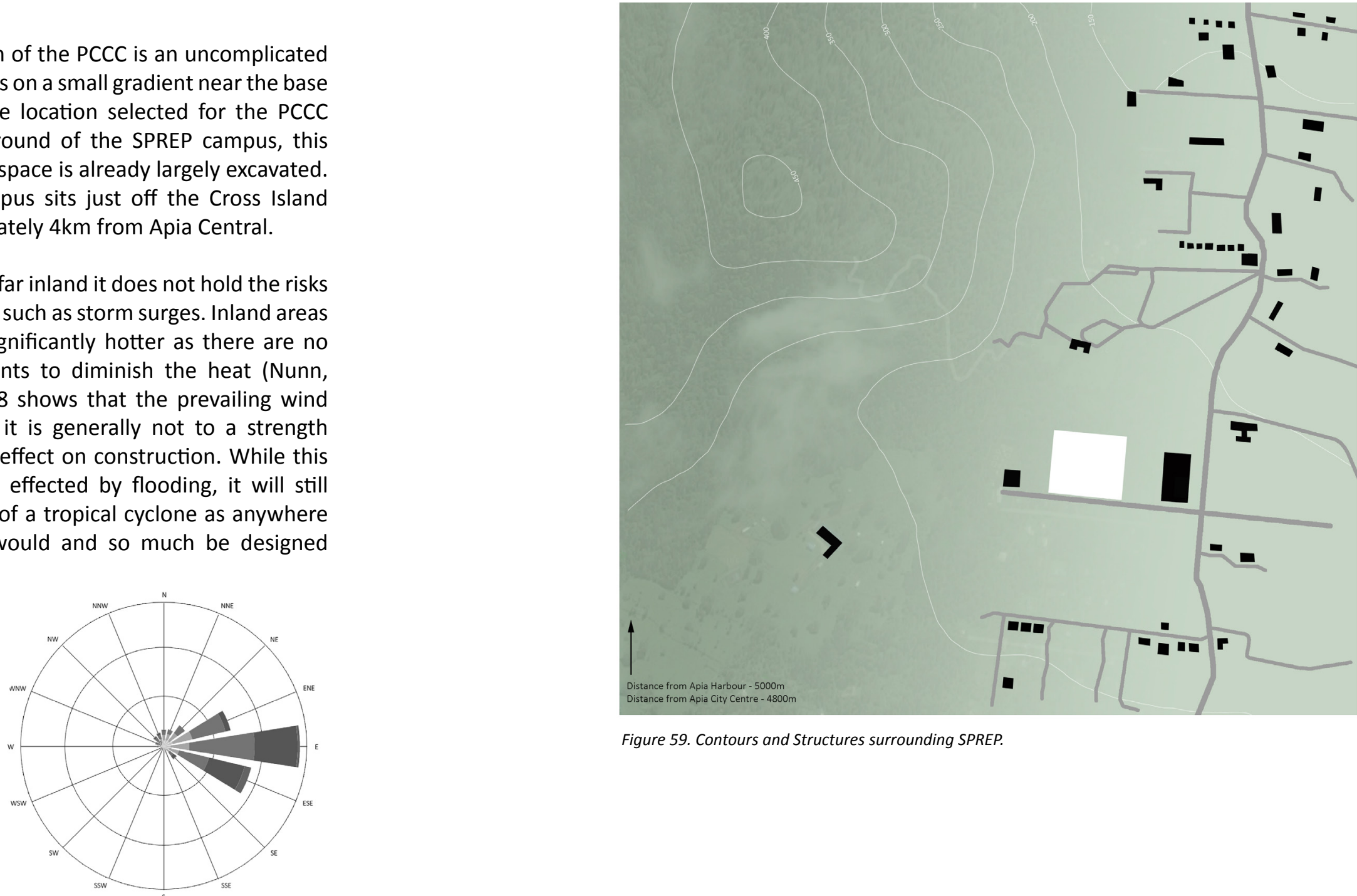

Figure 59. Contours and Structures surrounding SPREP. 


\section{SPREP DESIGN:}

The PCCC is to be constructed on the SPREP facility, as shown in Figure 60 . Site analysis of the site produced very few problems with the site as it is far inland and on land with an even gradient. The building footprint has been given, but this is the extent of the limitations.

The PCCC's presence on the internet is still very limited, but a copy of a conceptual image was procured, Figure 61. While this image does suggest a building with architectural merit, it is immediately clear that it does not suit the climate of Samoa, nor does it integrate with the traditional architecture. This is shown through the materials used and the Westernised design.

The irony of a Climate Research Centre that does not respond to the surrounding climate is also clear. This building appears constructed of concrete, a material that retains heat, as well as minimal windows, making ventilation difficult. From the research so far conducted, a far more suitable design should be put forward.

Further emails requesting information concerning the Figure 61 render were sent out (Appendices 26-30). In reply it was stated that there were not yet any official designs of the building, nor information concerning materials or construction techniques.

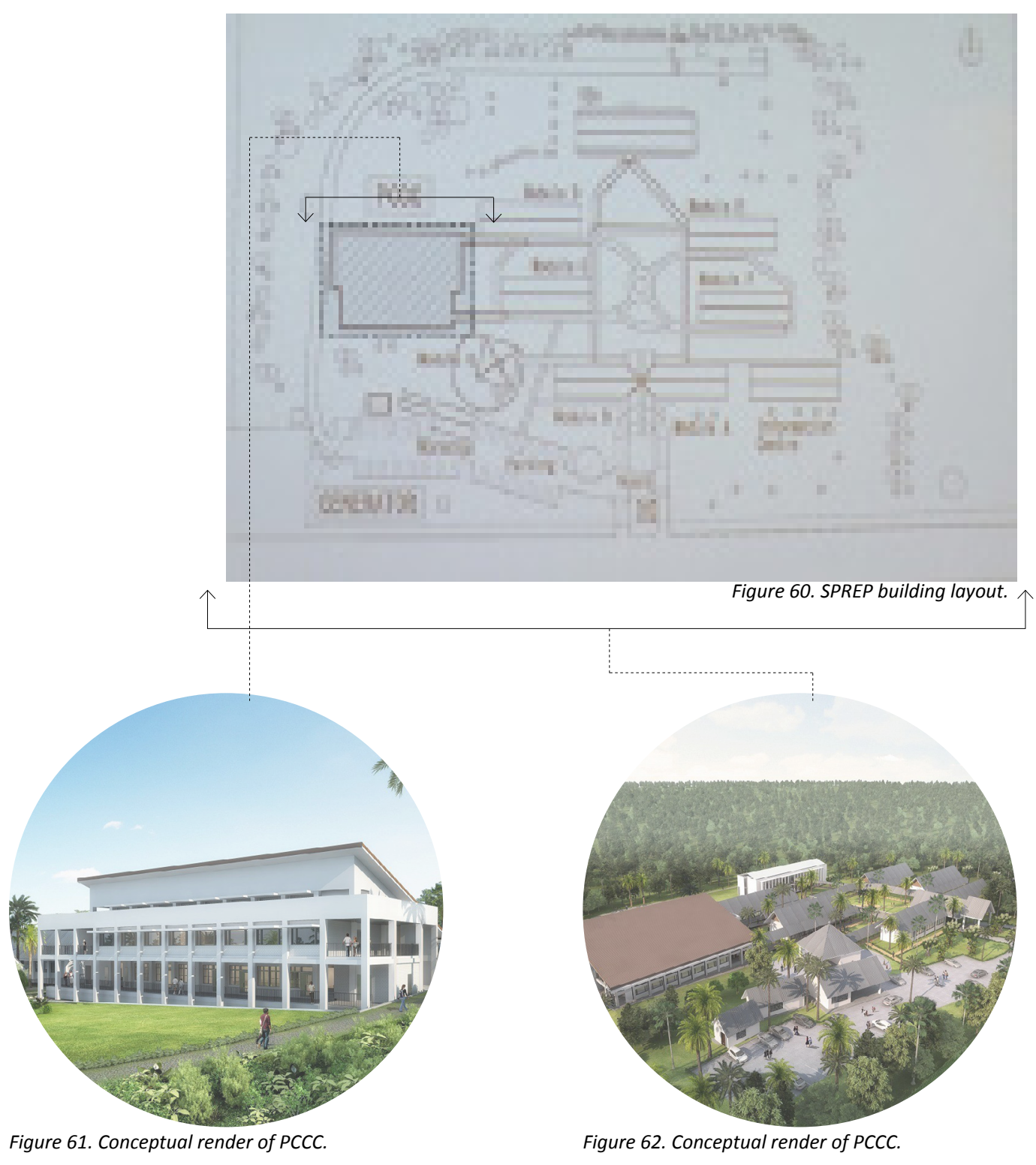




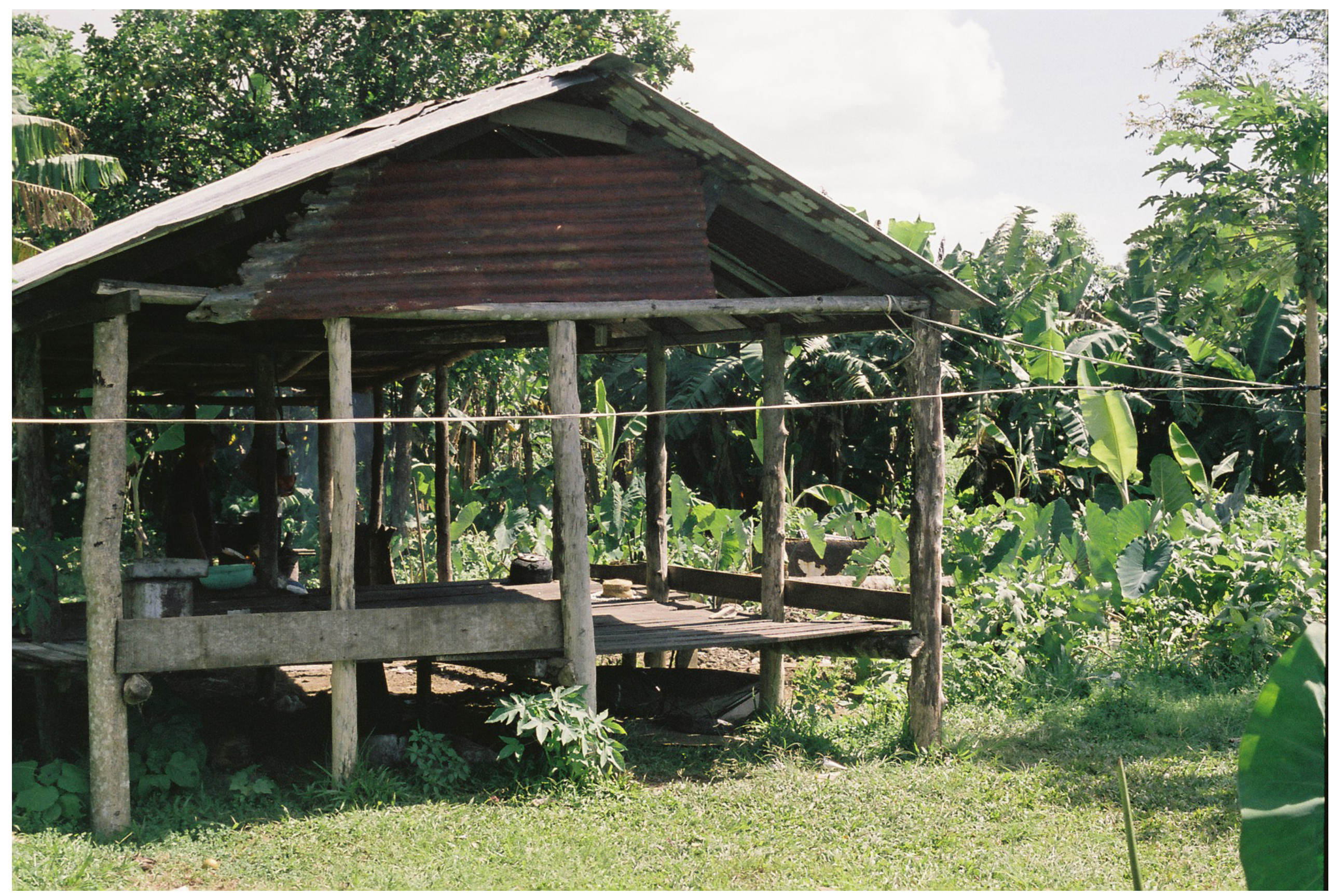




\section{DESIGN INTENTION:}

Currently, international architecture for the Pacific Islands is focused on post-disaster shelter relief. This is the design of a simple, affordable shelter to house people who have lost their homes. While this is an important contribution architecture can make, the changing climate makes it likely that these relief efforts may double in demand. Instead of assisting people after the damage is done, this project aims to develop architecture to assist before the disaster hits. This means developing a design that can withstand the effects of extreme weather with minimal damage. While it is vital that the building is resilient, this research has also determined the need for the people of Samoa to remain self-sufficient. This requires a design that can be easily constructed by local hands as well as materials that are accessible and affordable.

The need to alter construction methods as well as construction materials requires an intervention that is going to make a considerable impact. While the design of a simple shelter may be effective in the short term, changing the perception of a nation will require a far more substantial design.

Samoa is a strongly traditional country which has had many modern ideas thrust upon it, resulting in some haphazard architecture. It is important that this design recognises both elements of Samoa's community and combines the positives of each to create a hybrid design.
It is essential that traditional elements are incoporated to preserve the culture of the community. It is also important that modern ideas are incorporated so as to strengthen the design and to reaffirm Samoa as a fast 'Developing Country'.

This proposed design faces each of these issues in a way that benefits the people of Samoa. This design must encourage a positive future for Samoa, rather than simply mitigating what the country is currently facing. The design must respond to the harsh environment while taking into consideration predictions for a worsening climate. To create a design of this complexity requires restrictions to ensure that all issues are met equally. The following is a framework designed to achieve this. 
To develop the design described within the 'Design Intention' section requires the final step of the methodology, Research through Design. This section of the thesis is where the previously developed Hybridisation Framework will be applied.

While the Hybridisation Framework will structure the majority of the design, another key factor is the use of bamboo. It is key that this material is appropriately used to create a design with strong structural integrity as well as aesthetic appeal.

This design phase followed the following steps

- Sketch Iterations:

- Modelled Iterations

- Concept Design

- Developed Design

The results of these processes led to a final design.

The first phase, sketch iterations, is displayed from Figure 64 to Figure 68. These first drawings explored the many ways bamboo can be used. Also considered were the two contrasting designs of a traditional fale and a fale palangi. The result of this was often the combination of curved aspects, contrasted against stiff pieces of architecture. A running theme through these sketches is the consideration of the surrounding environment. The encompassing trees immediately encourage a permeable design.

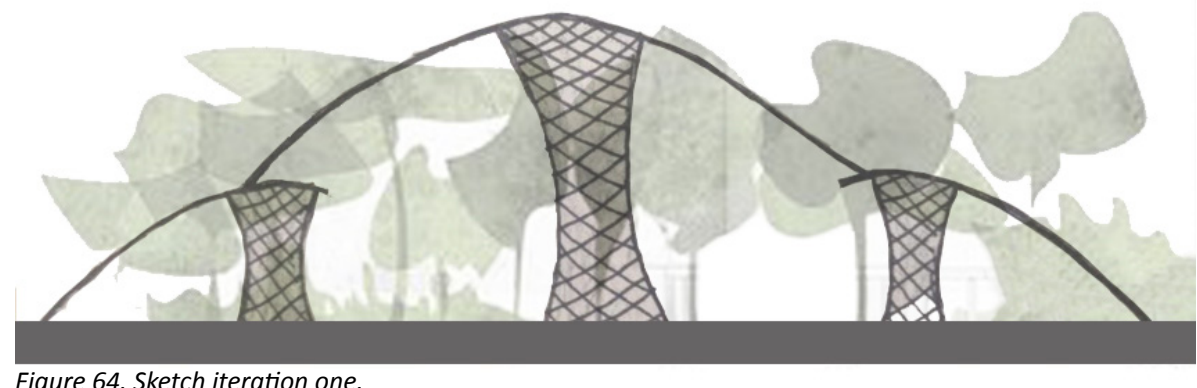

Figure 64. Sketch iteration one.

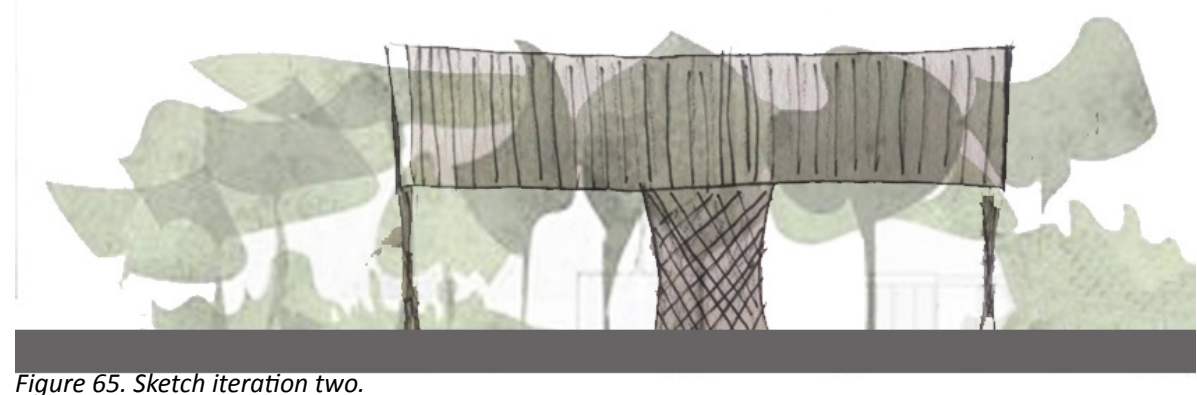

Figure 65. Sketch iteration two. 
To continue to the next phase of the design it has to be considered which design could be made into a realistic 3D model. The appeal and structural integrity of each design was also considered.

As the designs are currently all 2D, many could not realistically be made into 3D models. Instead of directly processing drawings into models, the most applicable and appealing elements were combined for the modelling stage.

This phase of design was highly unstructured, but made clear what ideas were already surfacing as key elements. These ideas included, a permeable façade, curved structure, high ceilings, and open floor areas.

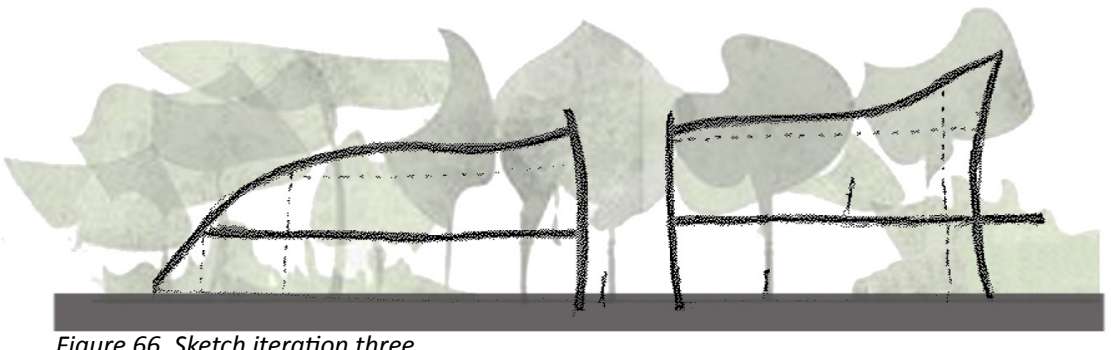

Figure 66. Sketch iteration three.

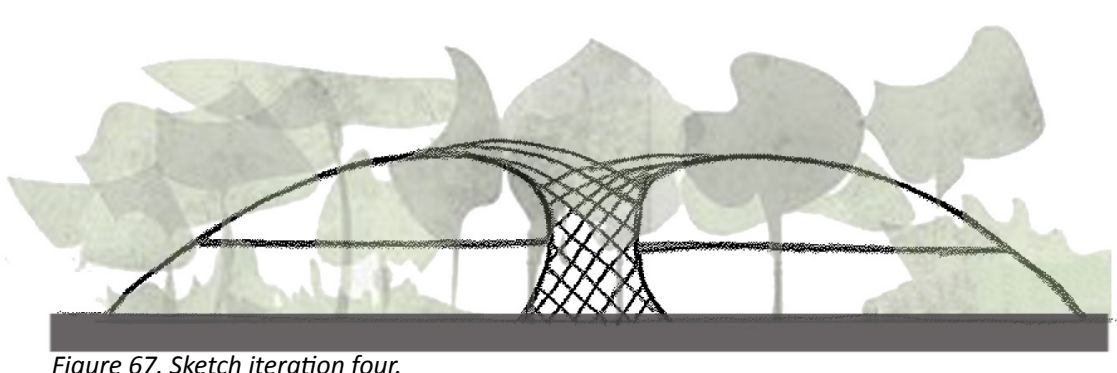

Figure 67. Sketch iteration four.

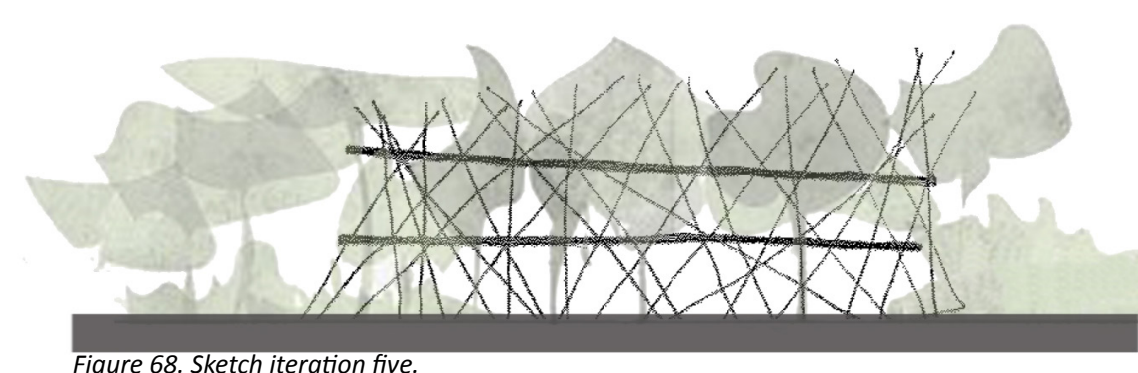

Figure 68. Sketch iteration five. 
The influence of the Samoan fale is vital to this design. The fale is not only a strong representation of Samoan culture, it is a design well suited to withstanding tropical cyclones. Other important elements to consider are permeability to allow ventilation as well as integration into the surrounding environment. To maximise on the use of bamboo, its structural properties should be integrated into the design, including its flexibility and low mass.

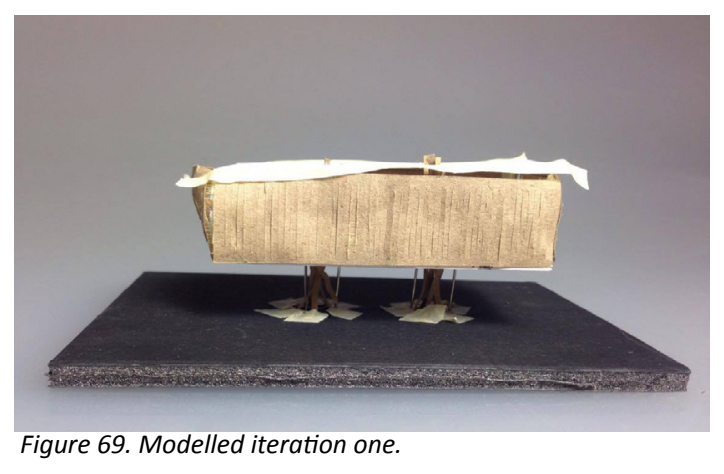

ITERATION ONE

This iteration was heavily influenced by the significance of structural columns in a traditional fale design. In this design the two columns would take all of the structural weight of the building. The elevation allows for passive ventilation as well as a cooling space beneath the structure. The use of a rectangular structure rather than a circular one implies a modern influence. However, the rigidity of the main structure is not designed for strong winds, despite the open facade

- Climate: Elevation allows for further cooling. Permeable structure to allow wind to pass through. - Community: Open space at bottom for public space.

- Culture: Columns similar to that of a Samoan fale. - Contemporary: Structured façades are common

in European buildings. Exterior walls are a European feature

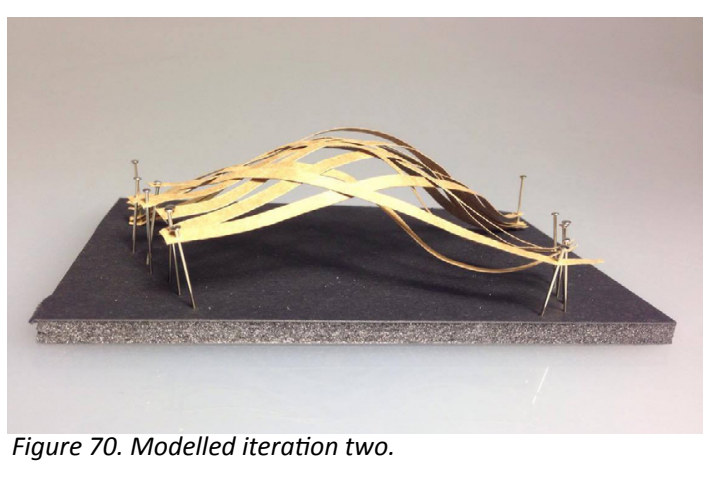

ITERATION TWO

This iteration combines two key elements of Samoan traditional design and bamboo. The lashing style of a Samoan construction is integrated with the flexibility of bamboo. The result is a curved building, which is highly suitable for strong wind conditions. A downside to the design is that the high quantity of curved areas lowers the amount of usable space inside the structure. The flexibility of bamboo is also exaggerated in this design.

- Climate: Permeable structure to allow wind to pass through.

- Community: Open façade allows the public to view inside.

- Culture: Curved roof is similar to that of a traditional fale The lack of walls also imitates the openness of a fale.

- Contemporary: While curved structures can appear modern, this design lacks any contrast differing it from the traditional curve of a fale. 


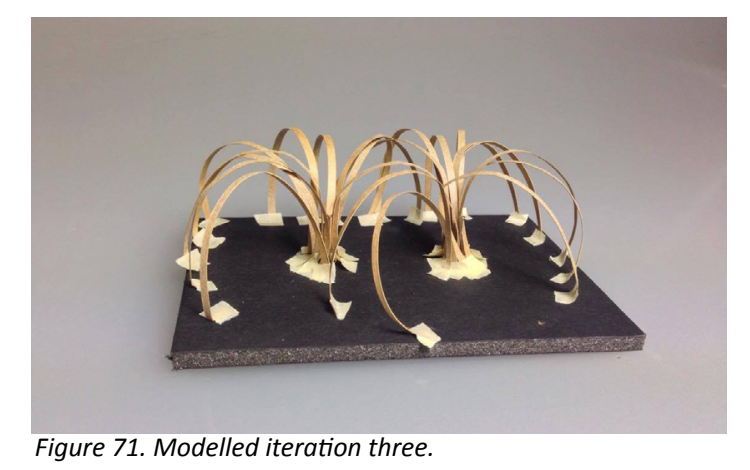

ITERATION THREE

This design takes the form of a traditional fale and constructs it entirely of bamboo. Of these four iterations, this design is the most reflective of the appearance of a traditional fale, but not the construction techniques. However, by pulling the structural elements back to the base of the perimeter, habitable space is greatly reduced.

- Climate: Permeable structure to allow wind to pass through

- Community: Open façade allows the public $t$ view inside.

- Culture: Curved roof is similar to that of a traditional fale.

-Contemporary: Several separate spaces, which can have different uses

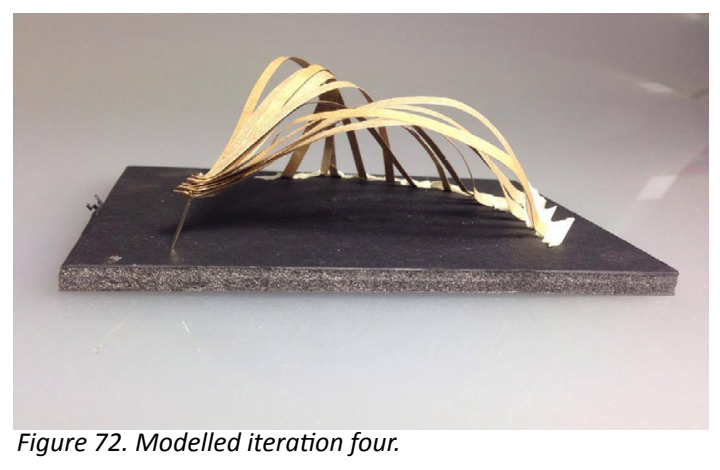

ITERATION FOUR

This design is most reflective of the flexibility of bamboo as a construction material.

The curved shape will withstand high winds in the same manner that the dome roof of a fale does. While this design is currently very exposed to the exterior environment, further structure would be needed if this design was to applied to a real life building. Exterior walls would most likely need to be added at the two openings.

- Climate: Permeable structure to allow wind to pass through

- Community: Open façade allows the public to view inside.

- Culture: This design has an open interior, which is similar to spaces found within a traditional fale. The lack of walls also imitates the openness of a fale.

- Contemporary: Gives the appearance of a modern structure. 


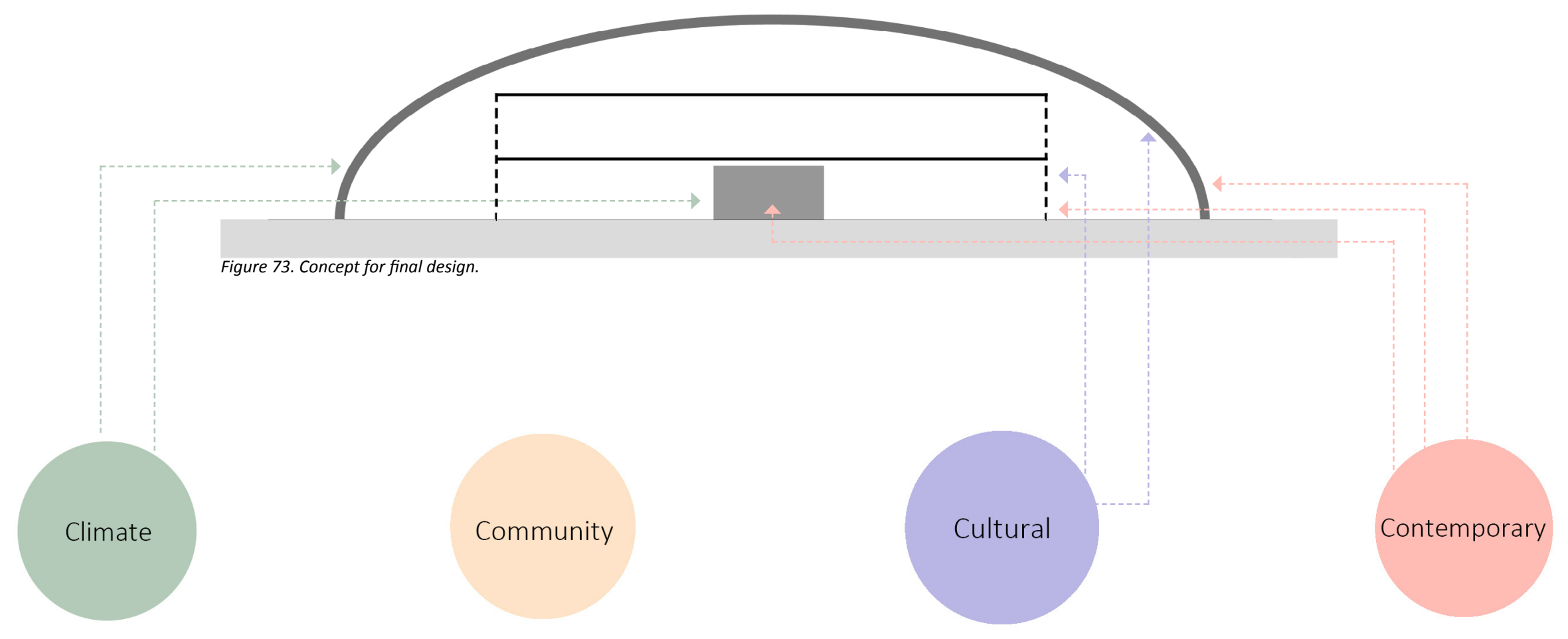

The exterior façade should respond to the environment of Samoa. It is essential that the structure of the building has high resilience to the extreme weather that Samoa can experience. Protecting the inhabitants of the building is also essential in extreme weather events and so the design should incorporate this.
The entire form should be beneficial to the community, from the exterior appearance to the use of the building. The design should include an area that can be used by the public at any time.
An exterior form that is heavily influenced by traditional Samoan building techniques. The interior spaces of the building should cater to the needs of the buildings functions and inhabitants.
While the exterior façade will be heavily influenced by climate and cultural elements of the area it is important that the façade also has a contemporary twist. This is important in cementing that the design is seen as modern and that is may be recognised across the world. The building itself should also have a certain aesthetic appeal so that people who view the buildings want to mimic the design. 


\section{Design Development}

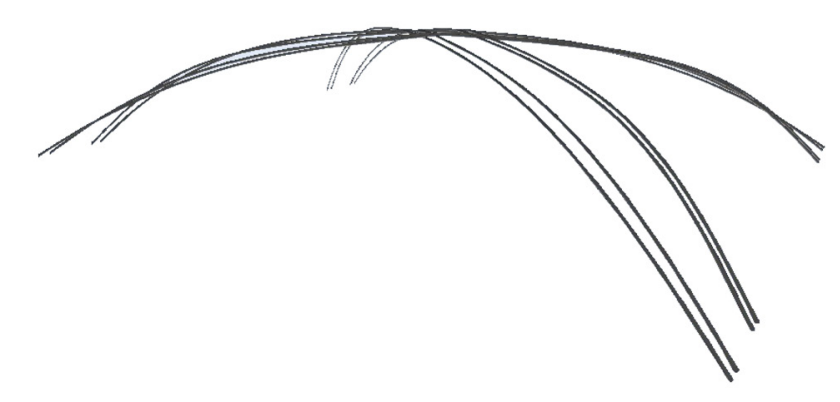

Figure 74. Developed design roof structure.

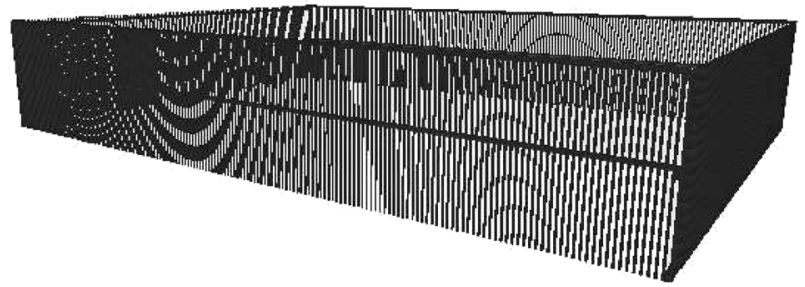

Figure 75. Developed design facade.

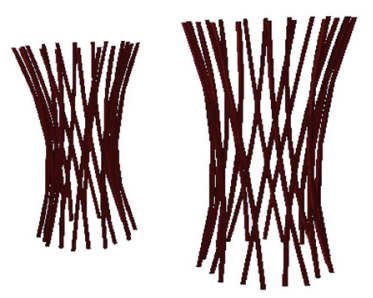

Figure 76. Developed design columns.
Despite the positives of each design, after reviews from peers, it became clear the Iteration One was the design with the most potential and was the most suited to the concept model. From here the process became digital, working primarily in Rhino and Grasshopper to create curved bamboo structures.

Further peer reviews resulted in scaling down the roof structure, Figure 74 , as it was not needed to support

the design. A redesign of the roof leant towards further representation of the Samoan culture.

As the column design, Figure 76, held the strongest representation of a traditional fale, this design feature was given a higher prominance. This resulted in a larger diameter to support the structure and a higher reach to increase the aesthetic impact.

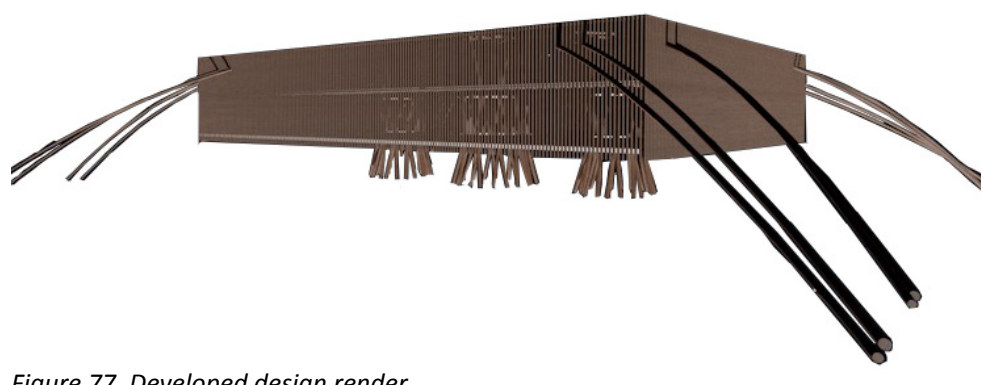

Figure 77. Developed design render. 
Chapter Four

Final Design 


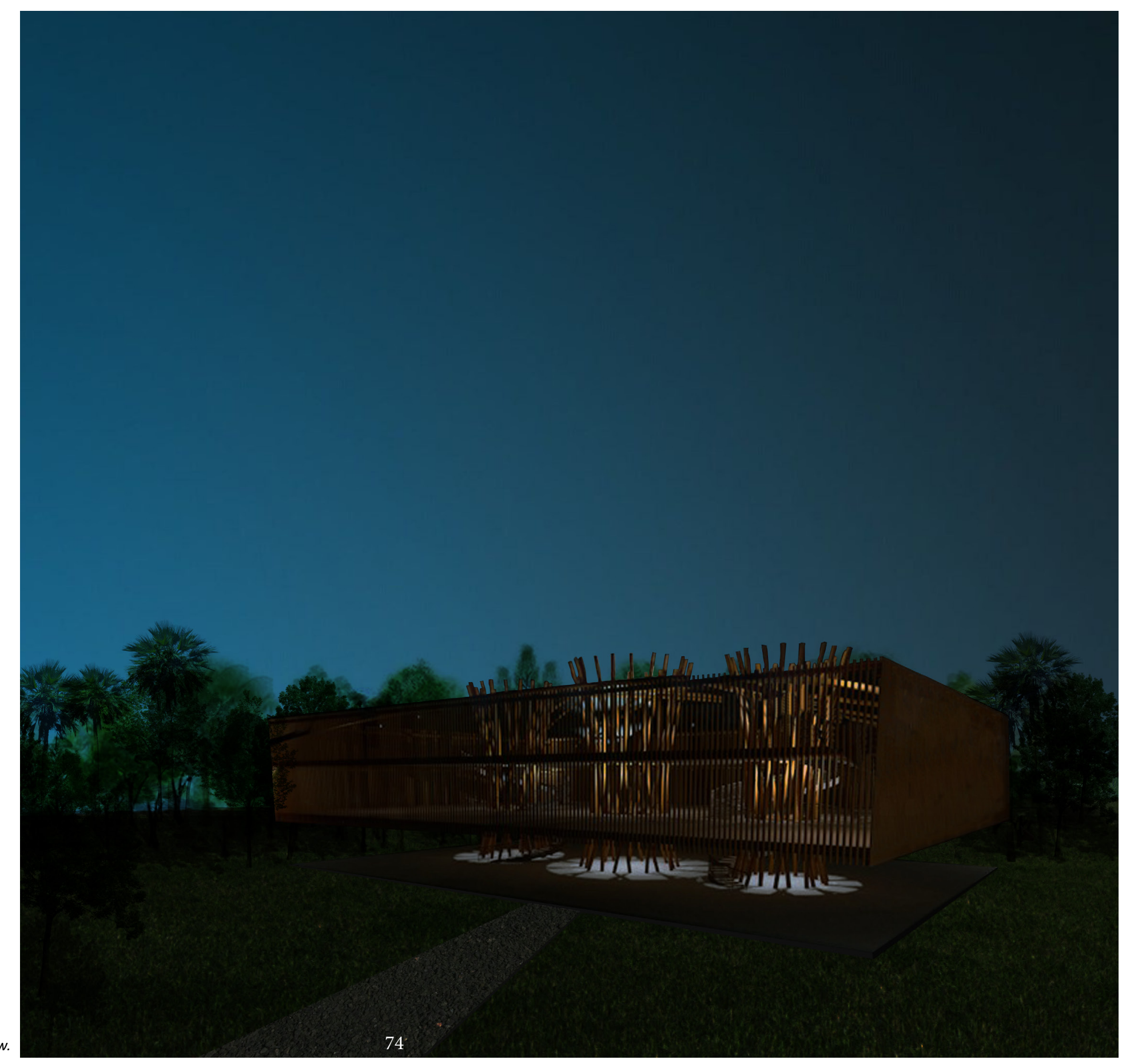




\section{DESIGN DESCRIPTION:}

\section{CULTURE:}

The design of the building focuses on following the Hybridisation Framework, but takes key design elements from both the fale and the fale palangi. The columns of the building are a focus point of the building, taken from the central columns used in a fale. The central columns of a fale are the key structure of the building, while the exterior columns have cultural, rather than structural significance. As the columns stand as the heart and support of the building, they are used to hold the entrance stairwells as well as an accessible elevator.

The use of a slatted façade is an interpretation of a modern design, being utilised in an extreme climate. The straight edge, decorative façade displays a European influence due to its linear arrangement. However, the slatted design is especially designed for the climate and invites in any cool breeze.

Finally, the roof structure displays a traditional influence. The curved roof is imitates the dome roof of a fale and is woven together to display, from above and below, a traditional Samoan binding technique. This roof is lashed to the exterior façade and the central columns.

The large open spaces will also lend themselves in times of need. Guest fales within villages often stand empty and are seen as a place of refuge.

\section{CONTEMPORARY + COMMUNITY}

This building is designed to be the first Climate Change Research Centre for Samoa. This building is structured to function in many different ways to accommodate the following.

- Daily office life

- International research functions

- Construction education

- Public access

- Cultural functions

The building's open floor plan displays a heavy influence from the traditional Samoan fale. This open plan offers two large spaces for functions and learning programmes to be held. To make the space multi-functional and suitable for extreme weather, the use of partitions is encouraged. This allows private office spaces to be created when required, that can be resized or opened up to suit any need.

\section{CLIMATE:}

This design combines the enclosed characteristic of a fale palangi with the exposure of a fale. This is shown through the use of the slatted bamboo walls. These provide privacy for the interior of the building, but do not seal the building off from the outside environment. The covered rooftop shelters inhabitants from rainfall, but any breeze is still allowed through the building. As the building is not fully sealed, air conditioning cannot be utilised. This meant that it was vital to encourage passive ventilation. This is achieved through the elevation of the building 1.5 stories of the ground. Elevating the building also promotes elevation as a building habit in defence against storm surges.

The exposure to the outside environment is also vital to allow this building to withstand a tropical cyclone. With the slatted exterior, high winds will meet no resistance as they can pass through the building, however, the close slats will prevent debris from entering the building. The curved roof structure takes influence from a fale roof. The gentle curve reduces uplift on the roof, making it less likely to be torn off. A key defensive element to cyclones is the use of bamboo as a construction material. The flexibility of the material allows it to bend in high winds which reduces tension. The use of lashings as a connection technique also allows joints a flexibility that makes them far less likely to fail in extreme weather events. 


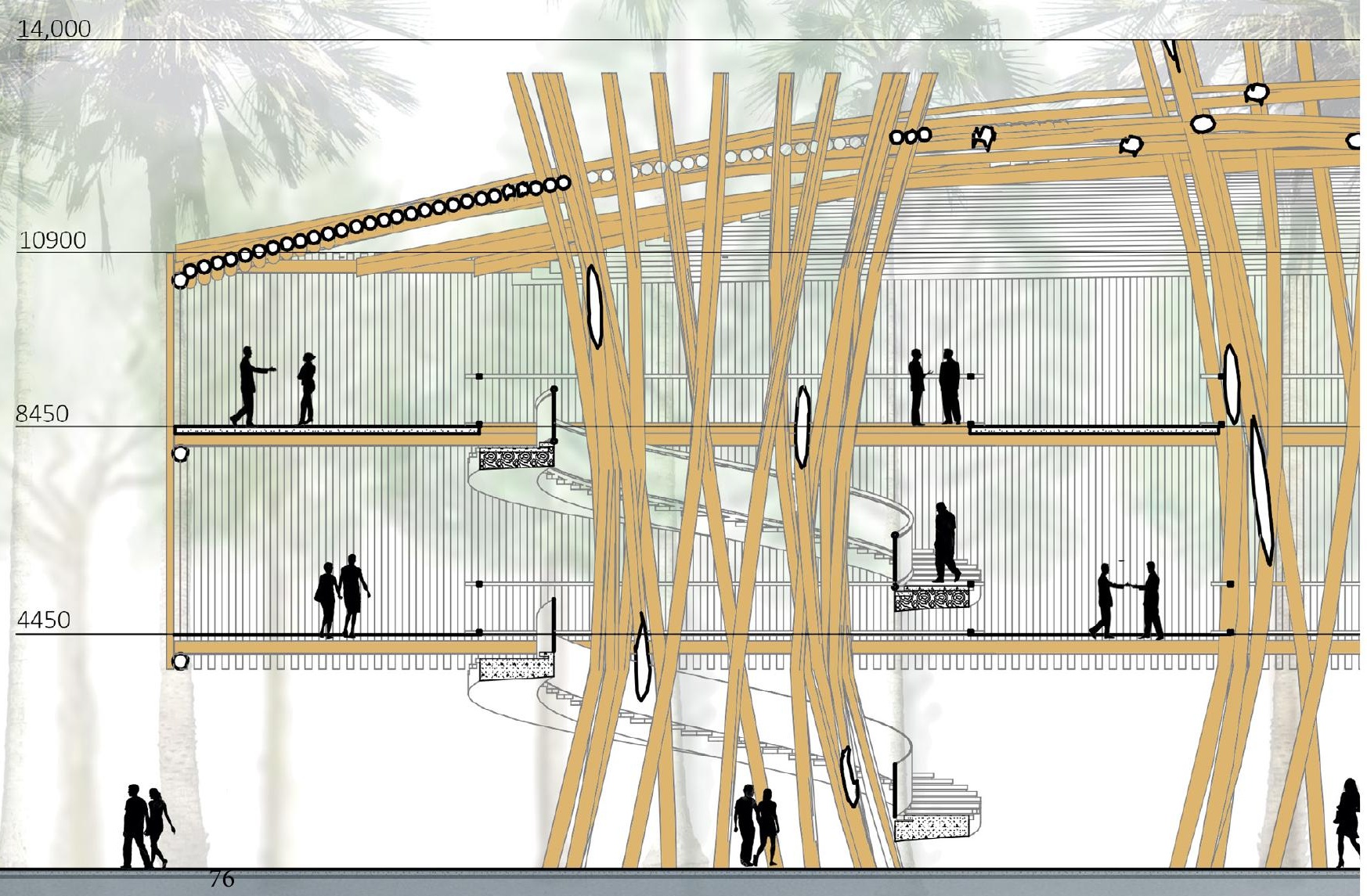




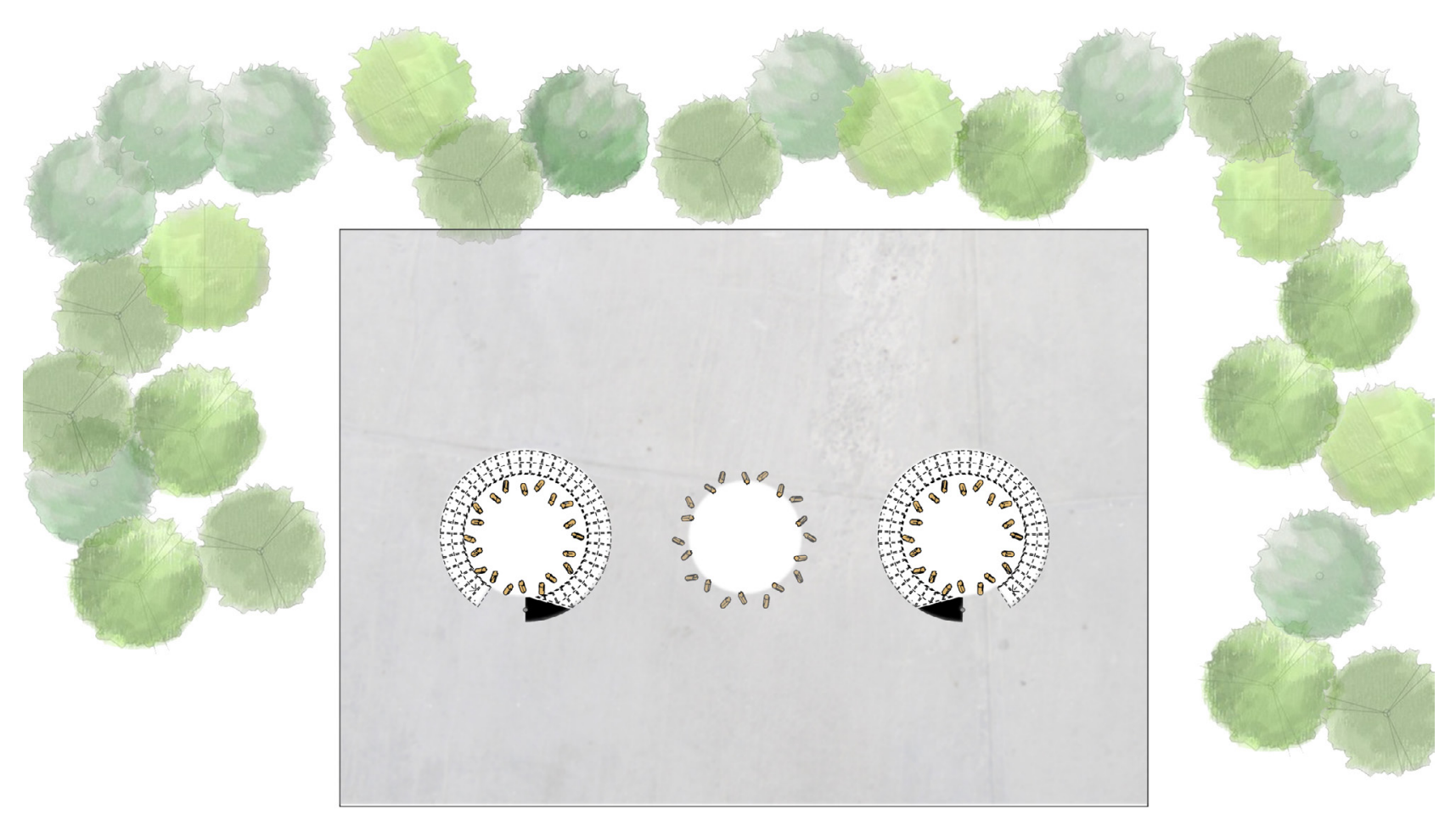

Ground Floor 


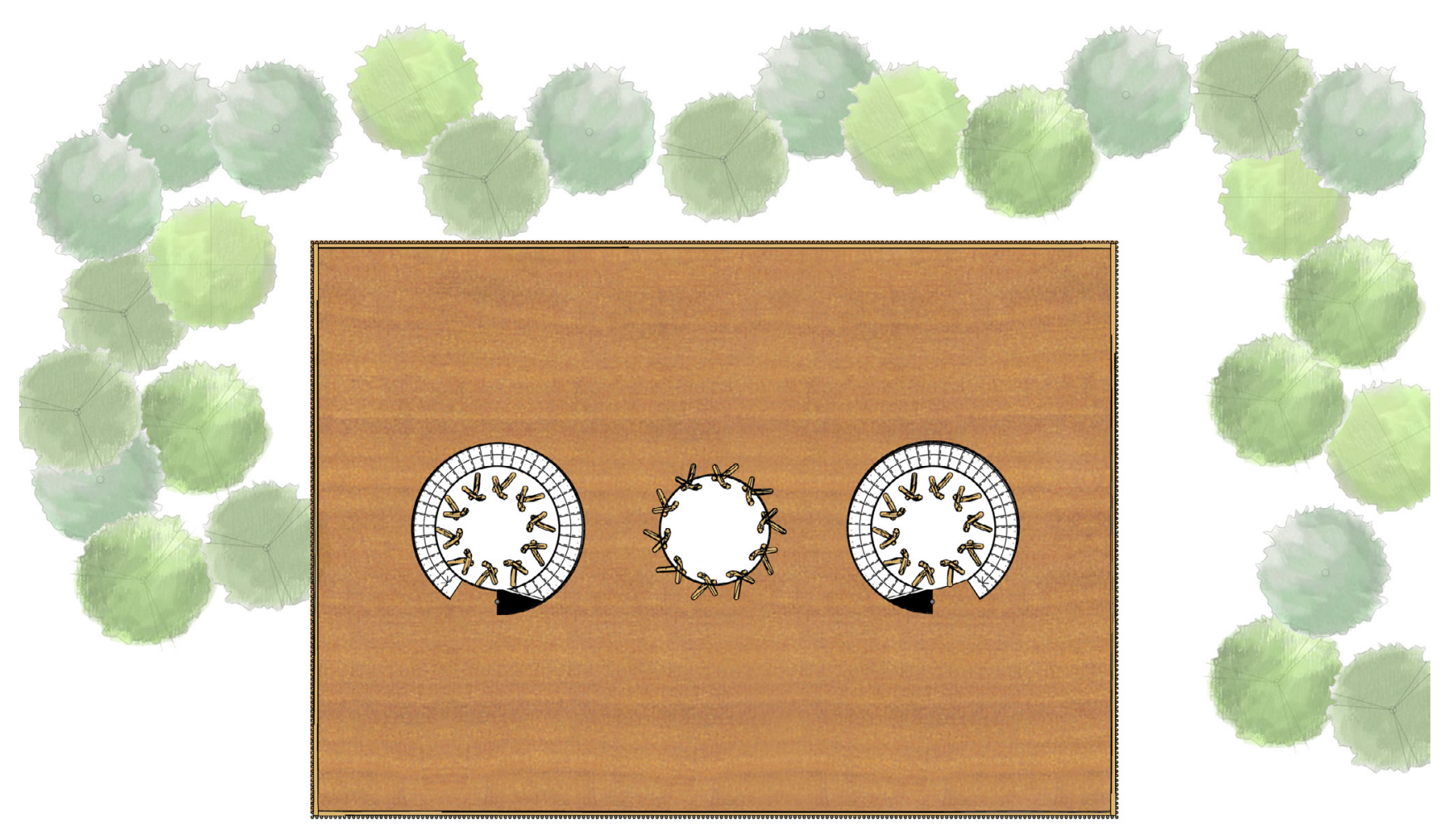

First Floor 


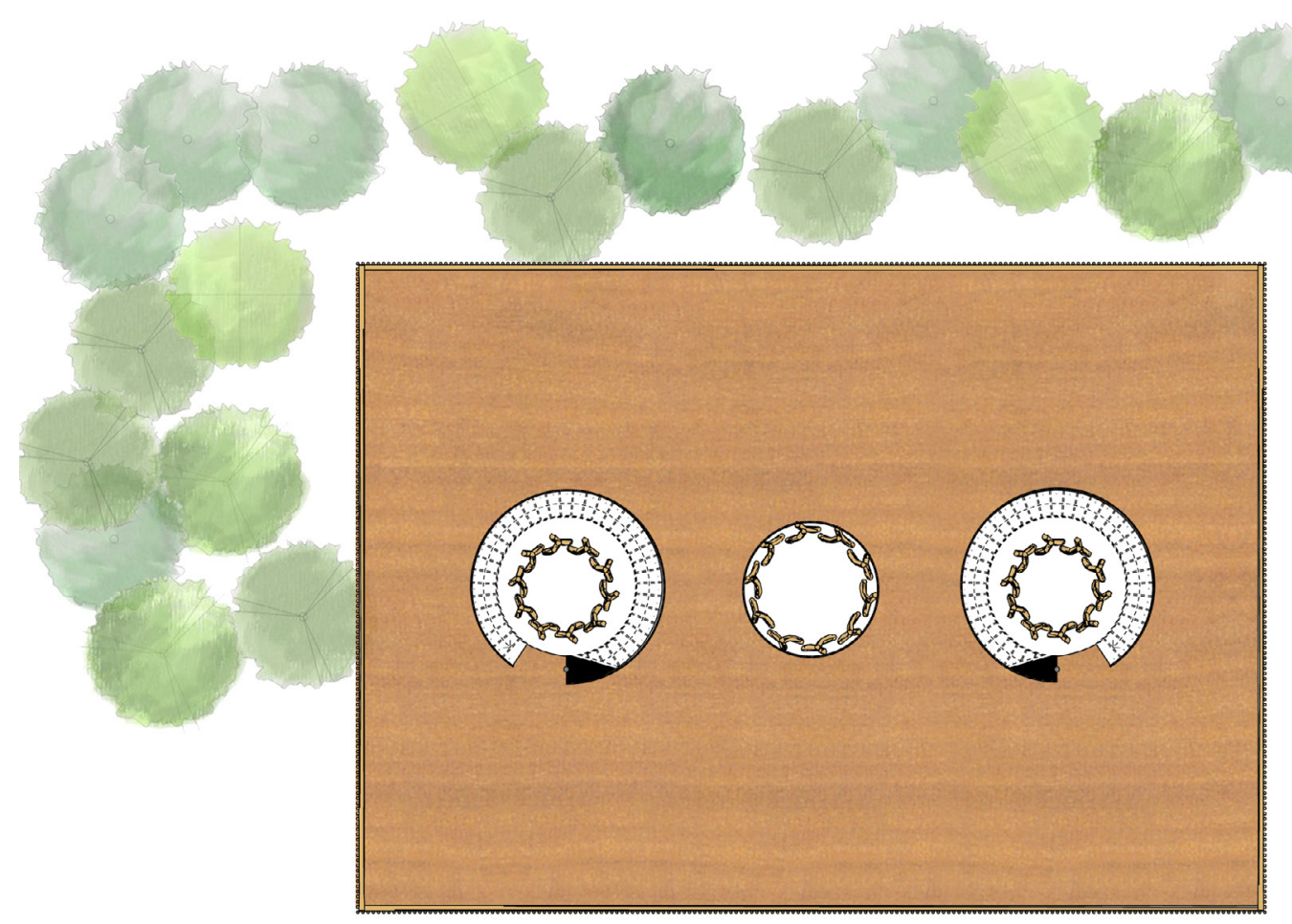

Second Floor 


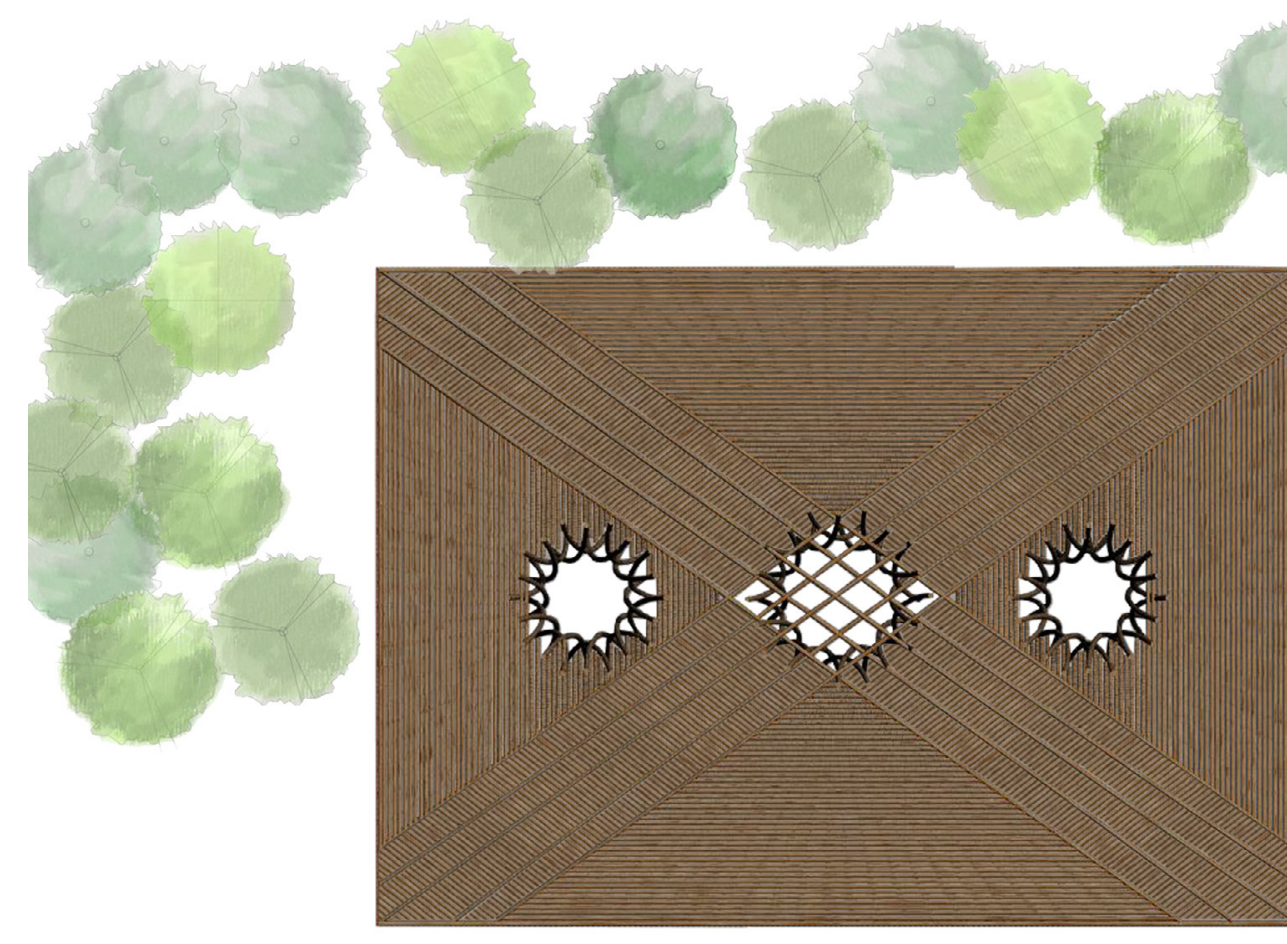

Birdseye View

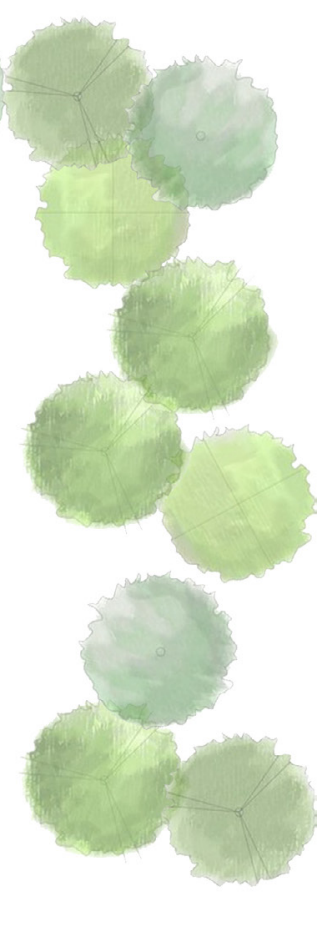




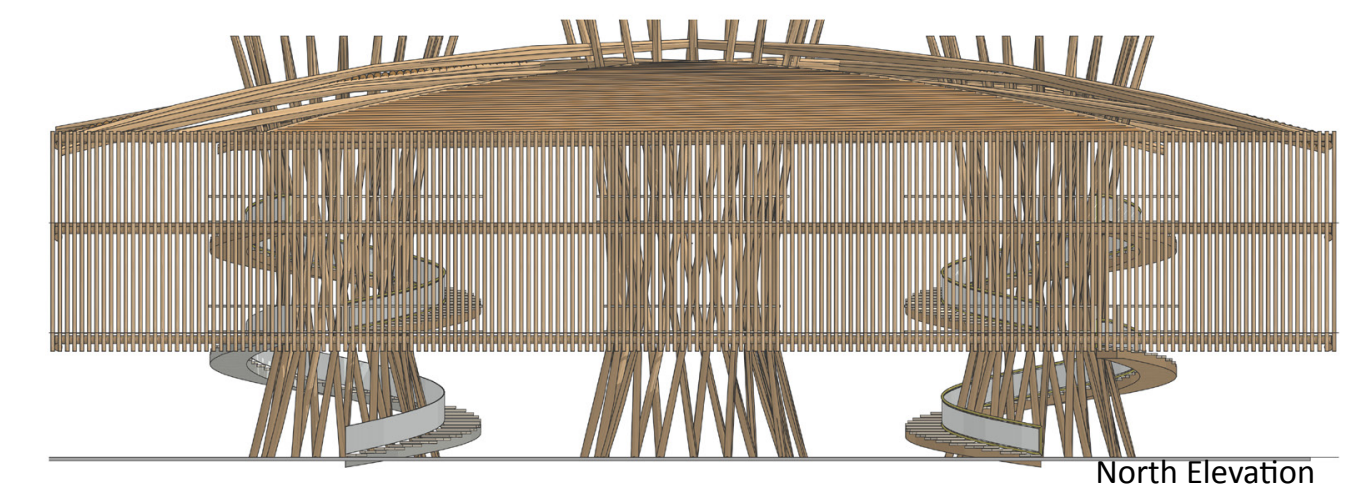

Figure 84. Final Design, North Elevation

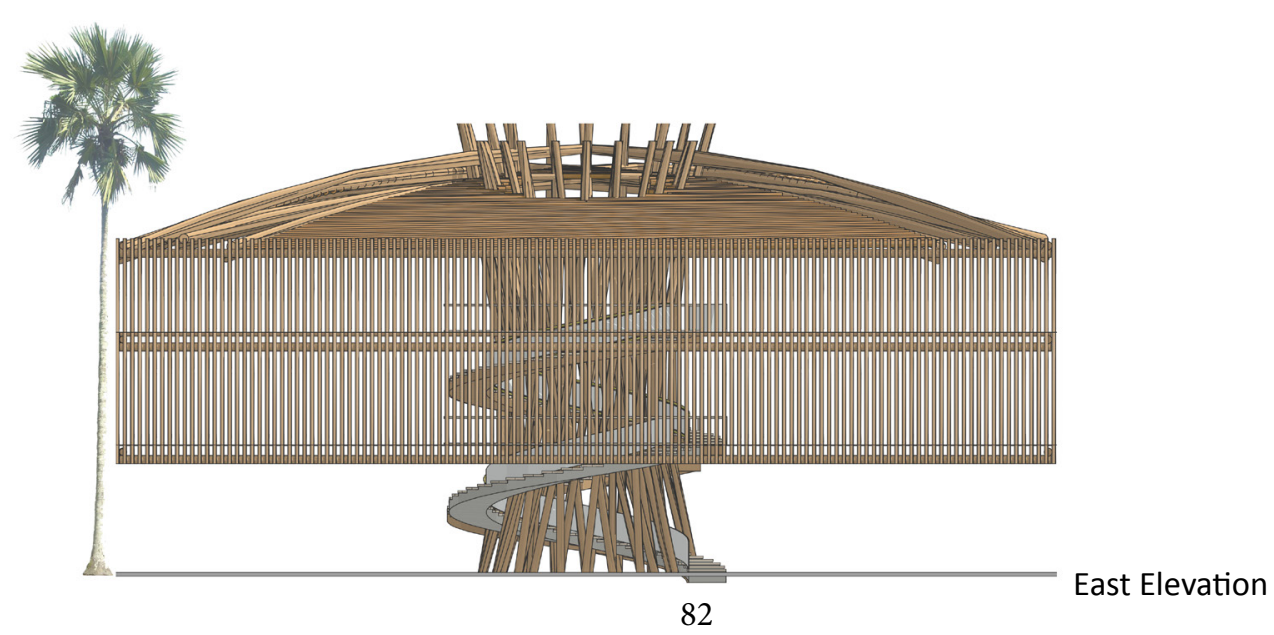

Figure 85. Final Design, East Elevation 


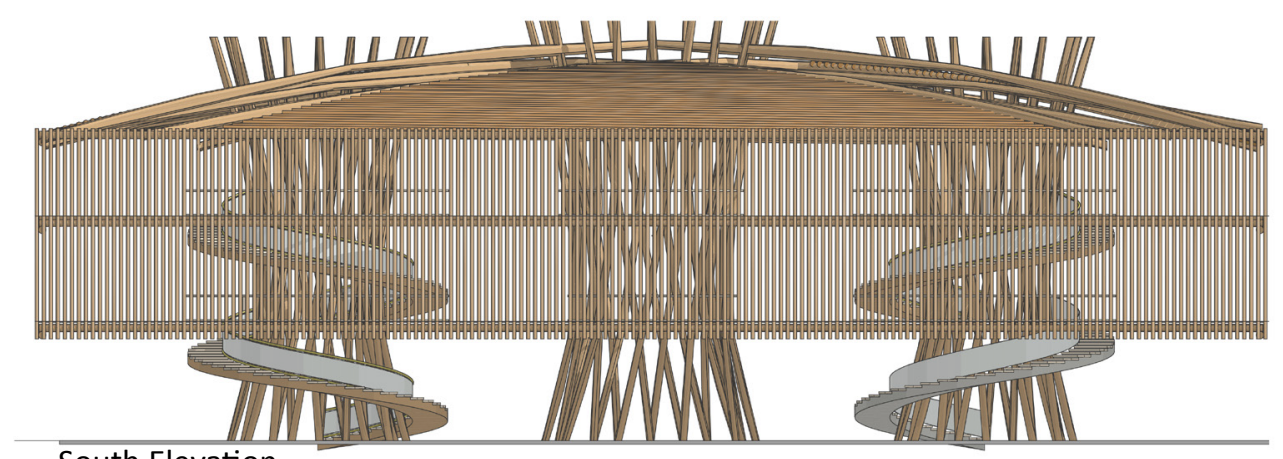

South Elevation

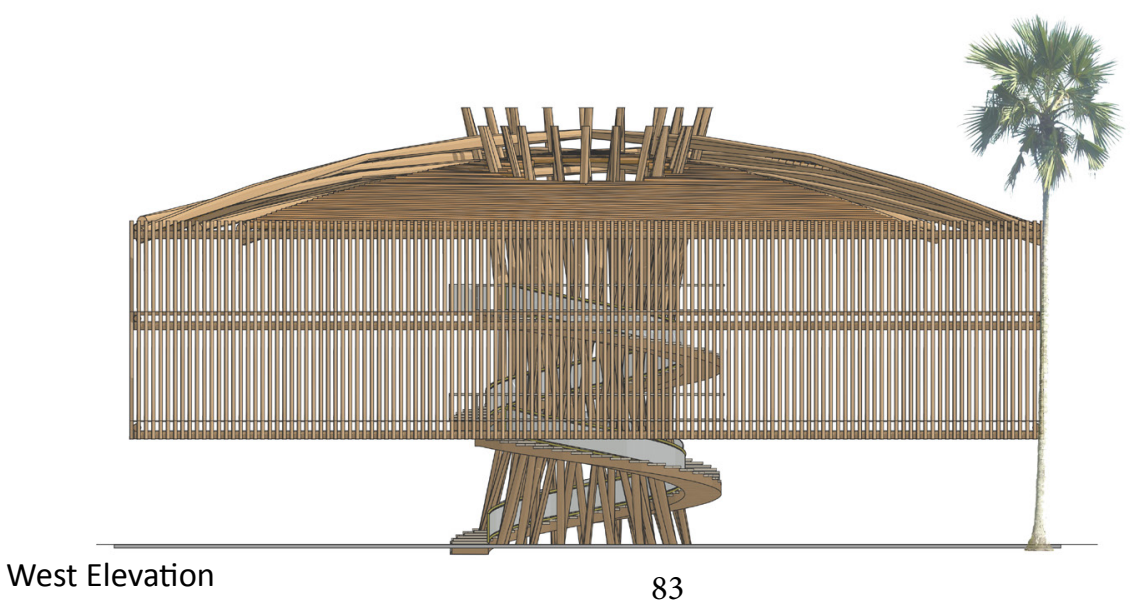




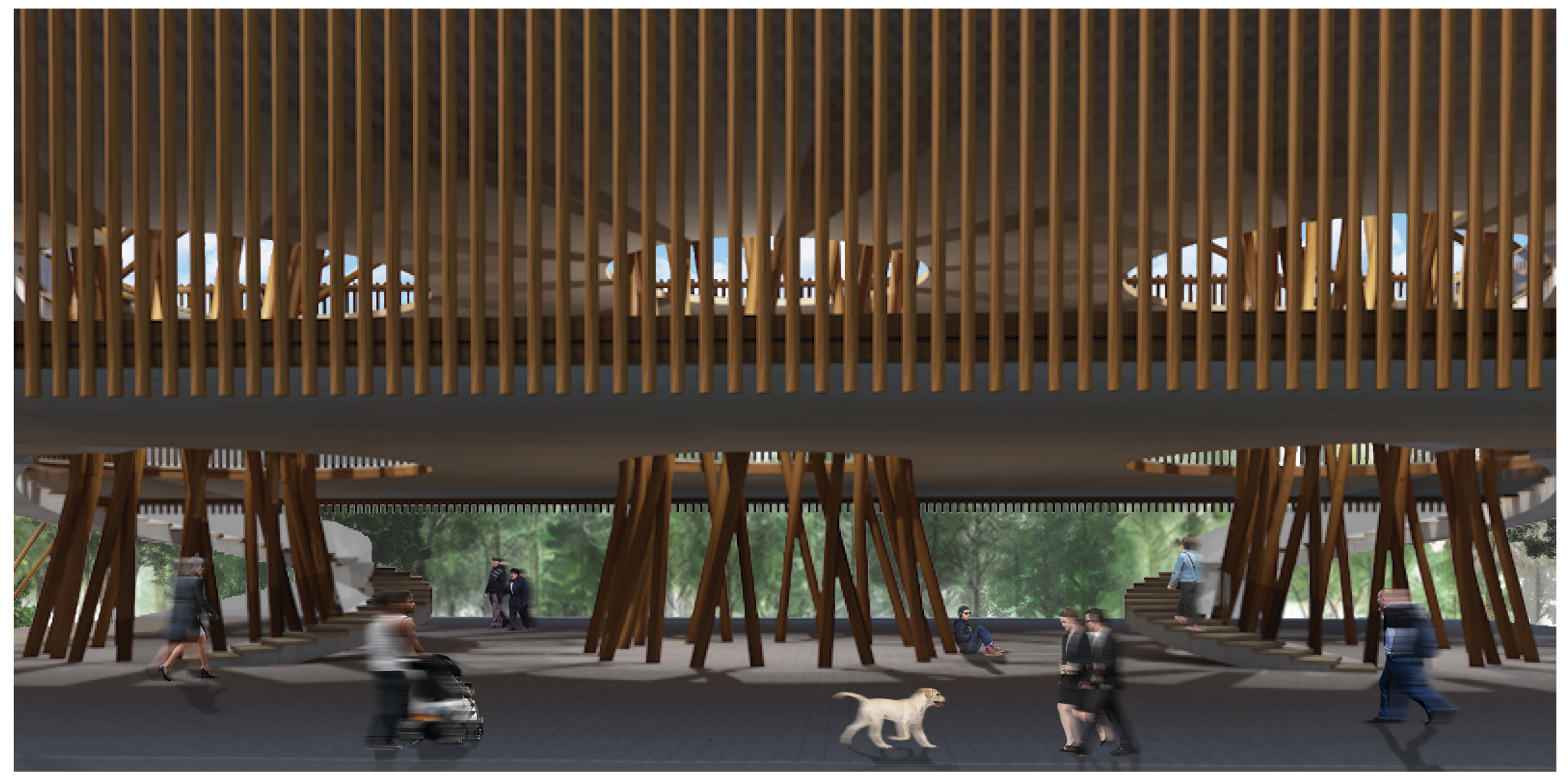


KEY ELEMENTS OF THE FINAL DESIGN:

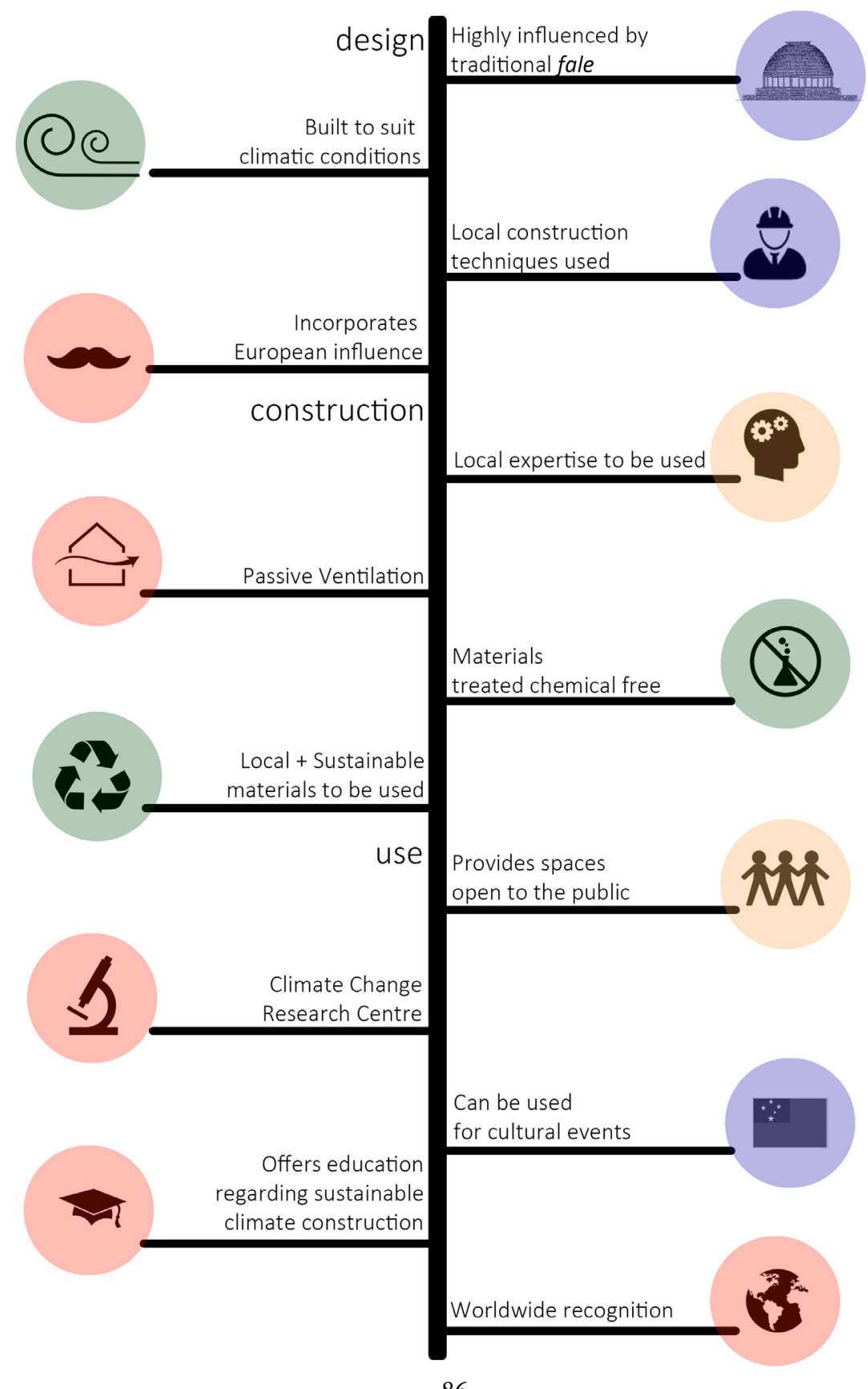




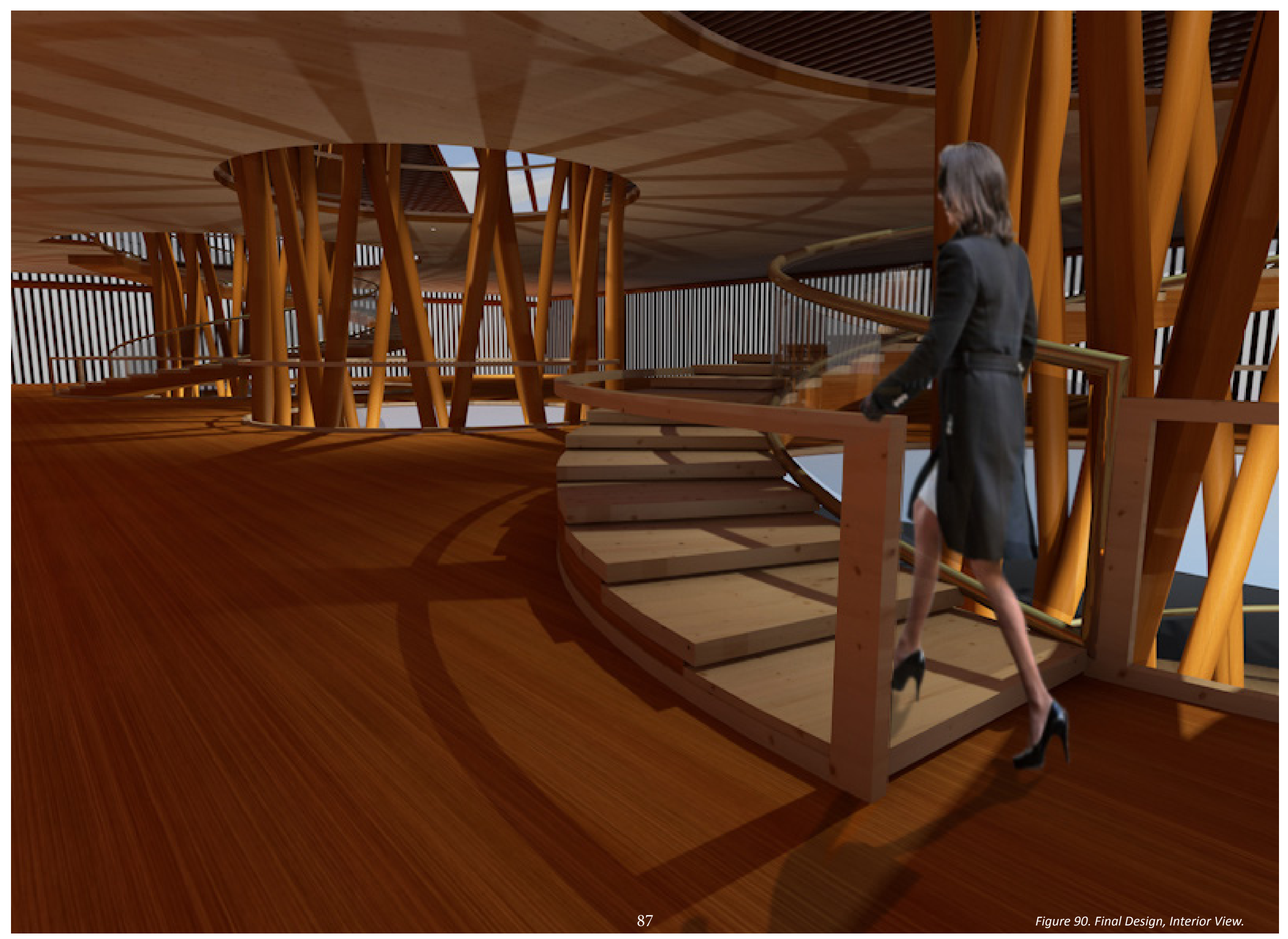




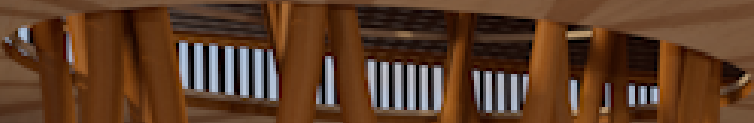
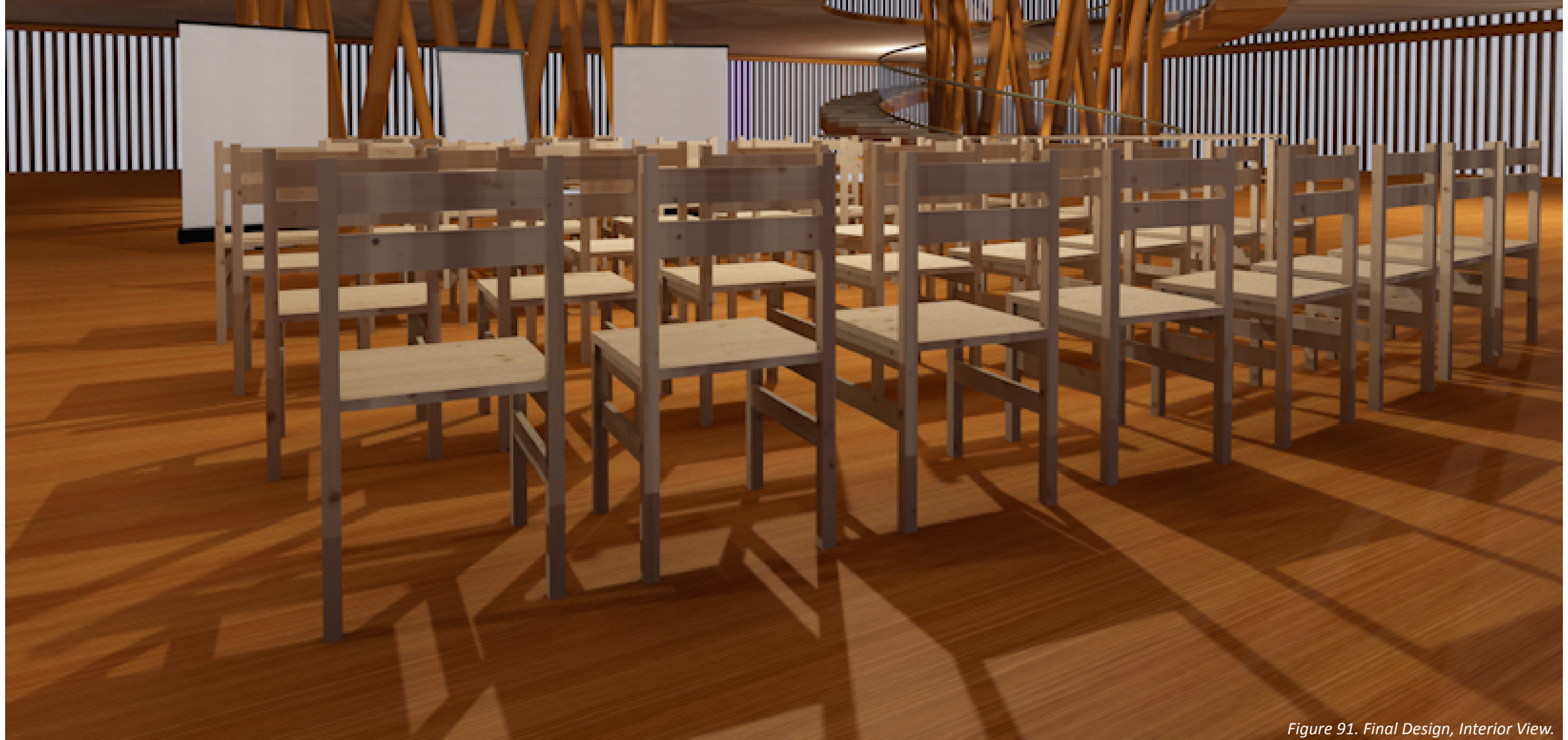


\section{BAMBOO CONSTRUCTION DETAILS:}

While bamboo has immensely strong tensile weight, its compression strength is not as high. For a building of this size, timber flooring had to be used to support the predicted loads the building would be carrying through compression (Schroder, 2014).

As is shown in the construction details, Figures 92 + 93 that steel bolts have been recommended for some fixings. This is due to the large scale of this structure and the heavy loads it will be carrying. When this construction style is applied to smaller scale buildings, such as family homes, the bolts will be unnecessary as lashing will fix structural elements satisfactorily.

The centre column is designed to hold the elevator as well as services. The two other columns are design to be open in the centre so as to funnel further light into the building as well as providing extra ventilation. These columns represent the strength of the columns found within a fale, which also hold the weight of the building.

"The main posts of a large fale tele or fale afolau are nothing if not massive, particularly in the fale tele the roof of which, rests entirely on them, the wall posts not being an absolute structural necessity"

(Higginson et al, 1992).
The slatted bamboo façade is both functional and has aesthetic value. The function is that natural light and ventilation can enter the building. This provides the building with same characteristics of a fale. While these give the building a certain permeability, the building has a privacy and therefore a security that the traditional fale could not provide. Aesthetically, the facade provide the building with an architectural quality that makes it pleasing to look at, without expense having to be made in the construction.

Both the columns and the façade provide a light quality, seen in Figure 90 and Figure 91, that allows inhabitants to appreciate the surrounding environment, without being inconvenienced by it.

The construction details displayed across the page are based off NZS3604 BRANZ timber building code. Construction is based off timber as bamboo is not detailed within the NZ Building Code. As this building has an extreme structure, allowances of an additional $100 \mathrm{~mm}$ have been applied to ensure structural integrity. Member sizings are based off Appendices 19-20. 
1 Structural bamboo column

2 Structural bamboo lashed to main column

3 Steel bolt fixing timber pin to joist

4 Timber pin acting as bamboo node to fix to joist

$5600 \times 90$ cantilievered timber joist @400crs
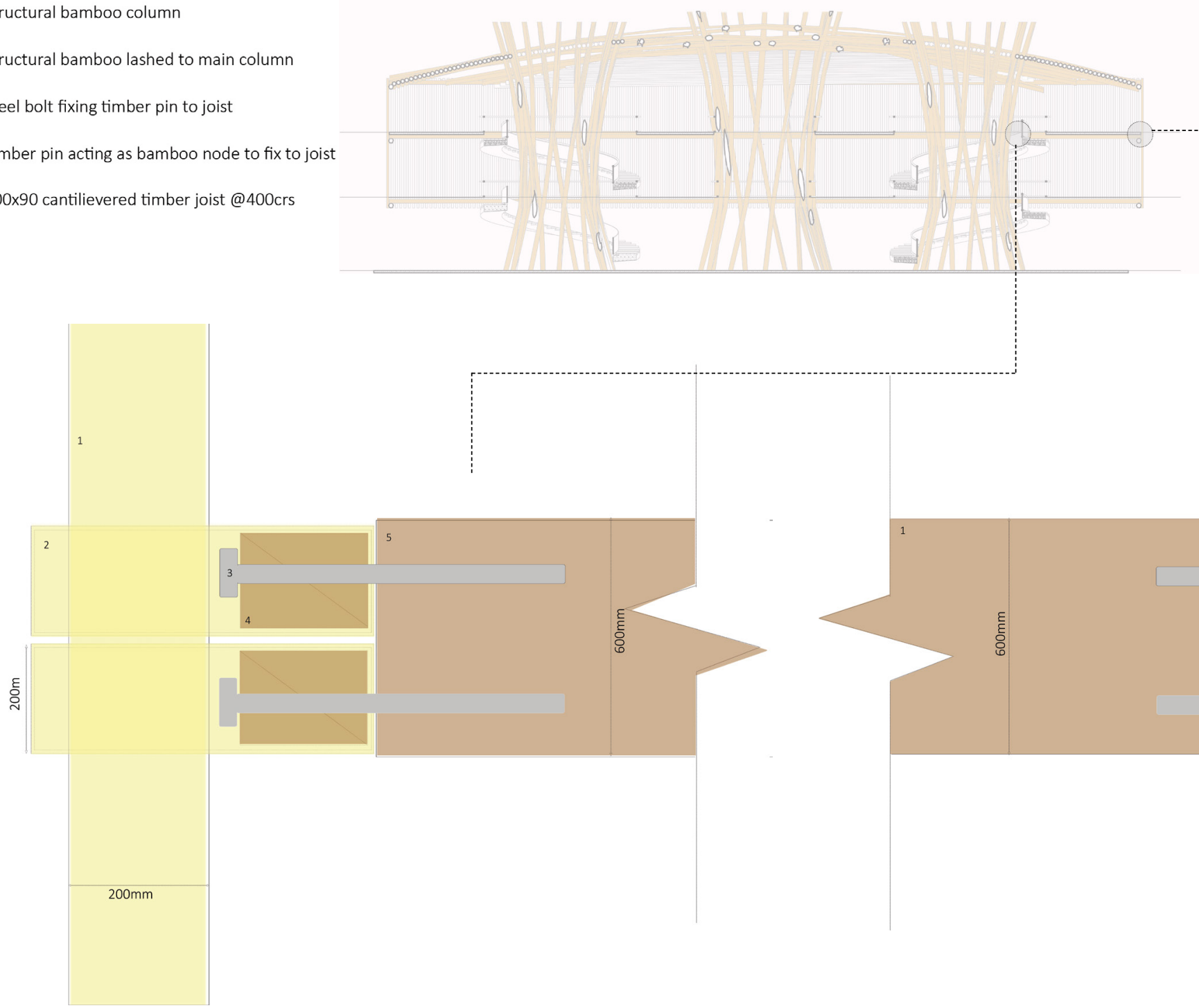

$1600 \times 90$ cantilievered timber joist @ 400crs

2 Steel bolt fixing timber pin to joist

3 Timber pin acting as bamboo node fixed to joist

4 Structural bamboo lashed to facade

$45 \times 90$ timber wedge to fix bamboo supports

6 Bamboo facade lashed to bamboo supports 
In the previous construction details the use of steel bolts is seen to connect timber and bamboo structure. This is due to the heavy loads that the building will be holding, meaning that timber is required for its compression strength (a property bamboo lacks).
In areas where bamboo is fixing to bamboo, as shown throughout the roof structure (Figure 94), traditional lashing techniques can be used. This lashing can be made of a range of materials, for a more traditional appearance, dried grasses or coconut rope can be used.
For a more modern appearance steel wire could be used, which would require less maintenance, but would have to be imported.

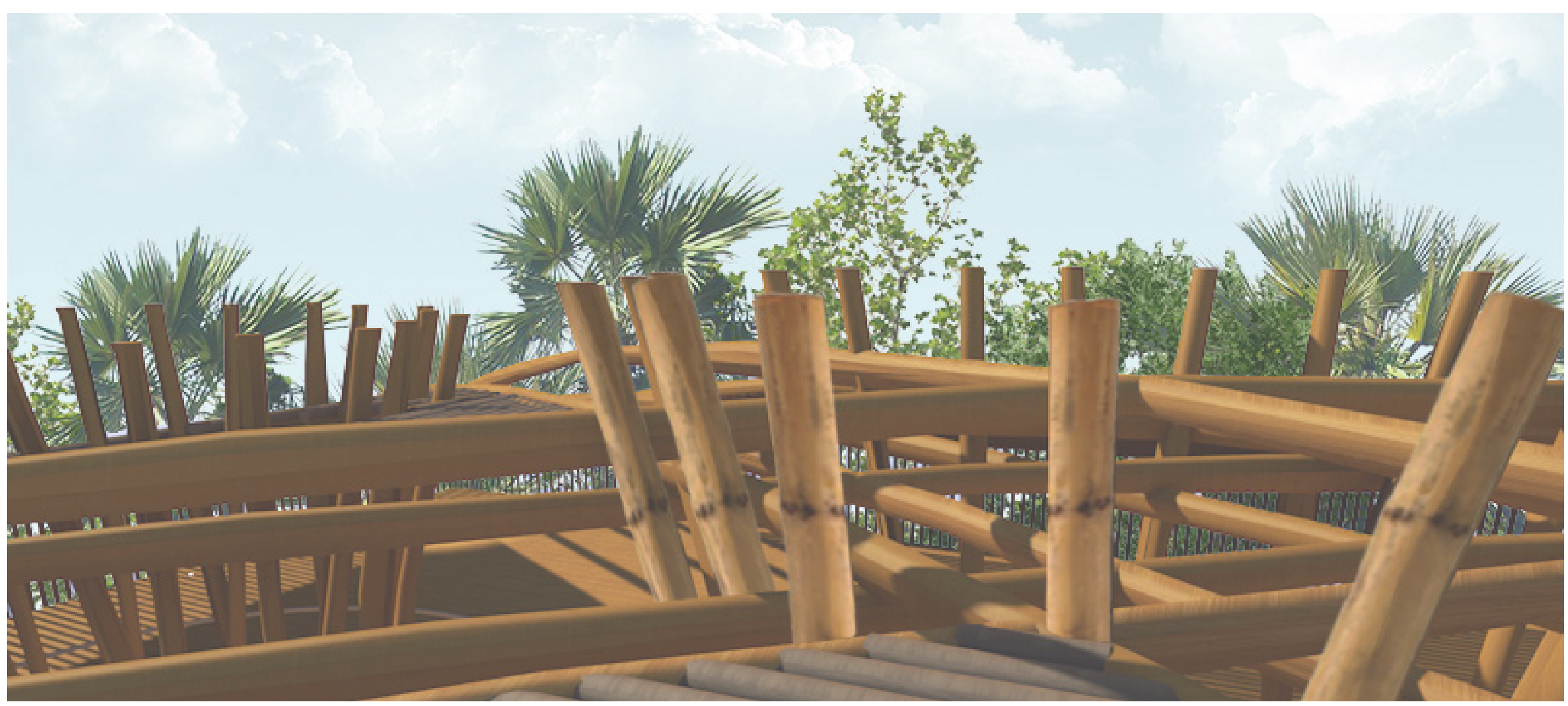




\section{SPREP DESIGN COMPARISON:}

Figures 95 and 96 display the stark contrast between the current SPREP designed Climate Change Centre and this the design resulting from this thesis research. Without further analysis the second building is more in sync with the surrounding environment, as well as having a higher visual impact.

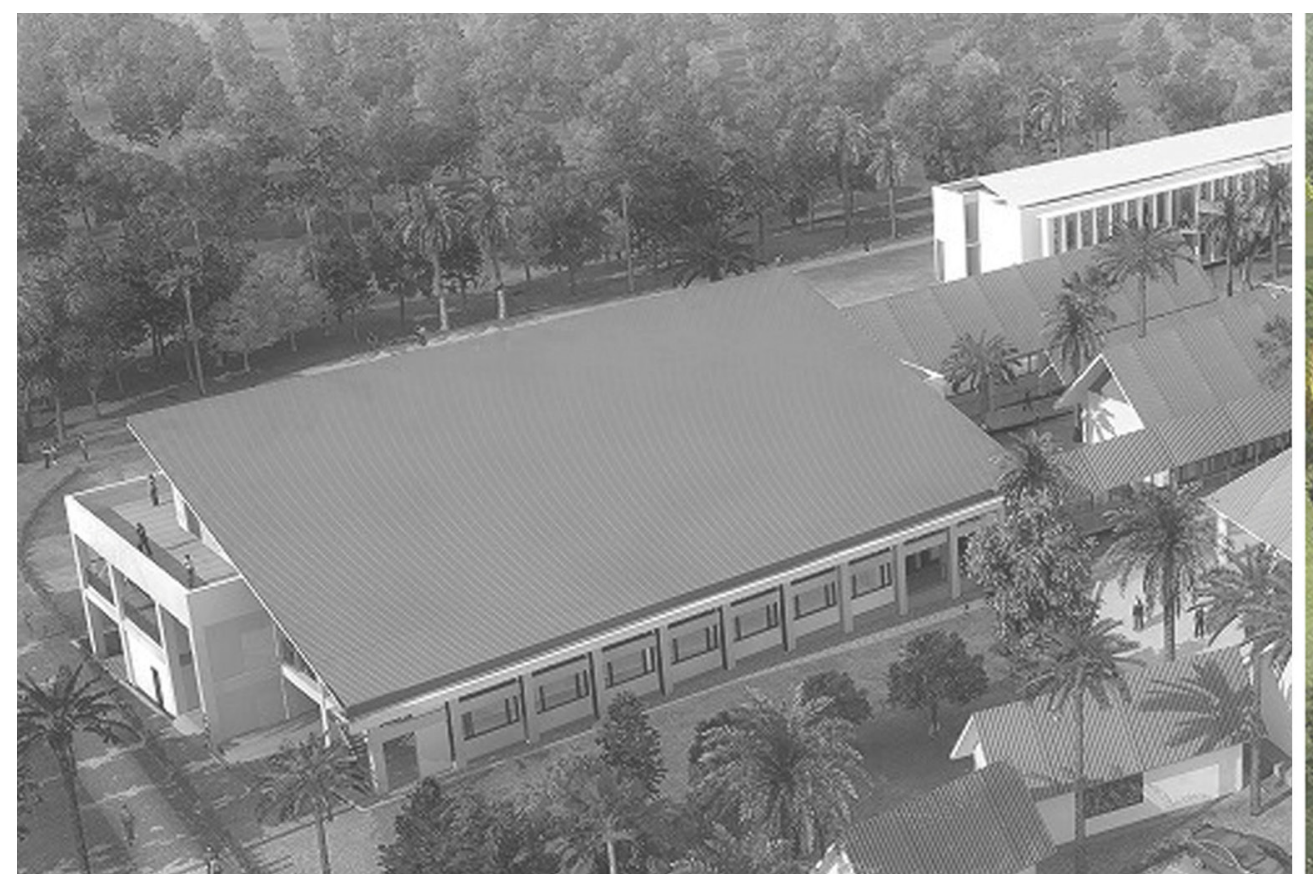

Figure 95. SPREP Conceptual Design on SPREP Site.

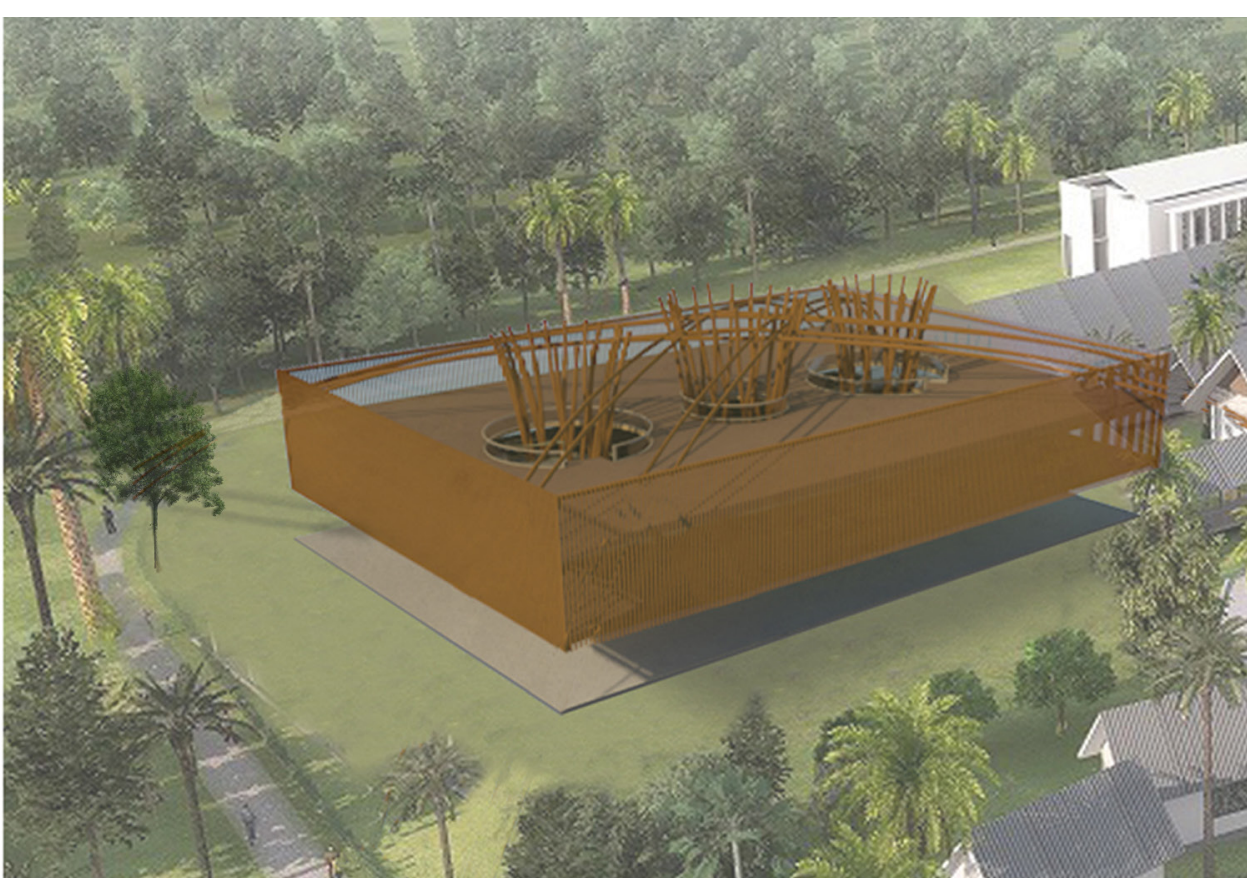


Chapter Five

Conclusions 


\section{ARCHITECTURAL CONCLUSIONS:}

A central question of this thesis asks, "Why has Samoan culture not developed stronger architectural resilience against Climate Change?". The effects of Climate Change and the poor architectural resilience were both researched in the Literature Review. In the Methodology, extensive interviewing determined the reasons for the lack of change, the most damning being a lack of education mixed with a hunger to appear 'modern'.

A changing climate is not only having negative effects on the lives of Samoan inhabitants, these changes are having effects seen all around the Pacific, as are the issues standing in the way of their architectural development. Hundreds of relief efforts have been documented to assist these countries in their times of need. The problem with this is that the countries are only helped once the damage is already done. This thesis has proposed a remedy to this issue, by providing a resolution to the question: "How can Samoan architecture be hyrbidised to influence increased architectural resilience against Climate Change?" . These issues must be addressed immediately, before the damage grows greater than ever before.

\section{Benefits to Samoa:}

The clear benefit of this thesis proposal is that, in the long run, many lives will be saved by the simple application of stronger and more resilient architecture. This could reduce the chance of the people of Samoa being driven from their homes and so, being able to continue their ways of life. Another positive is through the introduction of the Pacific Climate Change Centre (PCCC). The presence of this centre gives Samoa a higher international recognition.

The construction of a PCCC as a hybrid designed building will also get Samoa recognition within the architectural world. This is a phenomenon named the 'Bilbao Effect', which references Frank Gehry's Guggenheim, which resulted in significant economic development in Bilbao, Spain due to its worldwide status ('The Bilbao Effect'). A Climate Change Centre strategically designed and placed in a vulnerable country may have a similar effect.
Potential Improvements:

The design conclusion reached in this thesis is one of hundreds that it could have been. While the use of the Hybridisation Framework focused the design, there are still many different paths that could have been followed. The vague programme of a Climate Research Centre resulted in an open plan floor plan, while a closed floor plan may end up being the more suitable option.

The Hybridisation Framework compiled for this project is created from the influences of large scale buildings. This means that the resultant framework will not necessarily suit small scale buildings. In the event of a large scale weather event, it is generally these smaller houses that require the most assistance, especially for the families inhabiting them. This framework is not necessarily suited to be applied in these situations. It is instead designed to mitigate the existence of these situations in the future.

When the framework is applied to a large scale building, this building is seen around the country and potentially around the world. Smaller home owners are then influenced by the designs of these buildings and given education and opportunities to mimic the design styles and construction techniques. When applied correctly, these should then dramatically reduce the damage done to their houses during extreme weather events. 


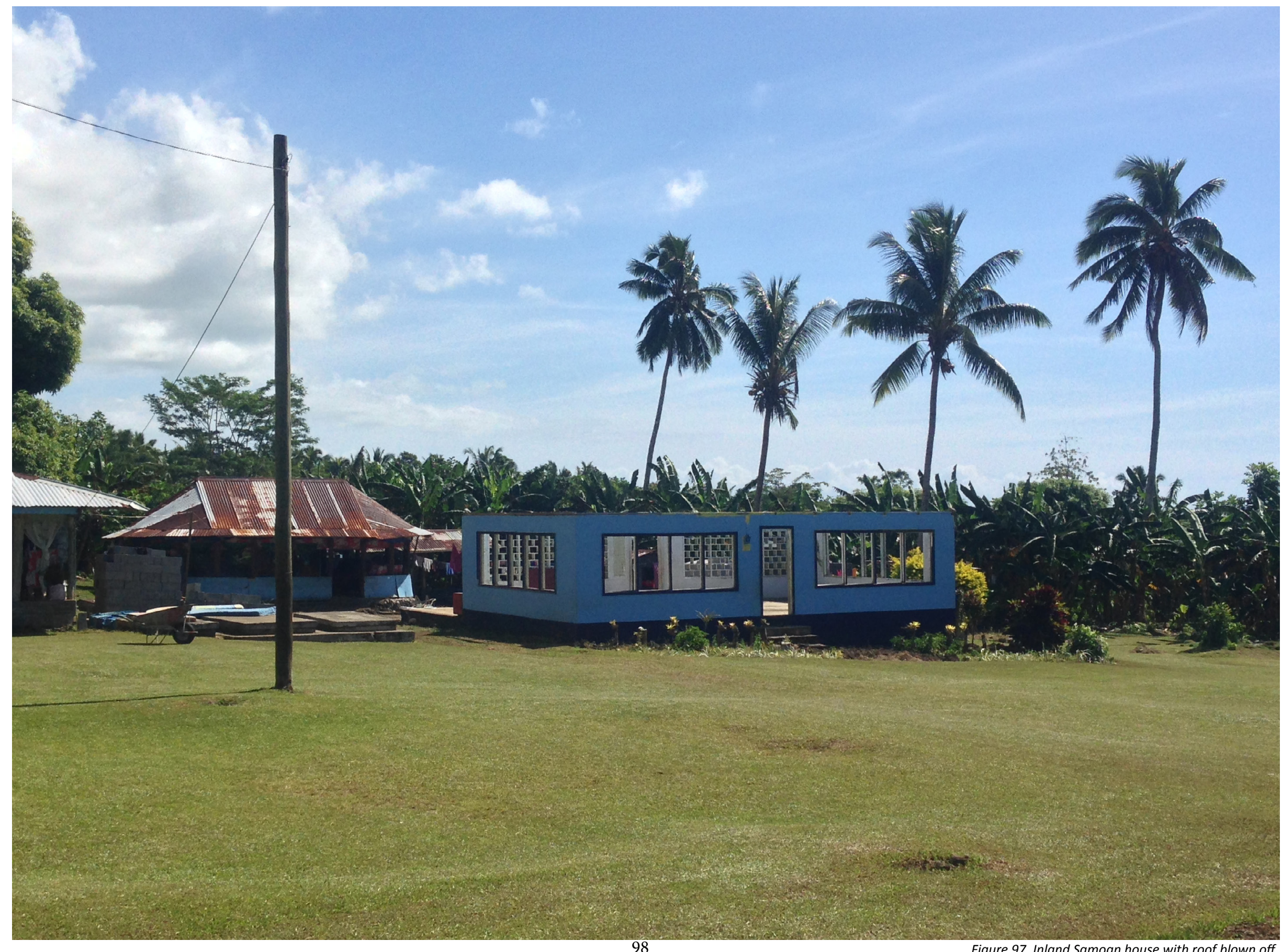


While this design embraces many contemporary construction techniques, future additions could be made. Additions such as rain water collection and the use of photovoltaics are not tied in with the structures design, but could certainly be considered to diminish the building's, already low, carbon footprint.
Future Use:

The construction processes followed in this design are radical for a small country. The introduction of a new material is a big step as much construction education would still be required even if many of the techniques are similar to those already learnt.

A large change like this will not always have the desired outcome, but with the right processes and education, a change like this could lead to furthering Samoa's independence.

The success of this building could have a widespread influence throughout other vulnerable Pacific Islands. The problems being faced in Samoa are becoming more common as Climate Change increases in intensity. A shift towards hybrid design, adapted to the country, could mean vastly improved architectural resilience throughout the Pacific. Allowing these countries to develop their self-sufficiency not only relieves other countries from disaster relief but, more specifically, preserves a country's traditions and culture. 
Chapter Six

\section{Bibliography + List of Figures}




\section{BIBLIOGRAPHY:}

- Acting on Climate Change \& Disaster Risk for the Pacific. The World Bank. 2013.

- Allen, Anne Elizabeth Guernsey. Space as Social Construct: The Vernacular Architecture of Rural Samoa. Diss. Columbia University, 1993.

- Architect. Personal Interview. 30 May, 2016.

- Centre Culturel Jean-Marie Tjibaou / Renzo Piano. ArchDaily, 4 August, 2015. Accessed September 2016.

www.archdaily.com/600641/ad-classics-centre-culturel-jean-marietjibaou-renzo-piano

- Climate Change Consultant. Personal Interview. 31 May, 2016.

- Diamond Island Community Center / Vo Trong Nghia Architects. ArchDaily, 3 December, 2015. Accessed September 2016.

www.archdaily.com/778269/diamond-island-community-center-vo-trongnghia-architects

- Feaunati, Carinnya. "Return to Paradise". MArch Thesis, Victoria University of Wellington, 2014.

- Heine, Mike. Personal Interview. August 2016.
- Hennessy, K. Power, S. \& Cambers, G. (eds) Climate Change in the Pacific: Scientific Assessment and New Research Vol. 1, Regional Overview; Vol. 2, Country Reports (Australian Bureau of Meteorology and CSIRO, 2011

- Higginson, F. L., and John Benyon. The Samoan Fale. Unesco Office for the Pacific States, 1992

- Housing New Zealand. 'Orama Nui: Housing Strategy for Pacific Peoples'. 2009.

- Jadhav, Raj. "Green Architecture in India: Combining Modern Technology with Traditional Methods". UN Chronicle, June 2007. Accessed September, 2016.

unchronicle.un.org/article/green-architecture-india-combining-moderntechnology-traditional-method

- Kabua, Amata. Pacific Climate Change Roundtable Conference. 1988 Secretariat of the Pacific Regional Environment Programme. Apia. Samoa. Keynote Address.

- Magee,Tamlyn. 'Post Tsunami Bamboo Housing Solutions'.

Permaculture Research Institute, 6 November, 2009. Accessed October 2016. permaculturenews.org/2009/11/06/post-tsunamibamboo-housing-solutions 
- Muir, John. My First Summer in the Sierra. 1911. The Riverside Press Cambridge. New York. (paraphrased).

- Nunn, Patrick. "Climate change and pacific island countries." Asia-Pacific Human Development Report Background Papers Series 2012/07 (2012): 1-89.

- "Pacific Climate Change Centre to begin construction in June next year". Secretariat of the Pacific Regional Environment Programme, 25 May, 2016. Accessed June 2016.

www.sprep.org/climate-change/pacific-climate-change-centre-to-beginconstruction-in-june-next-year

- Panko, Mary. Potangaroa, Regan. Waqabaca, Jokatama. 'Community Engagement: Rebuilding Samoan fale post 2009 tsunami". 2010. Microsoft PowerPoint File.

- Pilot Programme for Climate Resilience. Strategic Programme for Climate Resilience. May 2011. Samoa. The World Bank. 2011.

- Quantity Surveyor. Personal Interview. 31 May, 2016.

- Resident One. Personal Interview. 3 June, 2016.

- Resident Two. Personal Interview. 3 June, 2016.
- Resident Three. Personal Interview. 6 June, 2016.

- Samoa Bureau of Statistics. Population and Housing Census 2011. Apia, Samoa. Web. Accessed June 2016.

www.sbs.gov.ws/index.php/social-and-environmental-statistics/socialand-environment-statistics-docs

- Schroder, Stephane. 'Dendrocalamus asper'. Guadua Bamboo, 30 November, 2014. Accessed October 2016.

www.guaduabamboo.com/preservation/

- Schroder, Stephane. 'Durability of Bamboo'. Guadua Bamboo, 30 November, 2014. Accessed October 2016.

www.guaduabamboo.com/preservation/

- Schroder, Stephane. 'Trees vs. Guagua angustifolia'. Guadua Bamboo, 30 November, 2014. Accessed October 2016.

www.guaduabamboo.com/preservation/

- Takahashi, Akatsuki. Collaboration with the Government of Samoa. Workshop on Revitalization of Indigenous Architecture and Traditional Building Skills. 2015. Apia, Samoa. United Nations Educational, Scientific and Cultural Organization. Paris.

- 'The Bilbao Effect'. The Economist, 6th January, 2014. Accessed January 2017.

www.economist.com/news/special-report/21591708-if-you-build-it-willthey-come-bilbao-effect

- The Samoa National Urban Policy. Planning and Urban Management Agency Ministry of Natural Resources and Environment, 2013. 
- UNESCO Office for the Pacific States. The Samoan Fale. 1992.

UNESCO Principal Regional Office for Asia and the Pacific. Thailand.

- Urban Design Advisor. Personal Interview. 30 May, 2016.

- Yasmi, Yurdi, et al. "Forestry Policies, legislation and institutions in Asia and the Pacific." RAP PUBLICATION (2010)

- Ye, Ruiping. "Torrens and Customary Land Tenure: A Case Study of the Land Titles Registration Act 2008 of Samoa. Victoria U. of Wellington L. Rev. 40. (2009). 827.

- Schroder, Stephane. 'Trees vs. Guadua angustifolia'. 30 November, 2014. Accessed October 2016.

www.guaduabamboo.com/guadua/what-is-guadua-angustifolia 


\section{LIST OF FIGURES:}

- $\quad$ Figure 1. Abandoned fale. Author's Own (2016). Upolu, Samoa. [photograph]

- Figure 2. Fale palangi style home Author's Own (2016). Upolu, Samoa. [photograph]

- $\quad$ Figure 3. Samoan Palms. Author's Own (2016). Upolu, Samoa. [photograph]

- Figure 4. Samoa location within Pacific Islands. Map of Asian Islands. Map. aan daleeb.roccosiffredi.us/map-of-asian-islands. World Maps. Retrieved February 2017.

- $\quad$ Figure 5. The Islands of Savai'i and Upolu Map Compiled by Author (2016). Snazzymaps.com [map]

- Figure 5. Population Density Information.

Centre for International Earth Science Information Network. (2000). Sedac.ciesin columbia.edu [map]

- $\quad$ Figure 6: Flooring Materials. Author's Own. (2016) [graph]

- $\quad$ Figure 7. House Tenure. Author 's Own. (2016) [graph]

- $\quad$ Figure 8: Housing Type. Author 's Own. (2016) [graph]

- Figure 9: Roof Materials. Author 's Own. (2016) [graph]

- Figure 10: Wall Materials. Author's Own. (2016) [graph]
- $\quad$ Figure 11: Pros + Cons of the fale.

Pros + Cons of the fale. Author's Own (2016) [diagram]

- Figure 12: Traditional fale diagram. Feaunati. (2014) [diagram]

- $\quad$ Figure 13: Pros + Cons of the fale palangi. Pros + Cpns of the fale palangi. Author's Own. (2016) [diagram]

- $\quad$ Figure 14: Typical fale palangi.

'The Samoan Fale', 14 April, 2012.

www. urkiwikrossings.blogspot.co.nz. Retrieved April 2016.

- Figure 15: Diagram of South Pacific

Convergence Zone.

The average positions of the major climate features from November to April'. Map. pacificclimatechangescience.org/wp-content

Retrieved October 2016.

- Figure 16: IPA Designed Emergency Shelter. Panko, Mary. Potangaroa, Regan.

Waqabaca, Jokatama. 'Community Engagement: Rebuilding Samoan fale post 2009 tsunami". 2010. Microsoft PowerPoint File. Slide 12

- $\quad$ Figure 17: Economic loss caused by natural disasters.

The World Bank. Acting on Climate Change \& Disaster Risk for the Pacific. Fig 3.

- $\quad$ Figure 18: Damage caused in Samoa by

Tropical Cyclones.

Author's Own. (2016) [graph]

- $\quad$ Figure 19: Diamond Island location within

Ho Chi Minh, Vietnam.

Map Compiled by Author (2016). Snazzymaps.com [map]

- Figure 20. Diamond Island ceiling.

Diamond Island Community Center / Vo Trong Nghia Architects. ArchDaily, 3

December, 2015

www.archdaily.com/778269/diamond-island-community-center-vo-trong-nghiaarchitects

Retrieved September 2016 
- $\quad$ Figure 21. Diamond Island exterior

Diamond Island Community Center / Vo Trong Nghia Architects. ArchDaily, 3

December, 2015.

www.archdaily.com/778269/diamond-island-community-center-vo-trong-nghiaarchitects

Retrieved September 2016.

- Figure 22. Diamond Island structure.

Diamond Island Community Center / Vo Trong Nghia Architects. ArchDaily, 3

December, 2015

www.archdaily.com/778269/diamond-island-community-center-vo-trong-nghiaarchitects

Retrieved September 2016

- Figure 23: Key Elements of Diamond Island

Community Centre.

Key elements of Diamond Island Community Centre. Author's Own. Diagram. 2016.

- $\quad$ Figure 24. Te Whare Wānanga o Awanuiārangi location within Whakatane, NZ. Map Compiled by Author (2016). Snazzymaps.com [map]

- Figure 25. Interior view.

'Te Whare Wānanga o Awanuiārangi' [image] mccoyheine.co.nz/twwoa Retrieved August 2016

- $\quad$ Figure 26. Cantilever facade.

'Te Whare Wānanga o Awanuiārangi' [image] mccoyheine.co.nz/twwoa Retrieved August 2016

- $\quad$ Figure 27. Exterior view.

'Te Whare Wānanga o Awanuiārangi' [image] mccoyheine.co.nz/twwoa Retrieved August 2016

- $\quad$ Figure 28. Key elements of Te Whare Wānanga

O Awanuiārangi

Key elements of Te Whare Wānanga $O$

Awanuiārangi. Author's Own. Diagram. 2016.

- $\quad$ Figure 29. Sohrabji Godrej Green Business Centre location within Hyderabad, India. Map Compiled by Author (2016). Snazzymaps.com [map]

- $\quad$ Figure 30. Courtyard area.

Subramanian, Sunanda. 2012. Sohrabji Godrej Green Business Centre, Hyderabad. indiaenvironmentportal.org.in/files/file/'title'

Retrieved September 2016.
- Figure 31. Courtyard area.

Subramanian, Sunanda. 2012. Sohrabji Godrej Green Business Centre, Hyderabad. indiaenvironmentportal.org.in/files/file/'title'

Retrieved September 2016.

- $\quad$ Figure 32. Exterior view.

Subramanian, Sunanda. 2012. Sohrabji Godrej Green Business Centre, Hyderabad. indiaenvironmentportal.org.in/files/file/'title'

Retrieved September 2016.

- $\quad$ Figure 33. Key elements of Sohrabji Godrej Green Business Centre.

Key elements of Sohrabji Godrej Green Business Centre. Author's Own. (2016) [diagram]

- $\quad$ Figure 34. Tjibaou Centre location within New

Caledonia.

Map Compiled by Author (2016). Snazzymaps.com [map]

- $\quad$ Figure 35. Exterior view.

Centre Culturel Jean-Marie Tjibaou / Renzo Piano. ArchDaily, 4 August, 2015. www. archdaily.com/600641/ad-classics-centre-culturel-jean-marie-tjibaou-renzo-piano.

Accessed September 2016.

- $\quad$ Figure 36. Structural detail.

Centre Culturel Jean-Marie Tjibaou / Renzo Piano. ArchDaily, 4 August, 2015. www. archdaily.com/600641/ad-classics-centre-culturel-jean-marie-tjibaou-renzo-piano. Accessed September 2016.

- $\quad$ Figure 37. Kanak structure infront of building.

Centre Culturel Jean-Marie Tjibaou / Renzo Piano. ArchDaily, 4 August, 2015. www. archdaily.com/600641/ad-classics-centre-culturel-jean-marie-tjibaou-renzo-piano. Accessed September 2016 .

- $\quad$ Figure 38. Key elements of Tjibaou Centre.

Key elements of Tjibaou Centre.

Author's Own. (2016) [Diagram]

- Figure 39. Methodology Diagram. Methodology. Author's Own. (2016) [diagram] 
- Figure 40. ADRA housing in Samoa. Author's Own. (2016). Upolu,

Samoa.[photograph]

- Figure 41. Family home in central Upolu. Author's Own. (2016). Upolu,

Samoa. [photograph]

- Figure 42. Family home in central Upolu. Author's Own. (2016). Upolu, Samoa. [photograph]

- $\quad$ Figure 43. Tsunami House in Lepa, Samoa. Author's Own. (2016). Upolu, Samoa. [photograph]

- $\quad$ Figure 44. Tsunami House in Lepa, Samoa. Author's Own. (2016). Upolu, Samoa. [photograph]

- Figure 45. Green School ceiling, Ibuku. greenschool.org. 2016. Retrieved November 2016.

- $\quad$ Figure 46. John Hardy Workshop. Bali: Island of Wonders. international.johnhardy.com/visit-us-in-bali. Retrieved October.

- $\quad$ Figure 47. Bamboo Cathedral, Simon Velez.

- Bamboo Building. 2016. 'Bamboo Cathedrale by Simon Velez'. niftyhomestead. com/blog/bamboo-buildings. Retrieved October, 2016.

- $\quad$ Figure 48. Ecological Children Activity and Education Centre, 24H Architecture.

Bamboo Building. 2016. 'The Kid's Den is in the shape of a manta-ray'. niftyhomestead.com/blog/bamboo-buildings. Retrieved October, 2016.

- $\quad$ Figure 49. Ecological Children Activity and Education Centre, 24H Architecture.

Bamboo Building. 2016. 'Bamboo with printed paper backdrop'. niftyhomestead. com/blog/bamboo-buildings. Retrieved October 2016.

- Figure 50. Traditional Samoan lashing technique imitation. Author's Own. (2016). Wellington, NZ. [photograph]
- $\quad$ Figure 51. Traditional Samoan lashing technique imitation. Author's Own. (2016.) Wellington, NZ. [photograph]

- Figure 52. Traditional Samoan lashing technique imitation. Author's Own. (2016) Wellington, NZ. [photograph]

- Figure 53. Traditional Samoan lashing.

Allen, Anne. 1993. Space as a Social Construct: The Vernacular Architecture of Rural Samoa.

Fig 9: 'Lashing Decorations', 16

- Figure 54. Traditional bamboo lashing

Anne, Mary. 'Knot', Photograph, June 2010. hello961.blogspot.co.nz Retrieved

December 2016

- Figure 55. SPREP Facilities layout.

"Pacific Climate Change Centre to begin construction in June next year". Secretariat of the Pacific Regional Environment Programme, 25 May, 2016. www.sprep.org/climatechange/pacific-climate-change-centre-to-begin-construction-in-june-next-year Accessed June 2016

Figure 56. Proposed site for PCCC

Cayford, Joel. Photograph. 2016. Upolu, Apia

- $\quad$ Figure 57. PCCC location within Apia, Samoa Map Compiled by Author (2016). Snazzymaps.com [map]

- $\quad$ Figure 58. Windrose displaying prevailing wind

'Climate Samoa Is/ands'. Graph. meteoblue.com/en/weather/forcast. Retrieved October 2016.

- Figure 59. Contours and Structures surrounding SPREP. Author's Own. (2016). [diagram]

- $\quad$ Figure 60. SPREP building layout.

'Tokelau applauds Pacific's climate change centre to be based at SPREP'. Diagram, May 2016. tokelau.org.nz/Bulletin/May+2016 Retrieved July 2016 
- Figure 61. Conceptual render of PCCC

"Pacific Climate Change Centre to begin construction in June next year". Secretariat of the Pacific Regional Environment Programme, 25 May, 2016. www. sprep.org/climate-change/pacific-climate-change-centre-to-begin-construction-

in-june-next-year

Accessed June 2016

- Figure 62. Conceptual render of PCCC.

"Pacific Climate Change Centre to begin construction in June next year".

Secretariat of the Pacific Regional Environment Programme, 25 May, 2016. www. sprep.org/climate-change/pacific-climate-change-centre-to-begin-construction-

in-june-next-year

Accessed June 2016

- Figure 63. Inland housing constructed of 'found' materials. Author's Own. (2016) [photograph] Upolu, Samoa.

- Figure 64. Sketch iteration one. Author's Own (2016). Iteration One. [drawing].

- $\quad$ Figure 65. Sketch iteration two. Author's Own (2016). Iteration Two. [drawing].

- $\quad$ Figure 66. Sketch iteration three. Author's Own (2016). Iteration Three. [drawing].

- $\quad$ Figure 67. Sketch iteration four. Author's Own (2016). Iteration Four. [drawing].

- $\quad$ Figure 68. Sketch iteration five. Author's Own (2016). Iteration Five. [drawing].

- Figure 69. Modelled iteration one. Author's Own (2016). Wellington, NZ. [photograph]

- $\quad$ Figure 70. Modelled iteration two. Author's Own (2016). Wellington, NZ. [photograph]
- $\quad$ Figure 71. Modelled iteration three. Author's Own (2016). Wellington, NZ. [photograph]

- $\quad$ Figure 72. Modelled iteration four. Author's Own (2016). Wellington, NZ. [photograph]

- $\quad$ Figure 73. Concept for final design.

Author's Own. (2016). Concept for Final Design. [diagram]

- Figure 74. Developed design roof structure. Author's Own (2016). Developed design roof structure. [digital image].

- Figure 75. Developed design facade. Author's Own (2016). Developed design facade [digital image]

- $\quad$ Figure 76. Developed design columns. Author's Own (2016). Developed design columns. [digital image].

- $\quad$ Figure 77. Developed design render. Author's Own (2016). Developed design render. [digital image].

- $\quad$ Figure 78. Final design, PCCC Exterior Nighttime View. Author's Own (2016). PCCC Exterior Nighttime View. [render].

- Figure 79. Final Design, Longitudinal Section. Author's Own (2016). Longitudinal Section. [digital image].

- Figure 80. Final Design, Ground Floor Plan. Author's Own (2016). Ground Floor Plan. [digital image]. 
- Figure 81. Final Design, First Floor Plan. Author's Own (2016). First Floor Plan. [digital image].

- Figure 82. Final Design, Second Floor Plan. Author's Own (2016). Second Floor Plan. [digital image].

- Figure 83. Final Design, Roof View. Author's Own (2016). Roof View. [digital image].

- $\quad$ Figure 84. Final Design, North Elevation Author's Own (2016). North Elevation. [digital image].

- Figure 85. Final Design, East Elevation Author's Own (2016). East Elevation. [digital image].

- Figure 86. Final Design, South Elevation Author's Own (2016). South Elevation. [digital image].

- $\quad$ Figure 87. Final Design, West Elevation Author's Own (2016). West Elevation. [digital image].

- Figure 88. Final Design, Open Ground Floor Area. Author's Own (2016). Open Ground Floor Area. [digital image].

- Figure 89. Key elements of the Final Design. Author's Own (2016). Key elements of the Final Design. [diagram].

- $\quad$ Figure 90. Final Design, Interior View. Author's Own (2016). Final Design, Interior View. [digital image].
- $\quad$ Figure 91. Final Design, Interior View. Author's Own (2016). Final Design, Interior View. [digital image].

- Figure 92. Final Design, Bamboo Construction Detail. Author's Own (2016). Final Design, Bamboo Construction Detail. [diagram].

- $\quad$ Figure 93. Final Design, Bamboo Construction Detail. Author's Own (2016). Final Design, Bamboo Construction Detail. [diagram].

- Figure 94. Final Design, Roof Construction Detail. Author's Own (2016). Roof Construction Detail. [digital image].

- Figure 95. SPREP Conceptual Design on SPREP Site.

"Pacific Climate Change Centre to begin construction in June next year". Secretariat of the Pacific Regional Environment Programme, 25 May, 2016. www.sprep.org/ climate-change/pacific-climate-change-centre-to-begin-construction-in-june-nextyear Accessed June 2016

- $\quad$ Figure 96. Final Design on SPREP Site. Author's Own editing of Figure 95. (2016) [digital Image]

- Figure 97. Inland Samoan house with roof blown off. Author's Own (2016) [photograph] Upolu, Samoa. 
Chapter Seven Appendix 


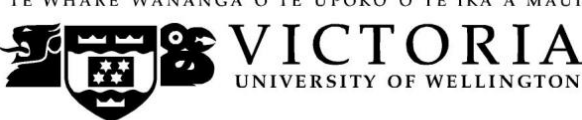

\section{MEMORANDUM}

\begin{tabular}{l|l}
\hline TO & Emily Cayford \\
\hline COPY TO & \\
\hline FROM & AProf Susan Corbett, Convener, Human Ethics Committee \\
\hline DATE & 18 May 2016 \\
\hline PAGES & 1 \\
\hline
\end{tabular}

SUBJECT $\quad$ Ethics Approval: 22821

Adapting Samoan Traditional Housing in the Face of Climate Change

Thank you for your application for ethical approval, which has now been considered by the Standing Committee of the Human Ethics Committee.

Your application has been approved from the above date and this approval continues until 30 November 2016. If your data collection is not completed by this date you should apply to the Human Ethics Committee for an extension to this approval.

Best wishes with the research.

Kind regards

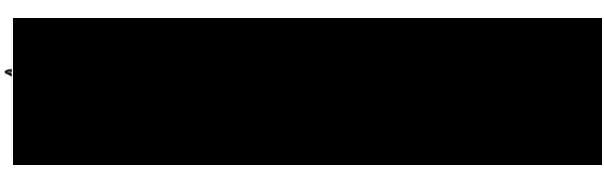

Susan Corbett

Convener, Victoria University Human Ethics Committee 


\section{9 啚行: VICTORIA}

\section{The Impact of Disaster on Samoa}

\section{CONSENT TO INTERVIEW \\ (Expert Participants)}

This consent form will be held for 5 years.

Researchers: Emily Cayford, Jessica Hulme

Master of Architecture (Prof), School of Architecture, Victoria University of Wellington

- I have read the Information Sheet and the project has been explained to me. My questions have been answered to my satisfaction. I understand that I can ask further questions at any time.

- I agree to take part in a (video/audio) recorded interview.

I understand that:

- I may withdraw from this study up to four weeks after the interview, and any information that I have provided will be destroyed.

- The information I have provided will be destroyed 3 years after the research is finished.

- $\quad$ Any information I provide will be kept confidential to the researcher and the supervisor. I understand that the results will be used for a Masters report and a summary of the results may be used in academic reports and/or presented at conferences.

- My name will not be used in reports, nor will any information that would identify me

- I can chose whether or not I wish for photos to be taken of my private residence

\section{9}

\section{The Impact of Disaster on Samoa}

\section{CONSENT TO INTERVIEW \\ (Local Participants)}

This consent form will be held for 5 years.

Researchers: Emily Cayford, Jessica Hulme

Master of Architecture (Prof), School of Architecture, Victoria University of Wellington

- I have read the Information Sheet and the project has been explained to me. My questions have been answered to my satisfaction. I understand that I can ask further questions at any time.

- I agree to take part in a (video/audio) recorded interview.

\section{I understand that:}

- I may withdraw from this study up to four weeks after the interview, and any information that I have provided will be destroyed.

- The information I have provided will be destroyed 3 years after the research is finished.

- $\quad$ Any information I provide will be kept confidential to the researcher and the supervisor. understand that the results will be used for a Masters report and a summary of the results may be used in academic reports and/or presented at conferences.

- My name will not be used in reports, nor will any information that would identify me

- I can chose whether or not I wish for photos to be taken of my private residence
I allow photos to be taken of my private residence Yes/No (Please circle one) Signature of participant:

Name of participant:

Date:

Contact details:
I allow photos to be taken of my private residence Yes/No (Please circle one)

Signature of participant:

Name of participant

Date:

113 Contact details 


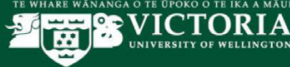

\section{FACULTY OF ARCHITECTURE \& DESIGN Te Wāhanga Waihanga-Hoaho}

VICTORIA UNIVERSITY OF WELLINGTON, PO Box 600, Wellington 6140 , New Zealand

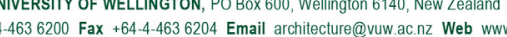

The Role of Architects in Post-Disaster Reconstruction

\section{INFORMATION SHEET FOR PARTICIPANTS (EXPERT PARTICIPANTS)}

Thank you for your interest in this project. Please read this information before deciding whether or not to take part. If you decide to participate, thank you. If you decide not to take part, thank you for considering the request.

We are Jessica Hulme and Emily Cayford. The two of us are Masters Students in Architecture at Victoria University of Wellington. This research project is work towards our final thesis.

\section{What is the aim of the project?}

This project is focused on determining the impact of extreme weather events, such as tropical cyclones and flooding, has on Samoan housing. The information will be used to assist design of future housing to withstand this extreme weather.

The project is also looking at how these weather events have effected Samoan residents and their livelihood. The project will investigate how the people of Samoa react during and after an extreme weather event.

This research has been approved by the Victoria University of Wellington Human Ethics Committee 22821

\section{How can you help?}

If you agree to take part we will interview you in either a public place, such as a café, or within your home. We will ask you questions about your experiences during disaster events. The interview will take approximately $30 \mathrm{mins}$. We will record the interview and write it up later.

You can stop the interview at any time, without giving a reason. You can withdraw from the study up to four weeks after the interview. If you withdraw, the information you provided will be destroyed or returned to you.

\section{What will happen to the information you give?}

This research is completely confidential. We will not name you in any of our reports, and we will not include any information that would identify you. Only our supervisor and ourselves will read the notes or transcript of the interview. The interview transcripts, summaries and any recordings will be kept securely and destroyed 3 years after the research ends.

\section{Photography}

To assist in our recording of the structures of Samoan housing we wish to take photos of participant's private residences. This is additional to the interview. If you do not wish to have photos taken of your private residence you can indicate this in the consent form. No residents will be included in the photos.

\section{What will the project produce?}

The information from this research will be used in our final thesis research reports. You will not be identified in this report. We may also use the results of this research for conference, presentations, and academic reports. We will take care not to identify you in any presentation or report.

\section{If you accept this invitation, what are your rights as a research participant?}

You do not have to accept this invitation if you don't want to. If you do decide to participate, you have the right to:

- choose not to answer any question;

- ask for the recorder to be turned off at any time during the interview;

- withdraw from the study up until four weeks after your interview;

- ask any questions about the study at any time;

- receive a copy of your interview recording;

- read over and comment on a written summary of your interview;

- agree on another name for us to use rather than your real name;

- be able to read any reports of this research by emailing any of us to request a copy.

- If at any point you are feeling an trauma or unease during the interview you may choose to not answer any question and/or leave the interview

If you have any questions or problems, who can you contact?

If you have any questions, either now or in the future, please feel free to contact either:

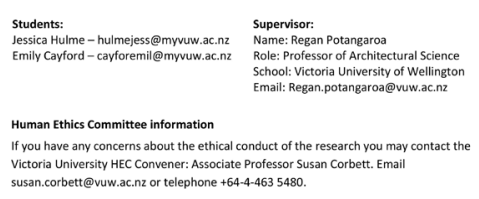




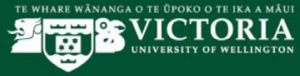

CHOOL OF ARCHITECTURE Te Kura Waihan

ACULTY OF ARCHITECTURE \& DESIGN Te Wahhanga Waihanga-Hoaho

VCTORIA UNIVERSITY OF WELLINGTON, PO Box 600, Wellington 6140, New Zealand
hone $+64-4-4636200$ Fax $+64-4-4636204$ Email archilecture@vuw.ac.nz Web www

The Role of Architects in Post-Disaster Reconstruction

\section{INFORMATION SHEET FOR PARTICIPANTS (LOCAL PARTICIPANTS)}

Thank you for your interest in this project. Please read this information before deciding whether or not to take part. If you decide to participate, thank you. If you decide not to take part, thank you for considering the request.

We are Jessica Hulme and Emily Cayford. The two of us are Masters Students in Architecture at Victoria University of Wellington. This research project is work towards our final thesis.

\section{What is the aim of the project?}

This project is focused on determining the impact of extreme weather events, such as tropical cyclones and flooding, has on Samoan housing. The information will be used to assist design of future housing to withstand this extreme weather.

The project is also looking at how these weather events have effected Samoan residents and thei livelihood. The project will investigate how the people of Samoa react during and after an extrem weather event.

This research has been approved by the Victoria University of Wellington Human Ethics Committee 22821.

\section{How can you help?}

If you agree to take part we will interview you in either a public place, such as a café, or within your home. We will ask you questions about your experiences during disaster events. The interview will take approximately 30 mins. We will record the interview and write it up later. You can stop the interview at any time, without giving a reason. You can withdraw from the study up to four weeks after the interview. If you withdraw, the information you provided will be destroyed or returned to you.

\section{What will happen to the information you give?}

This research is completely confidential. We will not name you in any of our reports, and we will not include any information that would identify you. Only our supervisor and ourselves will read the notes or transcript of the interview. The interview transcripts, summaries and any recordings will be kept securely and destroyed 3 years after the research ends.

\section{Photography}

To assist in our recording of the structures of Samoan housing we wish to take photos of participant's private residences. This is additional to the interview. If you do not wish to have photos taken of your private residence you can indicate this in the consent form. No residents will be included in the photos.

\section{What will the project produce?}

The information from this research will be used in our final thesis research reports. You will not be identified in this report. We may also use the results of this research for conference,

presentations, and academic reports. We will take care not to identify you in any presentation or report.

\section{If you accept this invitation, what are your rights as a research participant?}

You do not have to accept this invitation if you don't want to. If you do decide to participate, you have the right to:

- choose not to answer any question;

- ask for the recorder to be turned off at any time during the interview;

- withdraw from the study up until four weeks after your interview;

- ask any questions about the study at any time;

- receive a copy of your interview recording;

- read over and comment on a written summary of your interview;

- agree on another name for us to use rather than your real name;

- be able to read any reports of this research by emailing any of us to request a copy.

- If at any point you are feeling an trauma or unease during the interview you may choose to not answer any question and/or leave the interview

If you have any questions or problems, who can you contact?

If you have any questions, either now or in the future, please feel free to contact either:

\section{Students:}

Jessica Hulme - hulmejess@myvuw.ac.nz

Emily Cayford - cayforemil@myvuw.ac.nz

\section{Supervisor:}

Name: Regan Potangaroa

Role: Professor of Architectural Science School: Victoria University of Wellington

Email: Regan.potangaroa@vuw.ac.nz

\section{Human Ethics Committee information}

If you have any concerns about the ethical conduct of the research you may contact the Victoria University HEC Convener: Associate Professor Susan Corbett. Email susan.corbett@vuw.ac.nz or telephone +64-4-463 5480 


\section{Architecture of Samoa}

- How long have you and your family lived in this house?

- Were you relocated by a third party?

- How many people live in your household?

- How many members in the family are employed? What does everyone do?

- How many members stay at home for the longest time every day?

- How many hours do they spend at home on a daily basis?

- What did and do they do in a day on an hourly basis?

- Which space did you spend most time in before the disaster?

- Which space do you spend most time in now, after the disaster?

- Why have you decided to stay/move out of the current house?

- How long would you stay in the current place for?

- What would you change to improve the current layout of your home?

- What do your friends say about your current house?

- How has the structure of your house changed since you first moved in?

- How have the materials of your house changed since you first moved in?

- Does your current house have any issues with weather (rain/wind/flooding)?

- Do you prefer open or enclosed houses?

- Do you prefer separated living spaces?

- How many months/years did it take to build your house?

- Do you still meet at a Fale tele (big meeting house)?

- [lf not] Where do you meet with your community/neighbours instead of the Fale tele?

\section{Cyclone Evan}

- Did you have to be relocated after Cyclone Evan?

- Have you returned?

- How have outside organisations helped to restore your village?

- Do you feel safe in your current housing?

\section{Tsunami}

- Did you have to be relocated after the tsunami?

- Have you returned?

- How have outside organisations helped to restore your village?

\section{Future weather events + climate change}

- Have you noticed sea level rises while you have lived in Samoa?

- Have these affected you daily activities?

- Have these affected your residence?

- Do you prefer to be close to the ocean?

- If tides got higher, would you move inland?

\section{S)}

\section{The Impact of Disaster on Samoa}

(Expert Participants)

This consent form will be held for 5 years.

Researchers: Emily Cayford, Jessica Hulme ‘

Master of Architecture (Prof), School of Architecture, Victoria University of Wellington

- I have read the Information Sheet and the project has been explained to me. My questions have been answered to my satisfaction. I understand that I can ask further questions at any time.

I agree to take part in a (video/audio) recorded interview.

I understand thạt:

I may withdraw from this study up to four weeks after the interview, and any information that I have provided will be destroyed.

- The information I have provided will be destroyed 3 years after the research is finished

- Any information I provide will be kept confidential to the researcher and the supervisor. understand that the results will be used for a Masters report and a summary of the results may be used in academic reports and/or presented at conferences.

- My name will not be used in reports, nor will any information that would identify me.

- I can chose whether or not I wish for photos to be taken of my private residence

I allow photos to be taken of my private residence Yes/No (Please circle one)

Signature of participant:

Name of participant:

Date:

$30-5-16$

Contact details: 


\section{G VICTORIA}

\section{The Impact of Disaster on Samoa}

\section{CONSENT TO INTERVIEW \\ (Expert Participants)}

This consent form will be held for 5 years.

Researchers: Emily Cayford, Jessica Hulme

Master of Architecture (Prof), School of Architecture, Victoria University of Wellington

- I have read the Information Sheet and the project has been explained to me. My questions have been answered to my satisfaction I understand that I can ask futher questions at any time.

- I agree to take part in a (video/audio) recorded interview.

I understand that:

- I may withdraw from this study up to four weeks after the interview, and any information that I have provided will be destroyed.

- The information ! have provided will be destroyed 3 years after the research is finished.

- Any information I provide will be kept confidential to the researcher and the supervisor. I understand that the results will be used for a Masters report and a summary of the results may be used in academic reports and/or presented at conferences.

- My name will not be used in reports, nor will any information that would identify me

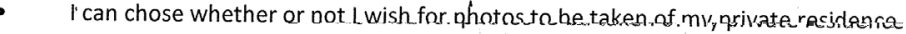

I allow photos to be taken of my private residence Yes/No (Please circle one) Signature of participant:

of participant:

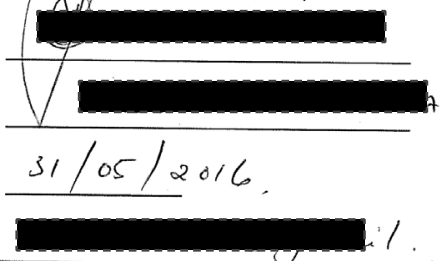

Contact details:

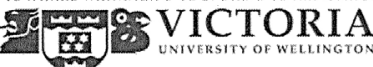

The Impact of Disaster on Samoa

CONSENT TO INTERVIEW

(Local Participants)

This consent form will be held for 5 years.

Researchers: Emily Cayford, Jessica Hulme

Master of Architecture (Prof), School of Architecture, Victoria University of Wellington

- I have read the Information Sheet and the project has been explained to me. My questions have been answered to my satisfaction. I understand that I can ask further questions at any time.

- I agree to take part in a (video/audio) recorded interview.

I understand that:

- I may withdraw from this study up to four weeks after the interview, and any information that I have provided will be destroyed.

- The information I have provided will be destroyed 3 years after the research is finished.

- Any information I provide will be kept confidential to the researcher and the supervisor. I understand that the results will be used for a Masters report and a summary of the results may be used in academic reports and/or presented at conferences.

- My name will not be used in reports, nor will any information that would identify me.

- I can chose whether or not I wish for photos to be taken of my private residence

I allow photos to be taken of my private residence Yes/No (Please circle one)

Signature of participant:

Name of participant:

Date:

Contact details: 


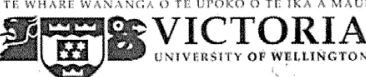

\section{The Impact of Disaster on Samoa}

\section{CONSENT TO INTERVIEW}

(Local Participants)

This consent form will be held for 5 years.

Researchers: Emily Cayford, Jessica Hulme

Master of Architecture (Prof), School of Architecture, Victoria University of Wellington

- I have read the Information Sheet and the project has been explained to me. My questions have been answered to my satisfaction. I understand that I can ask further questions at any time.

- I agree to take part in a (video/audio) recorded interview.

I understand that:

- I may withdraw from this study up to four weeks after the interview, and any information that I have provided will be destroyed.

- The information I have provided will be destroyed 3 years after the research is finished.

- Any information I provide will be kept confidential to the researcher and the supervisor. I understand that the results will be used for a Masters report and a summary of the results may be used in academic reports and/or presented at conferences.

- My name will not be used in reports, nor will any information that would identify me.

- I can chose whether or not I wish for photos to be taken of my private residence

I allow photos to be taken of my private residence Yes/No (Please circle one)

Signature of participant:

Name of participant:

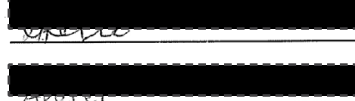

Date:

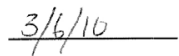

Contact details:
Appendix 11: Ethics. Consent Form. Details blacked in

accordance to Consent Conditions.

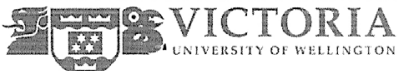

The Impact of Disaster on Samoa

CONSENT TO INTERVIEW

(Expert Participants)

This consent form will be held for 5 years.

Researchers: Emily Cayford, Jessica Hulme

Master of Architecture (Prof), School of Architecture, Victoria University of Wellington

- I have read the Information Sheet and the project has been explained to me. My questions have been answered to my satisfaction. I understand that I can aşk further questions at any time.

- I agree to take part in a (video/audio) recorded interview.

I understand that:

- I may withdraw from this study up to four weeks after the interview, and any information that I have provided will be destroyed.

- The information I have provided will be destroyed 3 years after the research is finished.

- Any information I provide will be kept confidential to the researcher and the supervisor.। understand that the results will be used for a Masters report and a summary of the results may be used in academic reports and/or presented at conferences.

- My name will not be used in reports, nor will any information that would identify me.

I can chose whether or not I wish for photos to be taken of my private residence

I allow photos to be taken of my private residence Yes/No (Please circle one) Signature of participant:

Name of participant:

Date:

Contact details:
$3 / / 5 / 16$ 


\section{VIVT) VICTORIA}

\section{The Impact of Disaster on Samoa}

\section{CONSENT TO INTERVIEW \\ (Expert Participants)}

This consent form will be held for 5 years.

Researchers: Emily Cayford, Jessica Hulme

Master of Architecture (Prof), School of Architecture, Victoria University of Wellington

- I have read the Information Sheet and the project has been explained to me. My questions have been answered to my satisfaction. I understand that I can ask further questions at any time.

- I agree to take part in a (video/audio) recorded interview.

I understand that:

- I may withdraw from this study up to four weeks after the interview, and any information that I have provided will be destroyed.

- The information I have provided will be destroyed 3 years after the research is finished.

- Any information I provide will be kept 'confidential to the researcher and the supervisor. understand that the results will be used for a Masters report and a summary of the results may be used in academic reports and/or presented at conferences.

- My name will not be used in reports, nor will any information that would identify me

- I can chose whether or not I wish for photos to be taken of my private residence

I allow photos to be taken of my private residence Yes/No (Please circle one) Signature of participant: Name of participant: Date
$30^{-12} M A / 2016$.

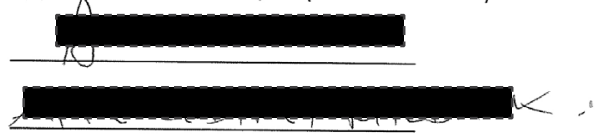

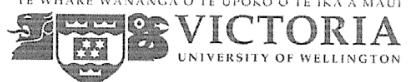

\section{The Impact of Disaster on Samoa}

CONSENT TO INTERVIEW

(Expert Participants)

This consent form will be held for 5 years.

Researchers: Emily Cayford, Jessica Hulm

Master of Architecture (Prof), School of Architecture, Victoria University of Wellington

I have read the Information Sheet and the project has been explained to me. My questions have been answered to my satisfaction. I understand that I can ask furthe questions at any time.

- I agree to take part in a (video/audio) recorded interview.

$I$ understand that:

I may withdraw from this study up to four weeks after the interview, and any information that I have provided will be destroyed.

- The information I have provided will be destroyed 3 years after the research is finished.

- Any information I provide will be kept confidential to the researcher and the supervisor. understand that the results will be used for a Masters report and a summary of the results may be used in academic reports and/or presented at conferences.

- My name will not be used in reports, nor will any information that would identify me.

- I. can chose whether or not I wish for photos to be taken of my private residence

I allow photos to be taken of my private residence Yes/No (Please circle one)

Signature of participant:

Name of participant:

Date:

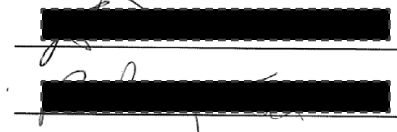

Contact details:

$\sim s$ 


\section{WOE VICTORIA}

\section{The Impact of Disaster on Samoa}

\section{CONSENT TO INTERVIEW}

(Expert Participants)

This consent form will be held for 5 years.

Researchers: Emily Cayford, Jessica Hulme

- Master of Architecture (Prof), School of Architecture, Victoria University of Wellington

- I have read the Information Sheet and the project has been explained to me. My questions have been answered to my satisfaction. I understand that I can ask further questions at any time.

- I agree to take part in a (video/audio) recorded interview.

I understand that:

- I may withdraw from this study up to four weeks after the interview, and any information that I have provided will be destroyed.

- The information I have provided will be destroyed 3 years after the research is finished.

- Any information I provide will be kept confidential to the researcher and the supervisor. I understand that the results will be used for a Masters report and a summary of the results may be used in academic reports and/or presented at conferences.

- My name will not be used in reports, nor will any information that would identify me.

- I can chose whether or not I wish for photos to be taken of my private residence

Iallow photos to be taken of my private residence Yes/No (Please circle one)

Signature of participant:

Name of participant:

Date:

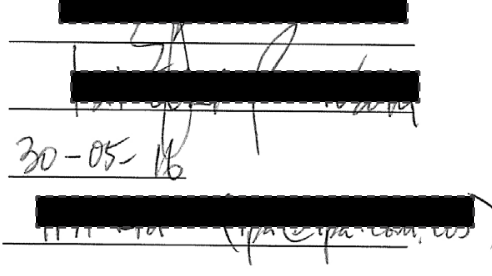

Contact details:
Appendix 15: Ethics. Consent Form. Details blacked in

accordance to Consent Conditions.

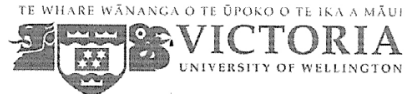

The Impact of Disaster on Samoa

CONSENT TO INTERVIEW

(Expert Participants)

This consent form will be held for 5 years.

Researchers: Emily Cayford, Jessica Hulme

Master of Architecture (Prof), School of Architecture, Victoria University of Wellington

- I have read the Information Sheet and the project has been explained to me. My questions have been answered to my satisfaction. I understand that I can ask further questions at any time.

- I. agree to take part in a (video/audio) recorded interview.

I understand that:

- I may withdraw from this study up to four weeks after the interview, and any information that $i$ have provided will be destroyed.

- The information I have provided will be destroyed 3 years after the research is finished.

- Any information I provide will be kept confidential to the researcher and the supervisor. I understand that the results will be used for a Masters report and a summary of the results may be used in academic reports and/or presented at conferences.

- My name will not be used in reports, nor will any information that would identify me.

I can chose whether or not I wish for photos to be taken of my private residence

I allow photos to be taken of my private residence Yes/No (Please circle one)

Signature of participant:

Name of participant:

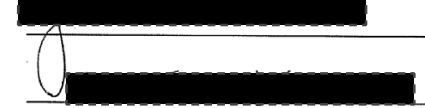

Date:

$31 / 05116$

Contact details: 


\section{TEDS VICTORIA}

\section{The Impact of Disaster on Samoa}

\section{CONSENT TO INTERVIEW}

(Expert Participants)

This consent form will be held for 5 years.

Researchers: Emily Cayford, Jessica Hulme

Master of Architecture (Prof), School of Architecture, Victoria University of Wellington

- I have read the Information Sheet and the project has been explained to me. My questions have been answered to my satisfaction. I understand that I can ask further questions at any time.

- I agree to take part in a (video/audio) recorded interview.

I understand that:

- I may withdraw from this study up to four weeks after the interview, and any information that I have provided will be destroyed.

- The information. I have provided will be destroyed 3 years after the research is finished.

- Any information I provide will be kept confidential to the researcher and the supervisor. understand that the results will be used for a Masters report and a summary of the results may be used in academic reports and/or presented at conferences.

- My name will not be used in reports, nor will any information that would identify me

- I can chose whether or not I wish for photos to be taken of my private residence

I allow photos to be taken of my private residence Yes/No (Please circle one)

Signature of participant:

$+$

Name of participant:

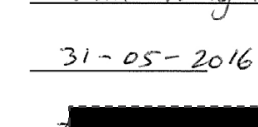

Date:

Contact details:

\section{T) VICTORIA}

\section{The Impact of Disaster on Samoa}

CONSENT TO INTERVIEW

(Expert Participants)

This consent form will be held for 5 years.

Researchers: Emily Cayford, Jessica Hulme

Master of Architecture (Prof), School of Architecture, Victoria University of Wellington

- I have read the Information Sheet and the project has been explained to me. My questions have been answered to my satisfaction. I understand that I can ask further questions at any time.

- I agree to take part in a (video/audio) recorded interview.

I understand that:

I may withdraw from this study up to four weeks after the interview, and any information that I have provided will be destroyed.

- The information I have provided will be destroyed 3 years after the research is finished.

- Any information' I provide will be kept confidential to the researcher and the supervisor. I understand that the results will be used for a Masters report and a summary of the results may be used in academic reports and/or presented at conferences.

- My name will not be used in reports, nor will any information that would identify me.

I can chose whether or not I wish for photos to be taken of my private residence

I allow photos to be taken of my private residence Yes/No (Please circle one) Signature of participant: Name of participant:

Contact details:

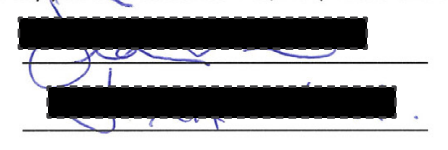

$30 \mathrm{May} 2016$

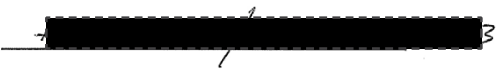




\section{VOV VICTORIA}

\section{The Impact of'Disaster on Samoa}

\section{CONSENT TO INTERVIEW}

(Expert Participants)

This consent form will be held for 5 years.

Researchers: Emily Cayford, Jessica Hulme

Master of Architecture (Prof), School of Architecture, Victoria University of Wellington

- I have read the Information Sheet and the project has been explained to me. My questions have 'been answered to my satisfaction. I understand that I can ask further questions a

- $\quad$ agree to take part in a (video/audio) recorded interview.

\section{I understand that:}

- I. may withdraw from this study up to four weeks after the interview, and any information that I have provided will be destroyed.

- The information I have provided will be destroyed 3 years after the research is finished.

- Any information I provide will be kept confidential to the researcher and the supervisor. understand that the results will be used for a Masters report and $a_{1}$ summary of the results may be used in academic reports and/or presented at conferences.

- My name will not be used in reports, nor will any information that would identify me.

- I can chose whether or not I wish for photos to be taken of my private residence

I allow photos to be taken of my private residence Yes (No)(Please circle one)

Signature of participant:

Name of participan:

Date:

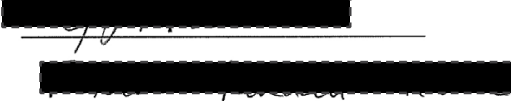

$$
30 / 05 / 16 \text {. }
$$

Contact details: 
Hith und Very High W/ind eqpours

We. 15

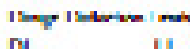

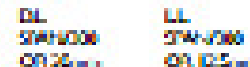

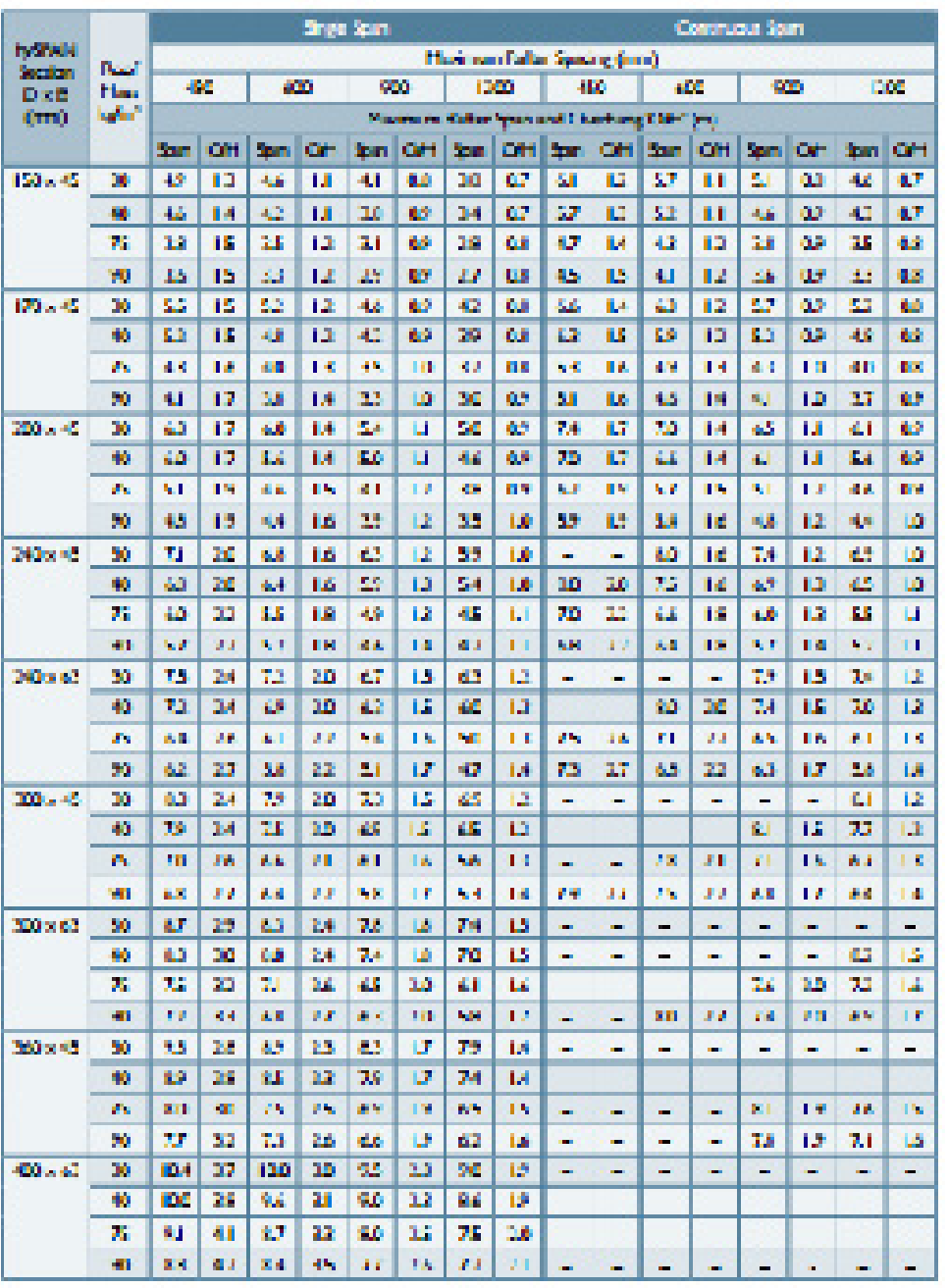

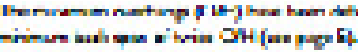

Overhang Span. Sometimes referred to as cantilever, overhang is the distance from the face of the support to the free end of the beam, measured along the beam as illustrated

For beams with overhangs, the backspan (see diagram) should be at least twice the length of the overhang in order to limit uplit forces on the backspan support.

$$
\text { BACSPPAN }
$$

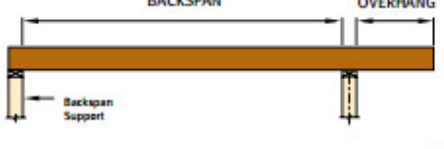

Beams with Overhang

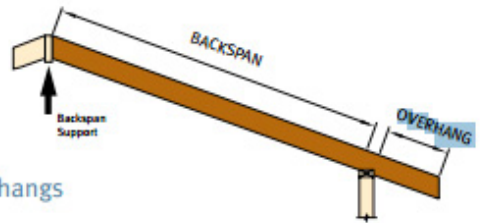


Cayford, Emily.

"The Effects of the Construction Industry on Samoa's Resilience"

This paper was accepted into the 2016 6th International Conference on Building Resilience.

The author presented at the conference. The paper was accepted under blind review.

The paper was written as a result of the research done for this thesis.

\section{6th International Conference o}

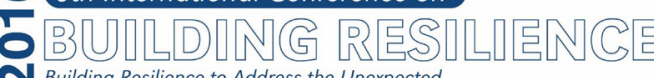

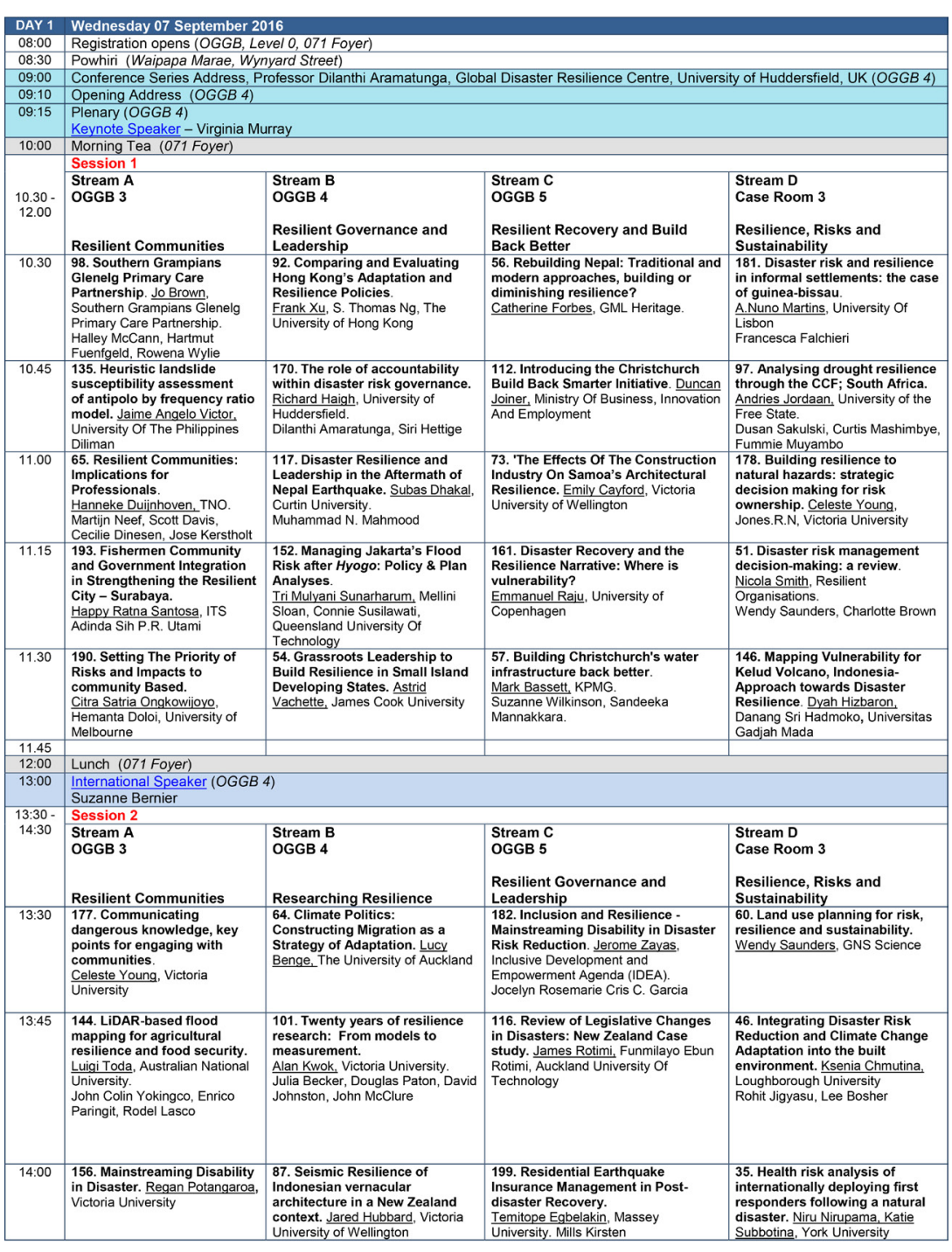

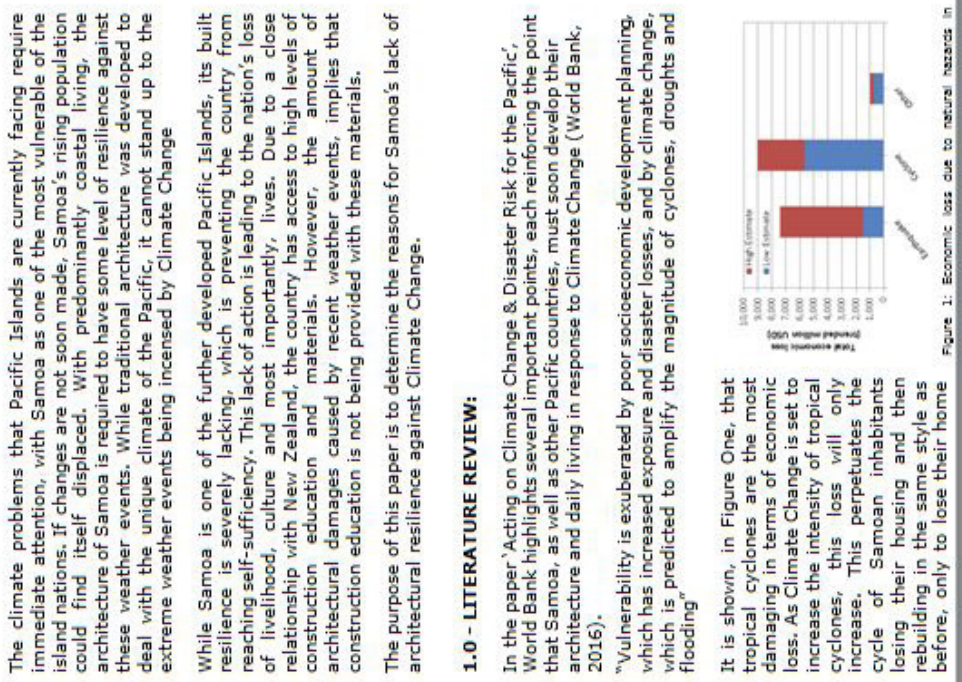

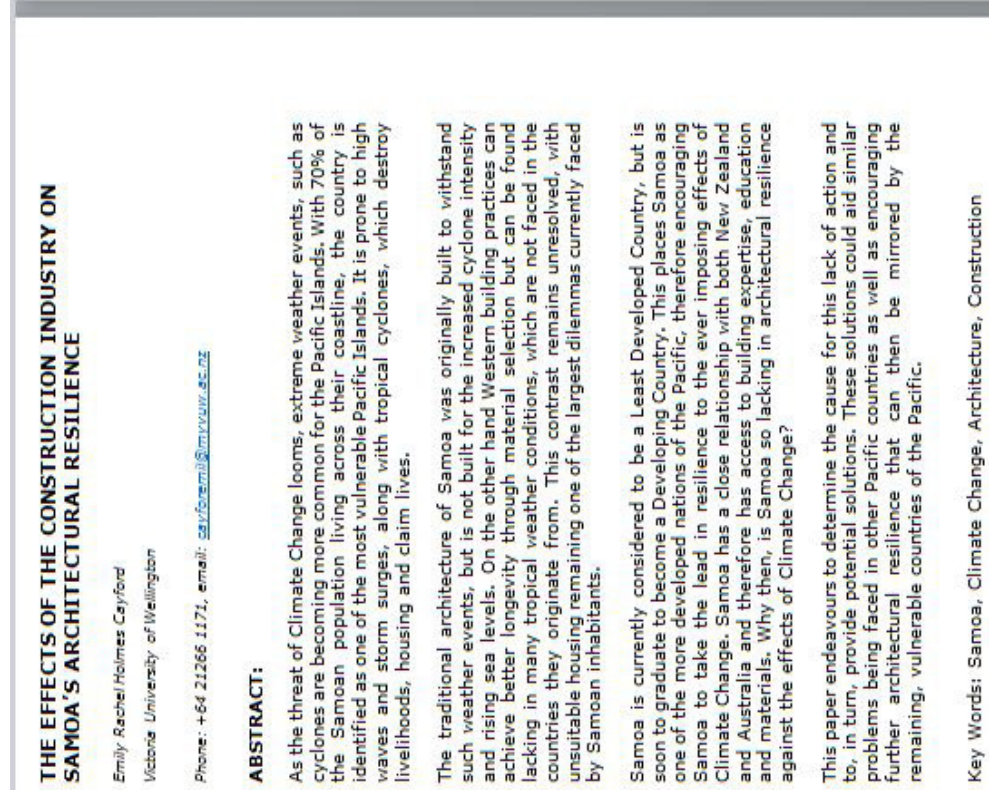




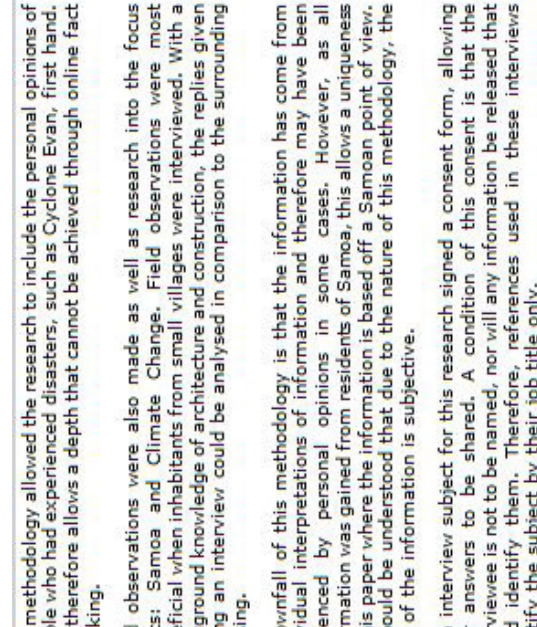

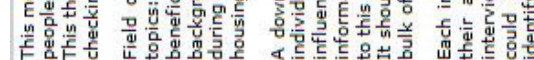

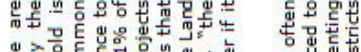

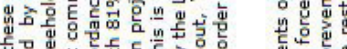

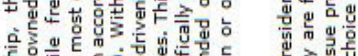

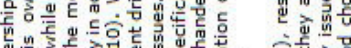

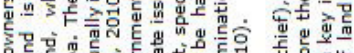

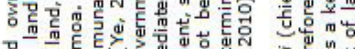

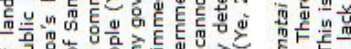

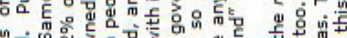

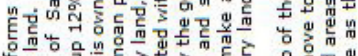

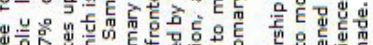

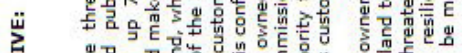

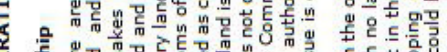

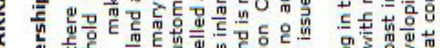
等

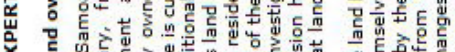

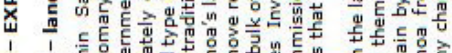

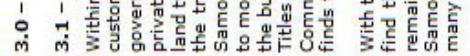

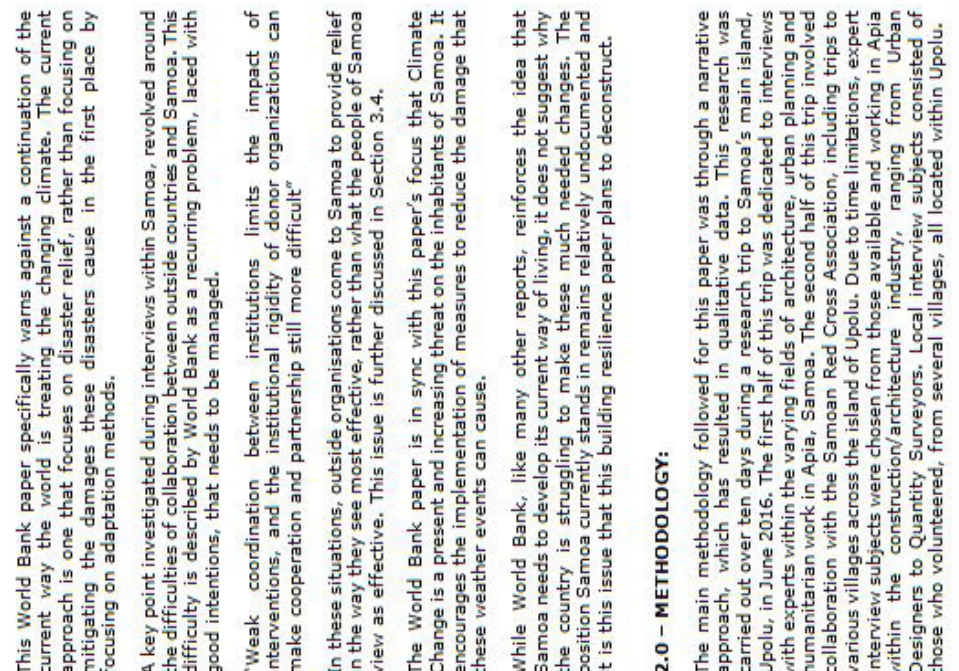

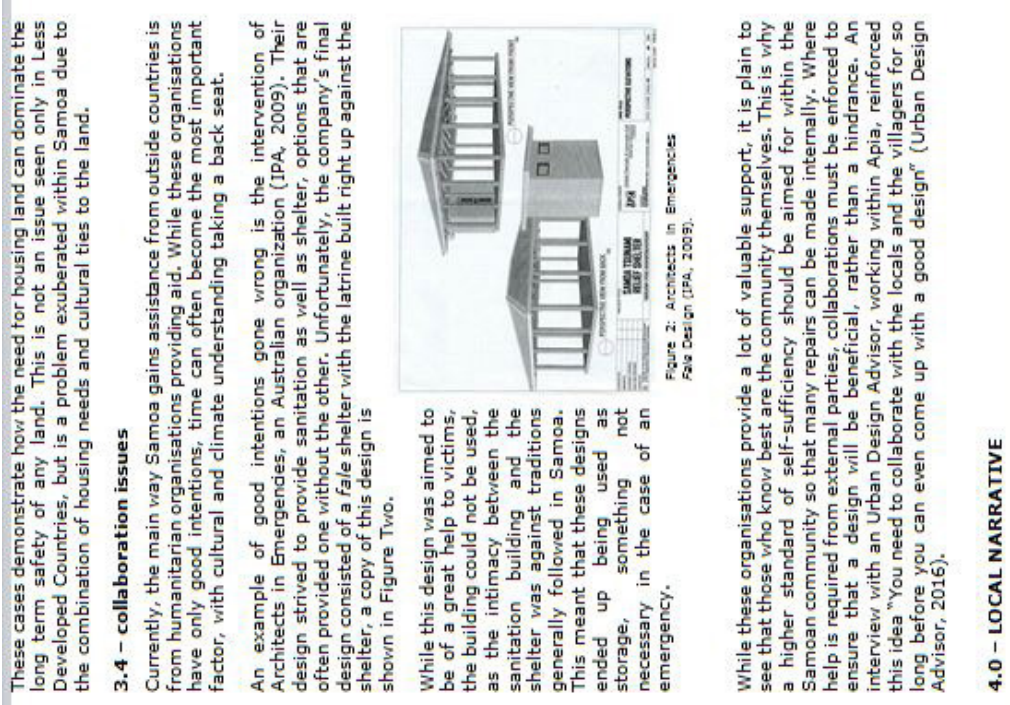

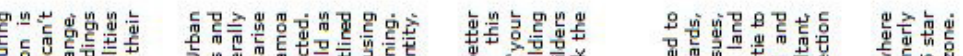

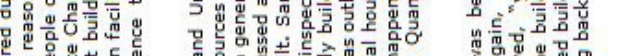

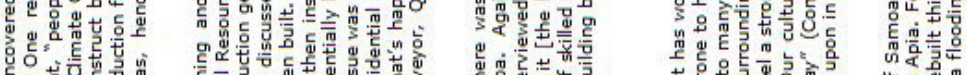
5

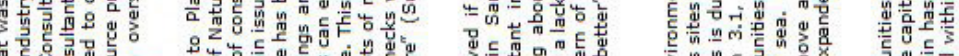

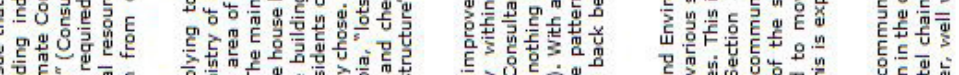

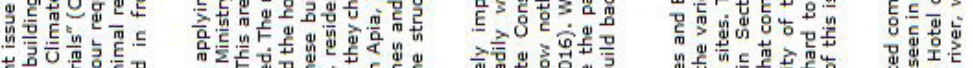

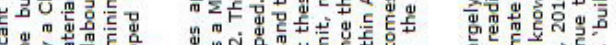

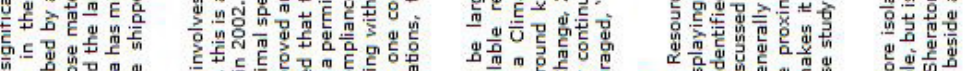

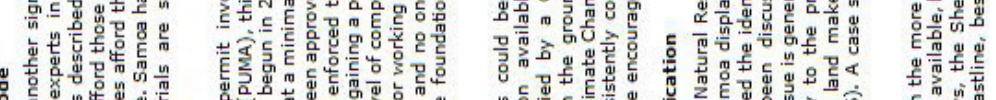

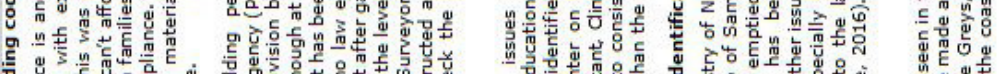

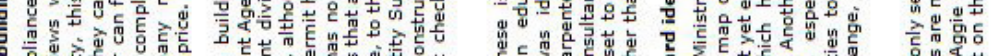

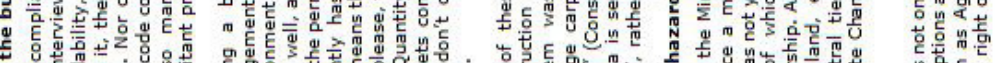
等 


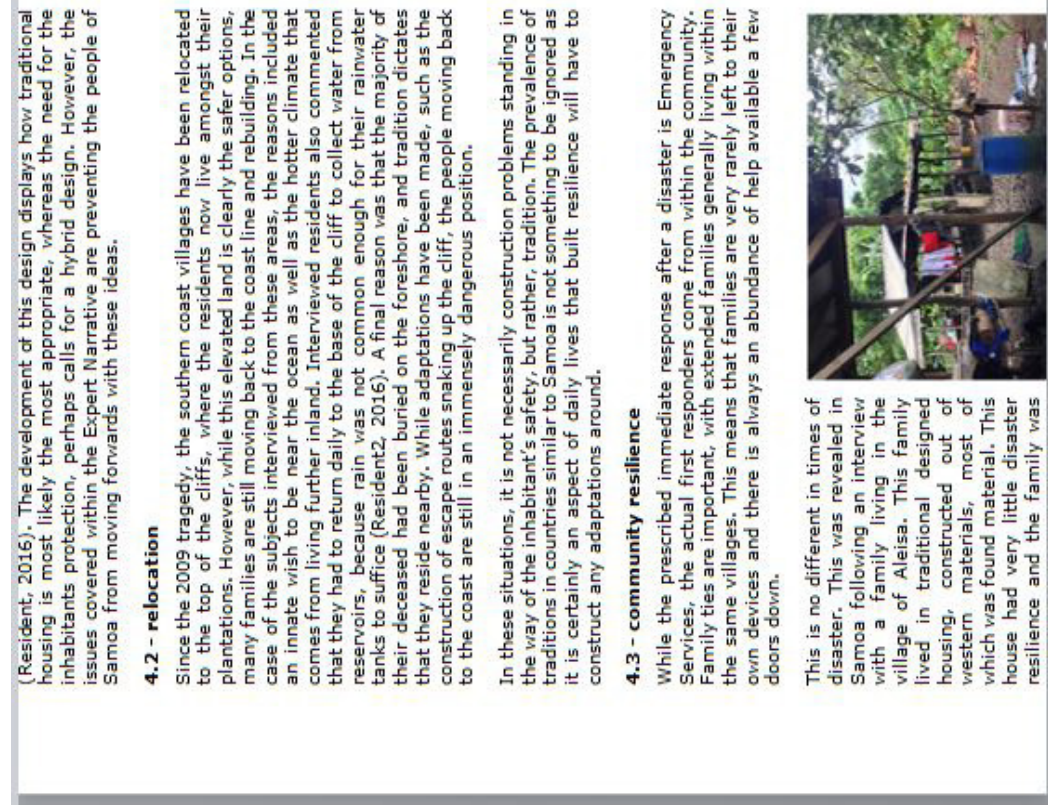

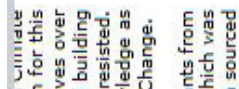

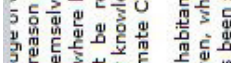

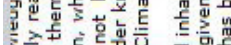

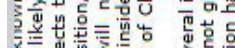

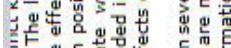

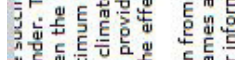

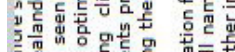

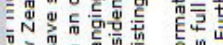

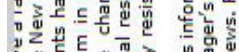

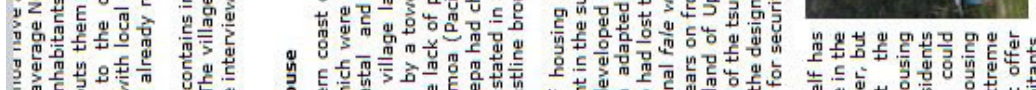

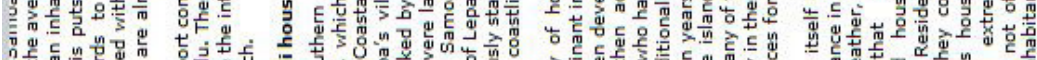
5.5.

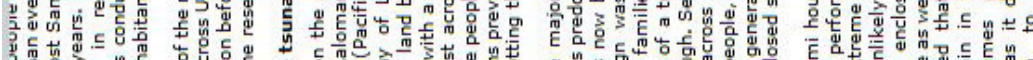

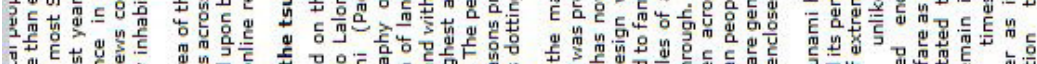

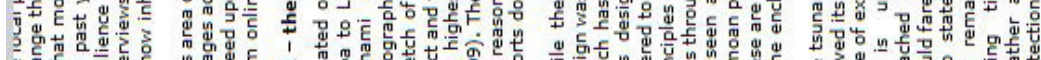

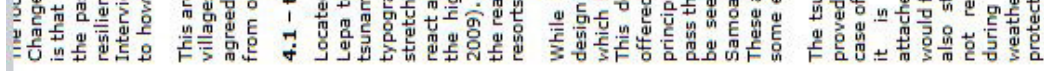

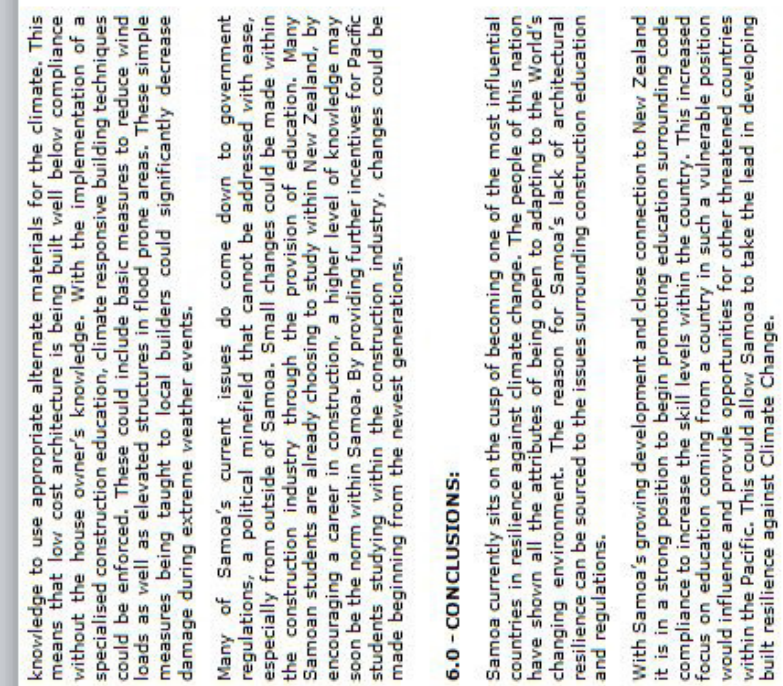

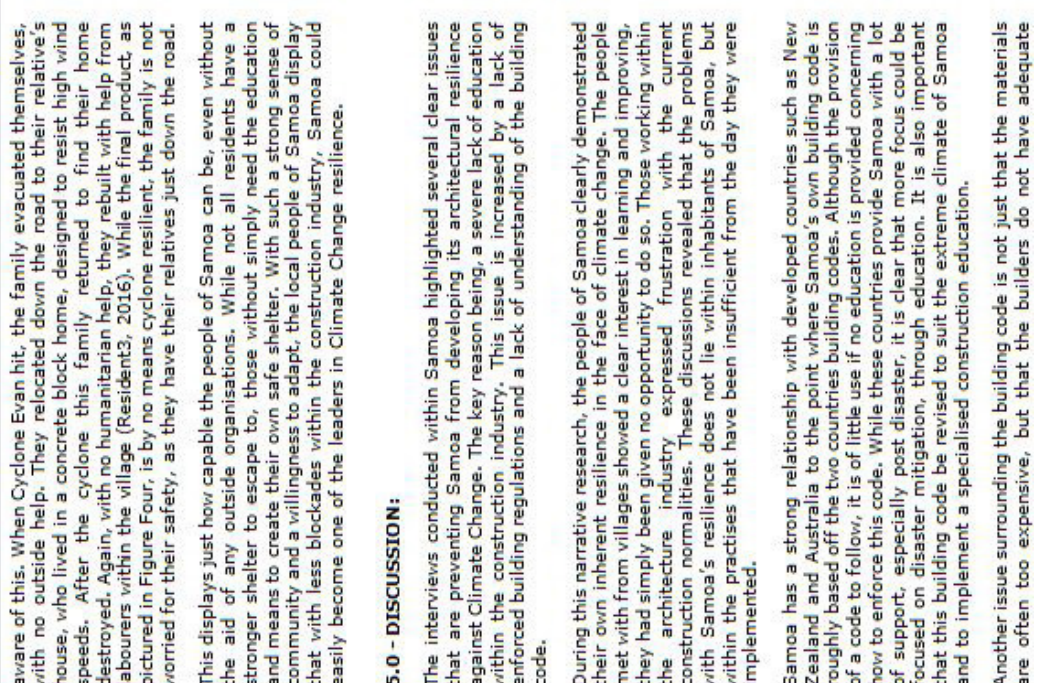


Emily Cay <emilycayford@gmail.com>

to sprep $\nabla$

Hello,

My name is Emily Cayford, I am a 5th year architecture student studying at Victoria University in Wellington, New Zealand.

I have recently been doing research into architecture within Samoa in response to Climate Change. Within this research I came across the renders for the Pacific Climate Change Centre to be constructed in Apia.

I am very interested in this building, including it's material use, construction, programming, costs etc.

I have been struggling to find anymore information concerning the design and construction and I was wondering if I could perhaps be directed towards a source of information?

It would be an immense help to me and I would be very grateful.

Kind Regards,
Emily Cayford

Appendix 27. Email Corespondence with SPREP Representative

Angelica Salele <angelicas@sprep.org>

๔ $7 / 22 / 16$

to AP, Miraneta, me, Registry $/$

Hi Emily,

It is good to know there are others interested in bridging climate change and architecture within the Pacific. We hope you pursue this further in your career as an architect and wish you all the best with your future endeavours.

As for your request to see the building plans of SPREP's headquarters; I have spoken with my supervisor (CC'd in this email) and unfortunately we can't give out that kind of information as it is for internal distribution only. I hope you understand that it is a matter of security and SPREP confidentiality, and nothing personal.

Thank you again for your email, and your interest in SPREP.

If you have any further questions, I am happy to answer them.

Kind regards,

Angelica 
Appendix 28. Email Corespondence with SPREP Representative

From: Emily Cay [mailto:emilycayford@gmail.com]

Sent: Wednesday, 20 July 2016 2:31 PM

To: Angelica Salele

Subject: Re: Pacific Climate Change Centre

Hi Angelica,

Thank you so much for your response.

In further research throughout Samoa I have become interested in compiling my own designs for the region, this would be a part of my final thesis.

I have been analysing current significant buildings within Samoa and am interested in SPREPs current building on Avele Road and the potential for this site.

This may be too much to ask, but I was wandering if you have any access to past building plans of the buildings or anything in relation to the construction?

This would be an amazing help to me and I am, of course, very keen to follow the process of the Climate Change Research Centre.

Thank you again,

Kind Regards,

Emily Cayford

Appendix 29. Email Corespondence with SPREP Representative

On Wed, Jul 20, 2016 at 8:05 AM, Angelica Salele cangelicas@sprep.org $>$ wrote:

Talofa Emily,

Thank you for your email and your interest in SPREP.

The construction of the Pacific Climate Change Centre has not yet begun. The final minutes of discussion between JICA and the Government of Samoa, with SPREP, are to be submitted to the Government of Japan this month for approval. If it is accepted, then the next phase is the designing of the building, tendering the contractors, and finally the proposed construction to commence in June 2017.

At this point, there are no official designs of the building, or any further details regarding the materials that will be used, etc.

But please do keep following the progress of this building, as it will be the beginning of much progress for the Pacific regarding climate change.

The latest news on this project can be viewed on our website here: https://www.sprep.org/climate-change/pacific-climate-changecentre-to-begin-construction-in-june-next-year

Kind regards,

Angelica

Angelica Salele | Information Management Officer 
Emily Cay <emilycayford@gmail.com> to Angelica -

$\mathrm{Hi}$ Angelica,

That is completely understandable! If it is okay with you, l'd like to keep in contact as further information about the new design is released to the public.

Thank you so much for your responses.

Kind Regards,

Emily Cayford

$\cdots$ 